\title{
Dedifferentiation in chronic hibernating myocardium : programmed cell survival vs. programmed cell death
}

Citation for published version (APA):

Dispersyn, G. D. (2001). Dedifferentiation in chronic hibernating myocardium : programmed cell survival vs. programmed cell death. [Doctoral Thesis, Maastricht University]. Universiteit Maastricht. https://doi.org/10.26481/dis.20010620gd

Document status and date:

Published: 01/01/2001

DOI:

10.26481/dis.20010620gd

Document Version:

Publisher's PDF, also known as Version of record

\section{Please check the document version of this publication:}

- A submitted manuscript is the version of the article upon submission and before peer-review. There can be important differences between the submitted version and the official published version of record.

People interested in the research are advised to contact the author for the final version of the publication, or visit the DOI to the publisher's website.

- The final author version and the galley proof are versions of the publication after peer review.

- The final published version features the final layout of the paper including the volume, issue and page numbers.

Link to publication

\footnotetext{
General rights rights.

- You may freely distribute the URL identifying the publication in the public portal. please follow below link for the End User Agreement:

www.umlib.nl/taverne-license

Take down policy

If you believe that this document breaches copyright please contact us at:

repository@maastrichtuniversity.nl

providing details and we will investigate your claim.
}

Copyright and moral rights for the publications made accessible in the public portal are retained by the authors and/or other copyright owners and it is a condition of accessing publications that users recognise and abide by the legal requirements associated with these

- Users may download and print one copy of any publication from the public portal for the purpose of private study or research.

- You may not further distribute the material or use it for any profit-making activity or commercial gain

If the publication is distributed under the terms of Article $25 \mathrm{fa}$ of the Dutch Copyright Act, indicated by the "Taverne" license above, 


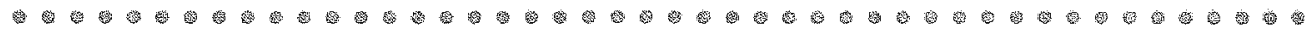
Dedifferentiation in chronic hibernating myocardium: programmed cell survival vs. programmed cell death 



\title{
Dedifferentiation in chronic hibernating myocardium
}

\author{
programmed cell survival vs. \\ programmed cell death
}

\section{PROEFSCHRIFT}

ter verkrijging van de graad van doctor

aan de Universiteit Maastricht,

op gezag van de Rector Magnificus,

Prof. dr. A.C. Nieuwenhuijzen Kruseman,

volgens het besluit van het College wan Decanen,

in het openbaar te verdedigen

op woensdag 20 juni 2001 om 16.00 urur

door

Gerrit Dieter Dispersyn

geboren op 24 juni 1974 te Schoten (Belgü̈) 


\section{Promotores:}

Prof.dr. M. Borgers

Prof.dr. F.C.S. Ramaekers

\section{Co-promotor:}

Dr. L. Ver Donck

\section{Beoordelingscommissie:}

Pró.dr. M.J.A.P. Daenten (voorzitter)

Prot.dr. H.J.G.M. Crijns

Prof.dr. A. van der Laarse (LUMC, Leiden)

Dr. C.P.M. Reutalingsperger

Profdr. F Van Meir (Universiteit Antwerpen)

The investigations described in this thesis were carried out at the department of Life Sciences, Janssen Research Foundation, Beerse, Belgium.

This study was financially supported by the Janssen Research Foundation. 


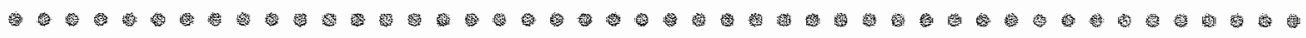

Voor mijn ouders 
(0) 2001 Gerrit D. Dispersyn

Vormgeving: Danny Van heusden, Van heusden \& Co.

ISBN $90-9014890-6$

D/2001/Gerrit Dispersyn, uitgever 
Contents

Chapter 1

\section{Introduction}

based on:

Apoptosis in chronic hibernating myocardium: sleeping to death? Gerrit D. Dispersyn, Marcel Borgers, Willem Flameng - Cardiovasc Res 45(3): 696-703, 2000.

Apoptosis in the heart: about programmed cell death and survival. Gerrit D. Dispersyn \& Marcel Borgers - News Physiol Sci 16: 41-47, 2001.

Chapter 2

Cardiomyocyte remodeling during myocardial hibernation and atrial fibrillation: prelude to apoptosis?

Gerrit D. Dispersyn, Jannie Ausma, Fred Thoné, Willem Flameng, Jean-Louis J.

Vanoverschelde, Maurits A. Allessie, Frans C.S. Ramaekers, Marcel Borgers - Cardiovasc Res 43(4): 947-957, 1999.

Chapter 3

45

\section{Changes in ultrastructural calcium distribution in goat atria during atrial fibrillation.}

Jannie Ausma, Gerrit D. Dispersyn, Hans Duimel, Fred Thoné, Luc Ver Donck, Maurits A. Allessie, Marcel Borgers - J Mol Cell Cardiol 32(3):355-364, 2000 
Chapter 4

61

PET reversed mismatch in an experimental model of subacute myocardial infarction.

Liesbet Mesotten, Gerrit D. Dispersyn, Alex Maes, Mirek Zietkiewicz, Johan Nuyts, Guy Bormans, Tjibbe de Groot, Marcel Borgers, Luc Mortelmans, Willem Flameng - Eur J Nucl Med, 28: 457-465, 2001.

Chapter 5

Dissociation of cardiomyocyte apoptosis and dedifferentiation in infarct border zones.

Gerrit D. Dispersyn, Liesbet Mesotten, Bart Meuris, Luc Mortellmans, Willem Flameng, Frans C.S. Ramaekers, Marcel Borgers - Submitted for publication.

Chapter 6

Hibernation-like dedifferentiation in cardiomyocytes cocultured with fibroblasts.

Gerrit D. Dispersyn, Eva Geuens, Luc Ver Donck, Frans C.S. Ramaekers, Marcel Borgers Cardiovasc Res, in press.

Chapter 7

Dynamic interactions with fibroblasts induce hibernation-like dedifferentiation in adult rabbit cardiomyocytes.

Gerrit D. Dispersyn, Karen Lemmens, Tom Van Dooren, Luc Ver Donck, Stefan van den Eijnde, Frans C.5. Ramaekers, Marcel Borgers 
Chapter 8

\section{General Discussion}

based on:

Clinical pathophysiology of chronic hibernating myocardium. Gerrit D. Dispersyn \& Marcel Borgers - in press.

Summary

Samenvatting

Dankwoord 
Chapter 1

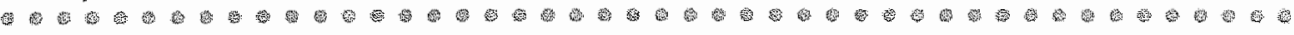

\section{Introduction}

based on:

Apoptosis in chronic hibernating myocardium: sleeping to death? Gerrit D. Dispersyn, Marcel Borgers, Willem Flameng Published in Cardiovasc Res 45 (3): 696-703, 2000.

Apoptosis in the heart: about programmed cell death and survival. Gerrit D. Dispersyn \& Marcel Borgers - Published in News Physiol Sci 16: 41-47, 2001. 


\subsection{Hallmarks of chronic hibernating myocardium}

The term "hibernating myocardium" describes an important clinical condition that characterises dysfunctional but viable myocardium as a result of an oxygen shortage due to a chronic or repetitive underperfusion accompanied by a limited coronary flow reserve. It has been suggested that the underpertused myocardium can retain its viability by down-regulating its function, thereby regaining the balance between the demand and the supply of oxygen. After revascularization, for example after coronary artery bypass grafting (CABG), the cardiac function of patients recovers, but in the setting of chronic hibernating myocardum this may take a few months to a year [1]. Although dysfunctional, hibernating myocardium partially retains the ability to respond to inotropic challenges. Myocardial function improves upon low-level dobutamine infusion, but deteriorates with a high-level infusion. The high glucose tracer analogue (fluorodeoxyglucose, FDG) signal, which can be obtained with positron emission tomography (PET) in hibernating segments, suggests that glucose uptake is stimulated in those areas, although direct evidence is missing [2-4]. In patients who show a delayed functional recovery after reperfusion, the hibernating myocardium undergoes structural remodeling. These structural changes are characterized by cellular and extracellular features. Important subcellular alterations are: redistribution of nuclear heterochromatin; depletion of sarcomeres; accumulation of glycogen (which might be related to the suggested glucose uptake stimulation (2); ; occurrence of aberrantly shaped but healthy mitochondria; and degradation of structured sarcoplasmic reticulum, giving rise to cardiomyocytes with structural hallmarks of fetal heart cells, i.e. a dedifferentiated phenotype [5]. Indeed, the structural alterations are accompanied by altered expression levels of several proteins, confirming the dedifferentiation hypothesis [6]. It remains unknown whether this dedifferentiation is reversible, however the recovery of function after reperfusion is suggestive for a normalization of the subcellular strteture of the cardiomyocytes. During dedifferentiation the cells do not become atrophic, but there is an increase in the amount of extracellular space $[7,8]$. This observation, and the knowledge that functional recovery after revascularization is often incomplete, gives rise to the question whether or not cell death occurs. Ultrastructural alterations in cardiomyocytes, suggestive of cellular apoptosis-like degeneration, have been detected in biopsy tissue from a limited number of patients $[9-11]$. Therefore, the following questions arose: does degeneration occur in chronic hibernating myocardium (CHM), and if $\mathrm{so}_{3}$ does cellular dedifferentiation eventually end up in degeneration of the cardiomyocytes?

In a chtonic situation, even low percentages of cell death could be of long-term clinical importance $[12\}$. If cell death were present, even a very low rate would result in a considerable percentage of cell loss after a long period. In that case, one would not expect functional recovery 
after revascularization, which can be seen in the majority of patients [13-15]. On the other hand, the basis of incomplete recovery emphasises the possible involvement of progressive cell death. If the latter does in fact play a role, revascularization without delay is indicated, although some data (discussed below) suggest that dedifferentiated cardiomyocytes are more resistant to oxygen shortage than normally structured cells in remote areas.

\subsection{Hallmarks of apoptosis}

Apoptosis was originally defined as an energy-dependent form of cell death with distinct phases of ultrastructural morphological features, like nuclear chromatin condensation and cellular shrinking, followed by break-up of the nucleus (karyorrhexis) and cellular budding with the formation of apoptotic bodies (plasma membrane delineated cellular particles containing cellular organelles and nuclear fragments), which are rapidly phagocytosed by neighboring cells $[16,17]$. Apoptosis contrasts with non-apoptotic cell death, called oncosis by Majno and Joris, which is characterized by depletion of intracellular ATP, cellular swelling, disruption of organelles and plasma membrane disruption, followed by an inflammatory reaction [7]. The morphological hallmarks of apoptosis, however, represent only the end stage of various subsequent phases. The initiation phase consists of the activation of the molecular machinery of apoptosis. Very little is known about the exact nature of the triggers. Factors likely to be involved in cardiomyocyte apoptotic cell death are mechanical - such as extensive stretch, and/ or elevated concentrations of neurohormonal factors - like angiotensin II and atrial natriuretic factor [18]. Alternatively, it is plausible that multiple intracellular and extracellular alterations which occur during ischemia and/or reperfusion, such as excess of NO, are involved in the induction of apoptosis [19], In the phase preceding the execution or degradation phase of apoptosis (characterized by morphological changes and DNA fragmentation), a specific class of aspartate-specific cysteine proteases become activated in a self-amplifying cascade $[16,20,21]$. These so-called "caspases" can be divided into an upstream and a downstream subgroup. Activation of upstream caspases - such as caspases 2, 8,9 and 10 - leads to the proteolytic activation of downstream caspases - such as caspases 3 and 7. These downstream caspases cleave an incompletely characterized set of proteins, such as nuclear proteins, proteins involved in signal transduction and cytoskeletal proteins. The contribution of the cleavage of the different caspase targets to the typical apoptotic morphological changes remains to be determined. However, proteolytic cleavage of nuclear proteins, such as lamin B cleavage, is important in inducing the typical nuclear features of apoptosis, like the chromatin condensation into sharply delineated "half-moon" shaped chromatin masses. Also, the externalization of 


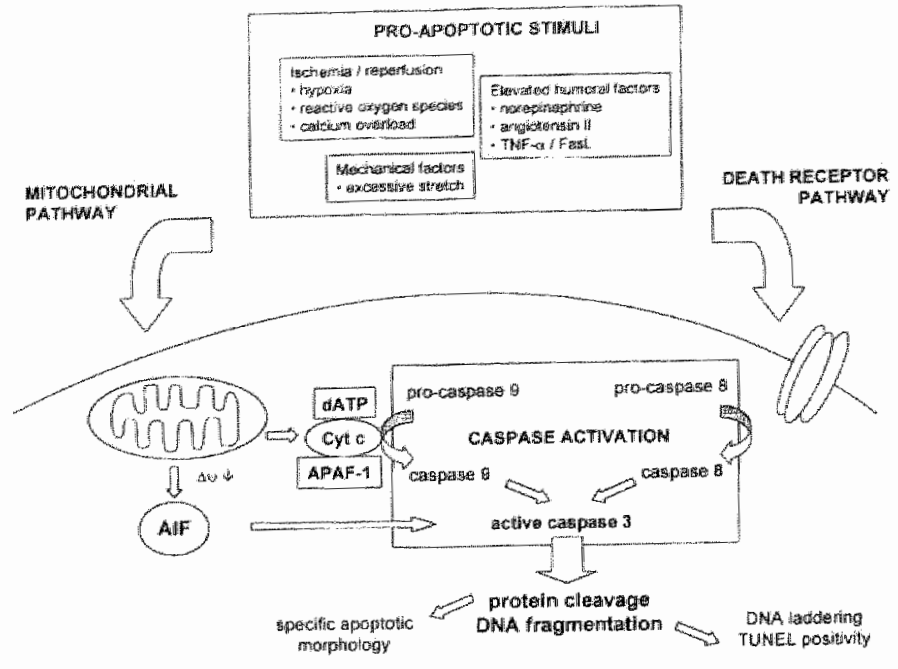

Figure i: A schematic representation of the most important factors imvolved in the apoptonc cascade (see text)

phosphatidylserine at the cell membrane is thought to be a consequence of caspase activity. Currently two major pathways leading to caspase activation are characterized $[16,20]$ (Figure 1). One is a mitochondrial pathway, which involves the mitochondrial release of cytochrome $c$, the 50 -called apoptosis-inducing factor (ATF) and probably other factors (like pro-caspase zymogens of caspases 2 and 9), into the cytosol [22). Unlike the release of AIr, the release of cytochrome $\mathrm{c}$ seems to depend on the opening of the mitochondrial permeability pore which is associated with a breakdown of the electrochemical gradient over the inner mitochondrial membrane. Cytochrome can activate pro-caspase 9 when it is complexed with apoptotic protease activation factor $\mathbb{1}$ (apaf-1) and ATP, whereas the exact mechanism of the stimulation of DNA fragmentation by AIF remains to be resolved. The second pathway leading to caspase activation is initiated by ligation of the death receptors. The best characterized pathways involve binding of Fas ligand (FasL) and TNF- $\alpha$ to their respective receptors (Fas and TNFR-1) [23]. Caspase 8 is the most upstrean caspase in these pathways, which is activated by a signaling complex at the activated receptors. An important target for the activated downstream caspase 3 is DFF45/ICAD (DNA fragmentation factor $45 /$ inhibitor of caspase-activateed DNAse) [24]. Its proteolytic inactivation leads to the release and activation of the associated DFF40/ CAD (DNA fragmentation factor 40/caspase-activated DNAse), an endogenous DNAse enzyme 
responsible for the internucleosomal DNA fragmentation during the last phase of apoptosis. The DNA fragmentation results in double-stranded DNA strands that contain single base 3 overhangs and blunt ends. The DNA fragments can be detected as a typical ladder pattern after electrophoresis of isolated DNA. Cells with fragmented DNA can be detected with the light microscope with the terminal transferase mediated DNA nick end labeling technique (TUNEL). This is the most widely used method for quantification of apoptosis. However, since it can also label non-apoptotic DNA fragmentation, it is also the most criticized method $[25,26]$. Nevertheless, if the method is used properly, it can provide the investigator with valuable information, making the quantification of different cell types in which DNA fragmentation occurs possible. Even under well-controlled conditions, when using the TUNEL method, one should investigate a large quantity of tissue in order to get an idea of the rate of apoptosis, when investigating chronic pathologies in which low rates of apoptosis are to be expected. Other immunohistochemical techniques for apoptosis detection can be used for confirming the TUNEL results, such as the detection of phosphatidylserine externalization by apoptotic cells by the annexin- $V$ method and the detection of activated (cleaved) caspase 3 . Nevertheless, EM must still be considered the gold standard as far as the identification of apoptotic cells is concerned. However, only limited studies seem to make use of this technique. Until now no previous reports show ultrastructural evidence of cardiomyocyte apoptosis in ischemia / reperfusion studies or in the setting of dilated cardiomyopathy. When EM is used, many structural changes have been proposed as pre-apoptotic changes. For example, margination and condensation of chromatin to various extents have been described as pre-apoptotic $[27-$ 29]. The reasons for this denotation are entirely unclear, since to our knowledge, there is no way to unambiguously distinguish these changes from similar changes occurring in pre-necrotic or irreversible necrotic cells. Only end-stage chromatin condensation (half-moon appearance) is a typical hallmark of an apoptotic nucleus 125,301 , which, however, is only seldom observed in cardiomyocytes. This assumption is further substantiated by Ohno et al., who found, using EM, TUNEL positivity in the majority of clearly necrotic cells [25]. To make the issue even more complex, Kanoh et al., recently demonstrated that a large number of TUNEL positive cardiomyocytes had ultrastructural features of neither apoptosis nor necrosis, but were instead considered "living" cells [31]. It should be emphasized that only by using various approprately applied techniques (reviewed in [32,33]) such as TUNEL, DNA laddering assays, detection of apoptosis related proteins and caspases activation assays, preferentially in combination with ultrastructural analysis, one can get a good appreciation of the occurrence and extent of apoptosis. 


\subsection{Apoptosis in chronic hibernating myocardium}

In the thinking about apoptosis and non apoptotic cell death, it is often suggested that the two types of cell death can be triggered by the same factors, but that the degree of the insult determines whether the jeopardized cells will die by oncosis or apoptosis. If this idea is correct it can be assumed that even a lesser insult than is necessary to cause apoptosis would trigger changes in the cell. This sub-lethal injury is likely to trigger several protective mechanisms, which can be subsumed under the term 'programmed cell survival' (Figure 2). As explained by Depré and Taegtmeyer, an example of programmed cell survival is the initial response of the heart to moderate ischemia [34]. Through modification of its gene expression and an enhanced anaerobic glucose metabolism, the resistance of the heart to the ischemic insult is increased. Preconditioning and hibernation are typical examples of this adaptive response [3]. In the context of chronic hibernation, the described dedifferentiation with the initiation of a "fetal gene program' should also be considered as adaptive [6]. There is a change in the expression not only of genes that are involved in energy metabolism but also of genes that code for contractile and structural proteins [5]. Hence the cardiomyocytes change from an "efficient contractility state' to an 'energy sparing state'. The associated structural changes could therefore

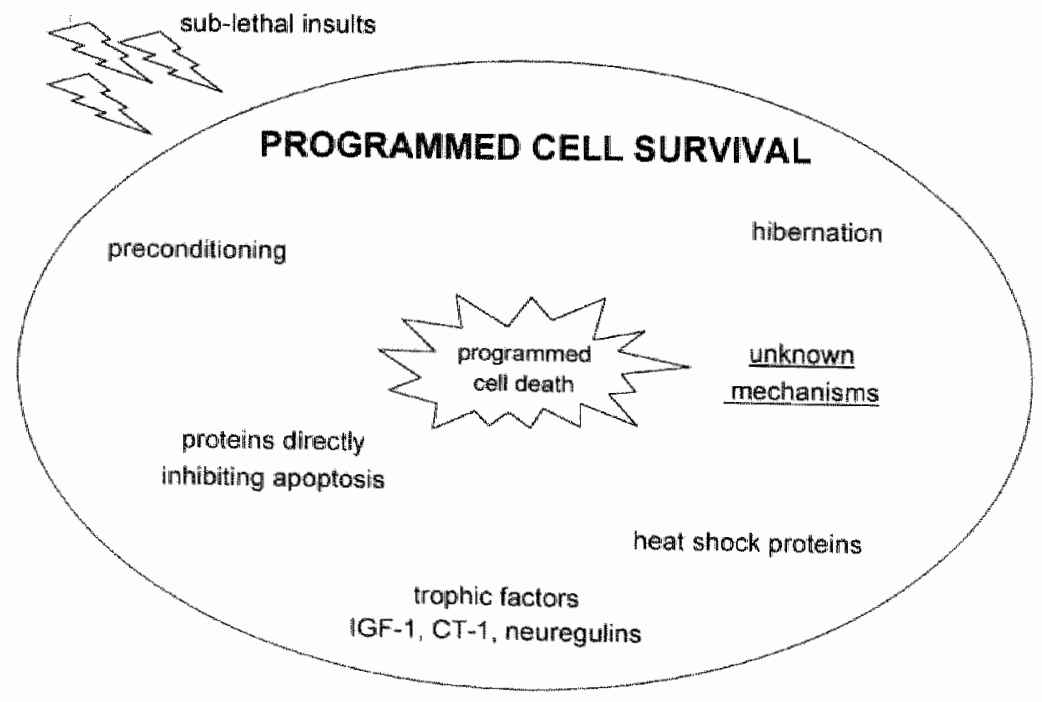

Figure 2: Programmed cell survival can be considered as a first line of defense against unfaworable croumstances. When these mechanisms fail to preserve cetl vability, the cell witl die possibly through apoptosis. 
be interpreted as purely adaptive and not degenerative [34]. This situation contrasts sharply with that observed in terminal stages of heart failure, in which not only the adult isoforms but also the fetal isoforms of some proteins are downregulated. Examples are the downregulation of both adult o-myosin heavy chain (MHC) and fetal B-MHC, and of both the adult GLUT4 glucose transporter and the fetal GLUT1 isoform. It is thought that these changes constitute a final maladaptive response predisposing to cell death, possibly through apoptosis 134]. Although cardiac hibernation is believed to be a protective response of the chronically or repetitively underperfused myocardium [3], some publications suggest that apoptosis is an important feature of chronic hibernating myocardium [9-11]. Therefore, important questions as to whether cardiomyocyte dedifferentiation represents a stable adaptive state enabling the cardiomyocytes to survive under unfavorable circumstances for a prolonged period of time, and whether dedifferentiation precedes degeneration (possibly through apoptosis) remain unsettled. The important question, of which factors can trigger cardionyocyte apoptosis in CHM, is far from answered. First of all, little is known about potential triggers for cardiomyocyte apoptosis; in addition, little research has been done in this field in CHM. Even the actual triggers for the typical functional and structural changes in CHM are unknown. It might be possible that the hypothesized triggers for cardiomyocyte dedifferentiation - possibly to a different extent - also may cause apoptosis.

Since chronic hibernating myocardium is originally defined as chronically underperfused $\| \mathbf{1}$, one could assume that the ischemia leads to cellular bypoxia. It is known from in witro experiments that hypoxia can trigger the death of cardiomyocytes through apoptosis $[36,37]$, but it is highly unlikely that chronic hibernating cardiomyocytes are truly hypoxic. It is generally believed that by down-regulating their function, cardiomyocytes adapt to the lowered oxygen availability and thereby restore the oxygen supply/demand ratio [1]. More direct evidence that cardiomyocytes from CHM are not hypoxic has come from the finding that high energy phosphate content is unaltered in CHM $|38|$. Moreover, cytochemical analysis provided evidence that those cells are not calcium-overloaded and mitochondrial oxidative phosphorylation is not uncoupled, as shown by a normal activity of cytochrome coxidase and the absence of proton translocating ATPase 138,39$]$. Nevertheless, it has been suggested that hibernating myocardium can be the result of a repetitive stunning because not the basal coronary flow, but the flow reserve would be diminished $[4,40]$. Therefore it cannot be excluded that repetitive periods of hypoxia occur, which could have been missed in the above mentioned study since biopsies are taken in the most favourable circumstances, i.e. under anesthesia where demand ischemia is unlikely to occur.

Another possible trigger for apoptosis with reference to $\mathrm{CHM}$ could be cardiomyocyte stretching. Because of the hypocontractility of the hibernating segments, it is clear that 
hibernating carliomyocytes undergo a different mechanical load than normal cardiomyocytes in remote segments. There is data from in vitro, ex wivo and in vivo studies to the effect that stretching of cardiomyocytes can trigger apoptosis of those cells [41-43]. However, the in vivo observation that apoptosis at the border zone of an infarct is the result of local mechanical stretch may be particularly difficult to interpret because of the co-ocurrence of stretch and oxygen shortage. If stretch were sufficient to trigger apoptosis the infarcted area woulld enlarge gradually, so that perhaps both stretch and oxygen shortage are needed to induce apoptosis. Restoration of oxygen supply would then be sufficient to stop the enlargement of the infarct. But on the basis of available evidence, it cannot be ruled out that delayed cardiomyocyte death is a direct consequence of the ischemic injury without the involvement of stretch. On the other hand, some data suggest that physical stretch causes the cardiomyocytes to be more susceptible to other apoptosis-triggering conditions, thereby supporting the hypothesis that stretch is a significant player in structural remodeling. Stretch is known to induce cardiomyocytes to increase (i) angiotensin II secretion, (ii) the amount of AT-1 receptors and (iii) the synthesis of P53, all changes which can be counteracted by IGF-1, a factor known to be able to inhibit apoptosis $[44-46]$.

\subsection{Is dedifferentiation protective?}

There is indirect evidence that dedifferentiated cardiomyocytes from CHM tolerate ischemia better than non-dedifferentiated cardiomyocytes. Indeed, in CHM biopsies taken after coronary bypass surgery, ultrastructural abnormalities - such as loss of intramatricial granules in the mitochondria and subsequent mitochondrial swelling - suggestive of acute ischemia can be observed in normally structured cardiomyocytes without dedifferentiation features, but not in those that are clearly dedifferentiated [39]. This may indicate that dedifferentiated cardiomyocytes are better protected against ischemia. It could be hypothesized that endogenous protective mechanisms, like an increased expression of certain heat shock proteins are upregulated in $\mathrm{CHM}$, although direct evidence of such up-regulation is missing. Nevertheless, it is known that ischemic preconditioning induces the efficient translation of stress proteins [47. Several of these chaperones are subsequently translocated to the nucleus, possibly to protect against degradation of DNA that has become more susceptible for this due to a transformation of the chromatin organization into a nuclease-sensitive conformation (as is the case in apoptosis) 148,49$]$. Heat shock proteins, like Hsp 70, Hsp 27 and $\alpha \beta$-crystallin, are known to protect against ischemic cardiac damage, however there is no evidence that these stress proteins play a role in chronic situations like chronic hibernation. In pig hearts it has been shown that mRNA expression of $\mathrm{Hsp} 70$ is upregulated following brief total coronary 
occlusions and after chronic high grade LAD stenosis [50]. Whether this applies also to CHM in patients remains to be investigated; but in cases of chronic heart failure (DCM and ICM), protein expression levels of $\mathrm{Hsp} 72, \mathrm{Hsp} 27$ and $\mathrm{Hsp} 90$ were not significantly changed, whereas the levels of chaperonin Hsp60 nearly doubled [51].

An important question is whether degenerative changes occur at a later stage of chronic hibernating myocardium; in other words: how long can dedifferentiated cardiomyocytes survive? As suggested earlier, it is possible that in patients with a longer history of CHM, apoptosis does in fact become a common feature. Whether dedifferentiation eventually ends up in apoptosis is a key question, which is very difficult to answer since validation of chronic hibernation in animal models has only just started.

\subsection{Aim of this thesis}

A major drawback in the search for apoptosis in CHM is the limited amount of tissue that can be investigated. For obvious ethical reasons, per patient only 1 or at most 2 needle biopsies of about $15 \mathrm{mg}$ can be taken. These small biopsies contain only a limited number of cardiomyocytes (around 180,000 cardiomyocyte nuclei) [52]; hence it can be readily understood how an occasional apoptotic cell could be overlooked, especially if only part of the biopsy is used for apoptosis detection, which is most often the case. Logically, it is very difficult to interpret negative results as to the relevance of apoptosis in this pathological condition.

Likewise it is very difficult to investigate the nature of the dedifferentiation process: what is its trigger, how does it develop and does it indeed include aspects of programmed cell survival? It is clear that for answering these questions, both validated animal models of chronic hibernating myocardium and cellular models of hibernation-like cardiomyocyte dedifferentiation are needed. The animal models would provide us with unlimited amounts of tissue for research, and the cellular model would enable to directly identify pathways leading to dedifferentiation and define putative protective mechanisms.

Therefore the aim of this thesis is to investigate whether or not cardiomyocyte dedifferentiation is associated with cellular degeneration by investigating both human cardiac biopsies and animal hearts in which cardiomyocyte dedifferentiation is seen, and whether the features of hibernation-like dedifferentiation can be mimicked in isolated and cultured cardionyocytes thereby providing a valuable in vitro model system for hibernating myocardium. 


\subsection{References}

1) Rahimtoola SH. The hibernating myocandium. Am Heart 1989;17:211-221.

2) Depré $C_{3}$ Vanoverschelde $\mathrm{J}$-L/, Taegtmeyer $\mathbb{H}$. Glucose for the Heart. Circulation 1999; 99:578588.

3] Kloner RA, Bolli R, Marban E, Reinlib L, Braunwald E. Medical and cellular implications of stunning, hibernation, and preconditioning: an NHLBI workshop. Circulation 1998; $97: 1848$ 1867

4) Vanoverschedde JL, Wijns $W$, Borgers $M$, et al. Chronic myocardial hibernation in humans. From bedside to bench. Circulation 1997;95:1961-1971.

5) Borgers M, Thoné F, Wouters L, Ausma I, Shivalkar B, Flameng W. Structural correlates of regional myocardial dysfunction in patients with critical coronary stenosis: chronic hibernation? Cardiovasc Pathol 1993; 2:237-245

6) Ausma J, Scharrt $G$, Thoné $F$, et al. Chronic ischemic viable myocardium in man: aspects of dedifferentiation. Cardiovasc Pathol 1995; 4:29-37

7) Ausma J, Cleutjens J, Thone F, Flameng W, Ramaekers F, Borgers M. Chronic hibernating myocardium: interstitial changes. Moll Cell Biochem 1995;147:35 42.

81 Elsässer $A$, Schlepper $M$, Zimmermann $R$, et al. The extracellular matrix in hibernating myocardium - a significant factor causing structural defects and cardiac dysfunction. Mol Cell Biochem 1998;186:147 158.

9) Schwarz ER, Schaper J, vom Dahl J, et al. Myocyte degeneration and cell death in hibernating human myocardium. i Am Coll Cardiol 1996;27:1577-1585.

I0] Llsässer A, Schlepper M, Klovekorn WP, et al. Hibernating myocardium: an incomplete adaptation to ischemia. Circulation 1997;96:2920-2931.

11. Angelini A, Calabrese F, Pettenazzo E, et al. Apoptosis in chronic ischemic myocardium in human. Circullation 1998; 98:1-769 (Abstract).

12) Colucci WS. Apoptosis in the heart Ipublished erratum appears in NEngl J Med 1997;336:1267). N Engl I Med 1996:335:1224-1226.

13) Flameng $W$, Wouters L, Sergeant $P$, et al. Multivariate analysis of angiographic, histologic, and electrocardiographic data in patients with cononary heart disease. Circulation 1984;70:7-17.

14! Shivalkar B, Maes A, Borgers $M$, et al. Ony hibernating myocardium invariably shows early recovery after cononary revascularisation. Circulation 1996;94:308-315. 
15] Depré $C$, Vanoverschelde $J \mathrm{~L}$, Melin JA, et al. Structural and netabolic correlates of the reversibility of chronic left ventricular ischemic dysfunction in bumans. An I Physiol 1995;268:-11265-1275.

16] Saraste A and Pulkki K. Morphologic and biochemical hallmarks of apoptosis. Cardiovase Res 2000;:45:528-537.

17] Majno G. and Joris I. Apoptosis, oncosis and necrosis: an overview of cell death. Am I Pathol 1995;146:3-15.

18] Sabbah HN. Apoptotic cell death in heart failure. Cardiovase Res 2000;45: 704-712.

19] Taimor $\mathrm{G}_{\mathrm{b}}$ Hofstaetter $\mathrm{B}_{3}$ Piper HM. Apoptosis induction by nitric oxide in adult cardiomyocytes via cGMP-signaling and its impairment after simulated ischemia. Cardiovasc Res 2000;45:588594.

20] Haunstetter A. and Izumo S. Apoptosis: Basic mechanisms and implications for cardiovascular disease. Circulation 1998;82:1111-1129.

21] Wolf BB and Green DR. Suicidal tendencies: Apoptotic cell death by caspase family proteinases. J Biol Chem 1999;274: 20049-20052.

22] Susin SA, Lorenzo HK, Zamzami $\mathbb{N}_{n}$ et al. Mitochondrial release of caspase-2 and -9 during the apoptotic process. J. Exp. Med. 1999;189:381-393.

23] Nagata S. Fas ligand-induced apoptosis. Annu Rev Genet 1999;33:29-55.

24.] Nagata S. Apoptotic DNA fragmentation. Exp Cell Res 2000; 256: 12-18.

25] Ohnoh $\mathrm{M}$, Takemura $\mathrm{G}$, Ohno H, et al. "Apoptotic" myocytes in the infarct area in rabbit hearts may be oncotic myocytes with DNA fragmentation: analysis by immunogold electron microscopy combined with in situ end labeling. Circulation 1998;98: 1422 1430.

26] Schaper J, Ellsässer A, Kostin S. The role of cell death in heart failure. Circulation 1999;85:867869.

27) Sharov VG, Sabbah HN, Shimoyama H, Goussev AV, Lesch M, Goldstein S. Evidence of cardiocyte apoptosis in myocardium of dogs with chronic heart failure. Am I Pathol 1996;148:141-149.

28] Lee YS, Chou YY. Electron microscopic observations of apoptotic cells in various etiologies of human cardiovascular diseases. Chin Med J 1998; 111:428-432.

29] Condorelli $G$, Morisco $C$, Stassi $G$, et al. Increased cardiomyocyte apoptosis and changes in proapoptotic and antiapoptotic genes bax and bcl-2 during left ventricular adaptations to chronic pressure overload in the rat. Circulation 1999:99:3071-3078. 
Arends MJ, Morris $\mathbb{R G}$, Wyllie AH. Apoptosis. The role of the endonuclease. Am I Pathol $1990 ; 136: 593-608$.

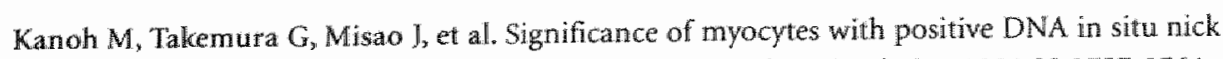
end-labeling (TUNEL) in hearts with dilated cardionyopathy. Circulation 1999;99:2757-2764.

Sanders EJ. Methods for detecting apoptotic cells in tissues. Histol Histopathol 1997;169-1177.

33] Allen RT, Hunter WJ 3rd, Agrawal DK. Morphological and biochemical characterization and analysis of apoptosis. J Pharmacol Toxicol Methods 1997;37;215-228.

34) Depre C and Taegtmeyer $H$. Metabolic aspects of programmed cell survival and cell death in the heart. Cardiovasc Res 2000;45:538-548.

35] Long X, Boluyt MO, Hipolito ML, et al. $p 53$ and the hypoxia-induced apoptosis of cultured neonatal rat cardiac myocytes. IClin Invest 1997;99:2635-2643.

361 Chen SI, Bradley ME, Lee TC. Chemical hypoxia triggers apoptosis of cultured neonatal rat cardiac myocytes: modulation by calcium-regulated proteases and protein kinases. Mol Cell Biochem $1998 ; 178: 141-149$.

37) Wiggers H, Noreng M, Paulsen PK, Nielsen TT. Metabolites in biopsies from hibernating myocardium show no evidence of chronic ischemia. Circulation 1998; 98: I-769 (Abstract).

381 Borgers $M$, De Nollin S, Thoné F, Wouters L, Van Vaeck L, Flameng W. Distribution of calcium in a subset of chronic hibernating myocardium in man. Histochem 1 1993;25:312-318.

39] Ausma J, Thoné F, Dispersyn GD, et al. Dedifferentiated cardiomyocytes from chronic hibernating myocardium are ischemia-tolerant. Mol Cell Biochem 1998;186:159-168.

40) Hacker TA, Renstrom B, Nellis SH, Liedtke AJ. Effect of repetitive stunning on myocardial metabolism in pig hearts. Am I Physiol 1997;273:111395-1402.

41. Cheng W, Li B, Kajsstura I, et al. Stretch-induced programmed myocyte cell death. I Clin Invest 1995:96:2247-2259.

42) Li Q, Li B, Wang $X$, et al. Overexpression of insulin-like growth factor-1 in mice protects from myocyte death after infarction, attenuating ventricular dilation, wall stress, and cardiac bypertrophy. J Clin Invest 1997;100:1991-1999.

431 Leri A, Claudio PP, Li Q, et al. Stretch-mediated release of angiotensin II induces myocyte apoptosis by activating $\mathrm{P} 53$ that enhances the local renin-angiotensin system and decreases the $\mathrm{BCl}-2 \times$ ton Bax protein ratio in the cell, J Clin Invest 1998;101:1326-1342.

44] Sadoshima J, Xu Y, Slayter HS, Izumo S. Autocrine release of angiotensin II mediates stretchinduced hypertrophy of cardiac myocytes in witro. Cell 1993;75:977-984. 


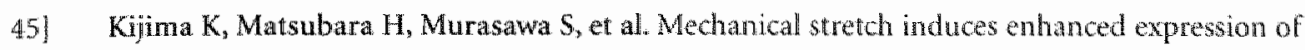
angiotensin Il receptor subtypes in neonatal rat cardiac myocytes. Circ hes 1996;79:887-897.

46] Leri $A$, Liu $Y$, Claudio PP, et al. Insulin-like growth factor-1 induces Mdm2 and down-regulates p53, attenuating the myocyte renin-angiotensin system and stretch-mediated apoptosis. Am I Pathol 1999:154:567-580.

47] Tanaka $M$, Fujiwara $H_{*}$ Yamasaki $K$, et all. Expression of heatt shock protein after ischemic preconditioning in rabbit hearts. Jpn Circ J 1998;62:512-516.

48] Arrigo AP, Suhan JP, Welch WI. Dynamic changes in the structure and intracellular locale of the mammalian low-molecular-weight heat shock protein. Mol Cell Biol 1988;8:5059-5071.

49] McMillan DR, Xiao X, Shao L, Graves K, Benjamin IJ. Targeted disruption of heat shock transcription factor 1 abolishes thermotolerance and protection against heat-inducible apoptosis. J Biol Chem 1998;273:7523-7528.

501 Bartling B, Hoffmann J, Holtz J, Schulz R, Heusch G, Darmer D. Quantification of cardioprotective gene expression in porcine short-term hibermat ting myocardium. I Mol Cell Cardiol 1999; 31:147158.

51] Knowlton AA, Kapadia S, Torre-Amione G, et al. Differential expression of heat shock proteins in normal and failing human hearts. J Mol Cell Cardiol 1998;30:811 818.

52] Adler CP, Friedburg H, Herget GW, Neuburger M, Schwalb H. Variability of cardiomyocyte DNA content, ploidy level and nuclear number in mammalian hearts. Virchows Arch 1996;429:1591.64. 
24 
Chapter 2

\section{Cardiomyocyte remodeling during myocardial hibernation and atrial fibrillation: prelude to apoptosis?}

Gerrit D. Dispersyn, Jannie Ausma, Fred Thoné, Willem Flameng, Jean-Louis J. Vanoverschelde, Maurits A. Allessie, Frans C.S. Ramaekers, Marcel Borgers 
Objechive similar stmictural changes in the myocardium can be observed in chromic hibernating myocardium and in myocardium taken from hearts suffering chronic atrial fibrillation. We investigated whether or not these changes are indicative of apoptosis.

Methods. Myoctardial biopsies from 28 stricty selected patients with chronic hibernating myocardium and heart samples from 13 goats whth pacing induced Chronic atrial fibrillation were used. Specual attention was paid to processing the filsstres immediately (Cxation / freezing) in order to prevent artificial degenerative changes, thereby excluding false positive identification of apoptosis. Infarcted areas or infarcted border zones were excluded from our study, Apoptosis was detected with light and electron microscopy and terminal deoxynucleotidyl transferase nick end labeling. Immunohistochemistry was used for detecting B 12 , P5 3 and PCNA proteins associated with apoptosis/ BNA chanage,

Resuls: The results obtained for chronic libernating left ventricular myocardium were sinilar to those for chronic fibrillating atrial myocardium. No apoptotic nucle, as characterized by extensive chromatin clumping, could be observed in nommal or dediferentiated cardionyocytes under the electron microscope. The end-labeling assay did not reveal any cardionyocytes with damag d DNA. Nor could we find any evidence of substantial expression of $\mathrm{Bd} / 2, \mathrm{P} 53$ or PCNA, a result indicitive of the absence of apoptotic threat or
DNA damage.

Conchusions Cardiomyocyte dedifferenthation, but not extensive degeneration through apoptosis, can be observed in chronic hibernating myocardium and chronic fibrillating atrium, Dediflerentiaton may be he best way to survive prolonged exposure to the unfavorable conditions umposed by increased wall stiess, a relative lowered oxygen environment, or both. 


\section{Introduction}

Myocardial hibernation is a condition whereby the heart downgrades its contractile function in response to a reduced blood supply. Consequently the heart tries to restore a normal - or near to normal - oxygen supply/demand ratio and succeeds in preserving myocardial viability [1]. Typical for myocardial hibernation is the recovery of function after restoration of the blood flow, which can occur rapidly (within hours; acute hibernation) or slowly to very slowly (weeks to months; chronic hibernation) [2]. A remodeling of the myocardial structure takes place in chronic hibernating myocardium (CHM). The structural changes that can be observed consist of depletion of sarcomeres (myolysis), sarcoplasmic reticulum and T-tubules, together with the appearance of large masses of glycogen, the reappearance of strands of rough endoplasmic reticulum, the transformation of normal mitochondria into numerous small abnormally shaped mitochondria and nuclei with altered chromatin distribution $[3,4]$. That these changes are not degenerative, but rather present a state of dedifferentiation, is suggested by the reoccurrence of "early development markers" of heart muscle during chronic hibernation. For example, $\alpha$-smooth muscle actin is expressed in CHM and also in embryonic/fetal heart muscle cells, but not in adult cardiomyocytes [4].

To our knowledge, no validated animal model for CHM has been reported to date. However, there is a model involving experimentally induced chronic atrial fibrillation (CAF) in goats $[5,6]$ that shows structural alterations resembling those seen in CHM. As in CHM, the main characteristic subcellular change concerns myolysis and glycogen accumulation. The affected cardiomyocytes also adopt a dedifferentiated phenotype, as indicated by the re-expression of some proteins normally expressed only in embryonic/fetal cardiomyocytes and the disappearance of proteins typical of adult heart muscle cells, such as cardiotin [7].

Although there is evidence to show that dedifferentiating cardiomyocytes in $\mathrm{CHM}$ and chronic fibrillating atrium (CFA) are not suffering from ischemia [8,9], some doubts remain as to whether dedifferentiation is a long-lasting viable state that has the potential to reverse to normal [10]. Cell death through apoptosis is indeed suggested by some very recent reports $\mid 11,12]$. Apoptosis is a highly regulated and energy-consuming form of intentional suicide for the cell, executed via a genetically regulated programme [13]. Apoptotic regulation seems to involve multiple pathways, resulting in either apoptosis induction or apoptosis inhibition. The upregulation of $\mathrm{Bcl}-2$ expression is known to be correlated with protection against apoptosis [14], and the overexpression of 553 results in apoptosis induction [15]. During apoptosis, the nuclear DNA is degraded in a specific way, resulting in double-stranded DNA fragments with sizes in multiples of 180 to $200 \mathrm{bp}$ [16]. Cardiomyocyte death via apoptosis has already been reported in postnatal cardiogenesis [17,18], and in myocardial infarction [19-23], but it also plays a role in idiopathic dilated cardiomyopathy [24], arrhythmogenic ventricular dysplasia 
[25] and in the progression to heart failure $[20,23,26]$,

The main objective of this work is to assess whether CHM or CAF eventually results in cardiomyocyte death through apoptosis. The search for apoptotic phenomena involved the use of electron microscopy and immunohistochemical detection of apoptosis-related proteins and DNA fragmentation.

\section{Material and Methods}

\section{Patients/Chronic Hibernating Myocardium}

The human cardiac tissue material used in this study consisted of transmural biopsies from 28 patients, the biopsies being obtained during coronary bypass surgery. Strict patient selection criteria were employed. The biopsies were taken from hypo/akinetic left ventricular segments at the time of coronary bypass surgery, as detailed in previous studies $[27-29]$. In brief, all the patients had severe LAD stenosis and a decreased wall motion and regional ejection fraction as evaluated by angiography and 2D echocardiography. None of the patients showed signs of infarction on ECG and viability of the tissue was verified by positron emission tomography (PET) and postoperative (3 to 6 months) recovery of regional contractile function and ejection fraction. The detailed individual patient characteristics regarding degree of stenosis, anterior wall abnormalities, flow-metabolic match or mismatch, and functional recovery after coronary bypass surgery, hawe been described in previous papers $[28,29]$.

The investigation conforms with the principles outlined in the Declaration of Helsinki (Cardiovascular Research 1997;35:2-3) and was approved by the ethical committees for research of the Universities of Leuven and Louvain. Importantly to this study, we restricted our observations to myocardial segments entrely devoid of infarctions, and we stress that all the tissue samples were processed immediately, in order to avoid post-operative degenerative changes.

\section{Animals/Chronic Atrial Fibrillation model}

In this study, 20 female goats were used. CAF was induced in 13 of these animals, and 7 with sinus rhythm were used as controls. Animal handling was carried out according to the Dutch Law on Animal Experimentation (WOD) and the European Directive for Protection of Vertebrate Animals used for Experimental and other Scientific Purposes. The investigation conforms with the Guide for the Care and Use of Laboratory Animals published by the US National Institutes of Health (NIH Publication $\mathrm{n}$. 85-23 revised 1996).

CAF was induced by electrical pacing with a fibrillation pacemaker. The animals were kept in sustained atrial fibrillation for $9-23$ weeks. The procedure has been described by Wijfels et al. 
[5]. At the end of the experimental period, the goats were anesthetized and the hearts were quickly removed. Parts of the left and right atrial free walls were cut into small blocks and prepared for morphologic and cytochemical examinations [6].

\section{Morphologic evaluation}

Light and electron microscopy were used to search for morphologic apoptotic phenomena and to exclude infarcted areas. Immediately after they had been taken, samples were fixed in $3 \%$ glutaraldehyde buffered to $\mathrm{pH} .4$ with $90 \mathrm{mM} \mathrm{KH}_{2} \mathrm{PO}_{4}$ for at least 2 hours, washed in the buffer supplemented with $220 \mathrm{mM}$ sucrose and postfixed with $2 \% \mathrm{OsO}_{4}$ in $50 \mathrm{mM}$ veronal acetate buffer for 1 hour. Dehydration in graded series of alcohol and embedding in epoxy resin were done by standard procedures. Ultrathin sections were cut from each sample, counterstained with uranium acetate and lead citrate, and examined in a Philips CM100 electron microscope.

For light microscopic evaluation, 2-micron thick sections were stained with periodic acidSchiff (PAS) and $0.1 \%$ toluidine blue. This staining procedure is effective in visualising contractile elements and glycogen, enabling the degree of sarcomere loss (myolysis) and the content of glycogen to be determined. These changes were scored visually by methods detailed elsewhere [3]. Cells were classified as affected if sarcomere depletion accounted for more than 10\%. All samples were examined for the possible appearance of changes characteristic of apoptosis, such as shrinking of the cell cytoplasm accompanied by a rise in cell density, condensation of the nuclear chromatin and its segregation into sharply delineated masses against the nuclear membrane, karyorhexis or the 'budding' phenomena and the occurrence of apoptotic bodies. At least two sections of both left and right atriall free wall from cach goat were evaluated using light microscopy. The number of evaluated nucleated cardiomyocytes in each section varied between 262 and 368 . Light microscopic evaluation of human biopsies comprised at least two sections per patient (one of the endocardial and one of the epicardial region). The mean number of evaluated nucleated cardiomyocytes in each section was 208 , ranging from 82 to 465 .

\section{Immunohistochemical staining procedures}

The following primary antibodies were used for immunohistochemistry:

1) A mouse monoclonal antibody, clone 124 (DAKO A/S, Glostrup, Denmark), against the human $\mathrm{BCl}-2$ oncoprotein (molecular mass $25 \mathrm{kDA}$, specific for an epitope residing between amino acids 41 and 54.

2) A mouse monoclonal antibody, clone DO-7 (DAKO), against the human tumor suppressor gene product $P 53$, both the wild type and mutant type. The antibody reacts with an epitope between amino acids 19 and 26 . 
3) The monoclonal antibody $\mathrm{PC10}$, against proliferating nuclear antigen (PCNA), whic was kindly provided by D. Lane, Dundee, UK.

4) A polyclonal rabbit anti digoxigenin antibody (Sigma Immunochemicals, St. Louis USA) used for the TUNEL assay.

Tissue samples were frozen in isopentane precooled with liquid nitrogen, immediately afte: having been taken, and stored at $-70^{\circ} \mathrm{C}$. Five micron frozen sections were cut and stored a $-20^{\circ} \mathrm{C}$ until use.

For the detection of apoptosis, $\mathrm{BCl}-2$ and $\mathrm{P} 53$, at least 6 sections per patient and at least \& sections per goat (4 of both left as right atrial free wall) were evaluated. The mean number of nucleated cardiomyocytes in each section from patient biopsies was 152 ranging from 27 to 442. The mean number of nucleated cardiomyocytes in the frozen sections from goat atrial free wall was 835 ranging from 440 to 1320 .

\section{Immunohistochemical detection of apoptosis}

The terminal deoxynucleotidyl transferase (TdT) mediated dUTP Nick End Labeling method (TUNEL) was used for detecting cells with nuclear DNA fragmentation, suggestive of apoptosis [30]. Frozen sections $5 \mu \mathrm{m}$ thick were air-dried before fixation in $4 \%$ paraformaldehyde (Merck, Darmstadt, Germany) in PBS brought to $\mathrm{pH} 7.4$ (10 minutes). After the sections had been washed in PBS ( $3 \times 10$ minutes), endogeneous peroxidase activity was blocked by incubation in $0.3 \% \mathrm{H}_{2} \mathrm{O}_{2}$ in $\mathrm{PBS}$, followed again by three washing steps ( 5 minutes each) in PBS. The sections were then treated with a solution of $0.1 \mathrm{M}$ citric acid and $0.5 \%$ Triton $\mathrm{X}-100$ ( $\mathrm{t}$ Octylphenoxypolythoxyethanol; Sigma) for 10 minutes at $0^{\circ} \mathrm{C}$ and rinsed $(2 \times 5$ minutes) in PBS and in $25 \mathrm{mM}$ Tris-HCl (pH 7.4) (3.5 minutes). For the TUNEL reaction, the sections were incubated for 1 hour at $37^{\circ} \mathrm{C}$ in a TdT reaction buffer $(10 \mu 15 \times \mathrm{TdT}$ reaction buffer $(\mathrm{pH}$ 6.6) supplemented with: $5 \mu 125 \mathrm{~m} \mathrm{M} \mathrm{CoCl}_{2}$, 0.5 $\mu \mathrm{l} \mathrm{TdT}\left(25 \times 10^{3}\right.$ units/ml; Boehringer Mannheim, Mannheim, Germany) and $0.5 \mu$ digoxigenin-11-2'-deoxy-uridine-5t-triphosphate (11 mM; Boehringer Mannheim) diluted to $50 \mu$ with distilled water.

The 5xTd reaction buffer consists of $1 \mathrm{M}$ potassium cacodylate (Merck), $125 \mathrm{mM}$ Tris- $\mathrm{HCl}$ (Sigma) and $1.25 \mathrm{mg} / \mathrm{ml}$ bovine serum albumin (BSA; Sigma). To finish the reaction, the sections were washed for 5 minutes in $4 x$ saline-citrate solution (SSC) and then in 0.1\% BSA in PBS ( $2 \times 5$ minutes). For the detection of the incorporated digoxigenin-linked nucleotides, the sections were incubated in a 1:100 dilution of the primary antibody (rabbit anti-digoxigenin) in PBS for 1 hour at room temperature, followed by three washing steps in PBS and incubation ( 45 minutes; room temperature) in a peroxidase-conjugated swine anti-rabbit antibody solution (diluted 1:100 in PBS). After the sections had been washed with PBS ( $3 \times 10$ minutes) and distilled water ( 5 minutes), peroxidase activity was detected, with 3-amino-9-ethylcarbazole 
(AEC, Sigma) used as chromogen. For this, $40 \mathrm{mg}$ AEC was dissolved in $10 \mathrm{ml} \mathrm{N}, \mathrm{N}$ dimethylformamide (Merck) and added to $190 \mathrm{ml} 0.05 \mathrm{M}$ sodium acetate buffer ( $\mathrm{pH} 4.95$ ). Hydrogen peroxide was added to a final concentration of $0.01 \%(\mathrm{v} / \mathrm{v})$. After incubation for 10 minutes, the sections were rinsed with tap water, counterstained with hematoxylin (Sigma), and mounted with Kaiser's glycerol gelatine (Merck).

\section{Immunohistochemical detection of $\mathrm{Bcl}-2$ and $\mathrm{P} 53$}

Five- $\mu \mathrm{m}$ thick frozen sections were air-dried, fixed in methanol $\left(-20^{\circ} \mathrm{C}\right.$ for 30 seconds) followed by acetone $\left(-20^{\circ} \mathrm{C}\right.$ for 15 seconds), and air-dried again. To block endogenous peroxidase activity, the sections were incubated for 15 minutes in $0.3 \% \mathrm{H}_{2} \mathrm{O}_{2}$ in phosphate buffered saline (PBS) and then rinsed in PBS ( $3 \times 10$ minutes). The sections were incubated in the primary antibody solution (diluted 1:25 in PBS) at room temperature for 1 hour, washed in PBS ( $3 \times 10$ minutes), and incubated in a solution containing the secondary, biotinylated horse anti-mouse antibody (Vector Laboratories, Burlingame, USA), at a dilution of 1:100 in PBS, for 45 minutes at room temperature. An avidin-peroxidase complex (diluted 1:100 in PBS) (Vectastain ABC kit, Vector Laboratories) was applied for 30 minutes. After rinsing the sections with PBS $(3 \times 10$ minutes $)$ and distilled water ( 5 minutes), staining (with AEC as chromogen), counterstaining, and mounting was performed as described above.

This procedure was performed on cardiac tissue from patients with $\mathrm{CHM}$, normal human cardiac tissue (from an explant donor), and cardiac tissue from both control goats and goats with CFA.

\section{Immunohistochemical detection of PCNA}

With exception of the fixation step and the applied antibodies, the procedure for PCNA detection was the same as for the detection of $\mathrm{BCl}-2$ and $\mathrm{P} 53$. After having been air - dried, the 5 - $\mu$ m cryostat sections were fixed in 3.7\% formaldehyde (Acros Organics, Geel, Belgium) in PBS for 2 minutes at room temperature. The primary antibody, $\mathrm{PCl} 0$, was applied diluted 1:25 in PBS, for 1 hour at $37^{\circ} \mathrm{C}$. The sections were incubated in a biotinylated goat anti-mouse antibody (diluted 1:100 in PBS) (Vector Laboratories) solution at room temperature for 30 minutes.

\section{Control reactions}

For the $\mathrm{Bcl}-2, \mathrm{P} 53$ and PCNA detection assays, negative controls consisted of incubations in which the primary antibody was omitted from the solutions. The negative controls for the TUNEL reaction consisted of incubations in a medium from which $T d T$ was omitted. As positive controls for the $\mathrm{Bcl}-2$ detection, we used cryostat sections of human lymphoma tissue, human 
spleen, goat lymph node and goat spleen [31]. For the P53 and PCNA detection, the positiv controls used were frozen sections of respectively UV-irradiated skin and reactive lymph nod. from human volunteers [32]. The positive control for the TUNEL reaction comprised frozer sections of guinea-pig thymus and DNAse-treated myocardium from mouse, control goat anc goat with CAF. Frozen sections of mouse and goat myocardium were fixed in a $4 \%$ paraformaldehyde solution and subsequently rinsed in PBS, as described above. They wer then incubated in a soltution of $1 \mathrm{Hg}$ DNAse I (Sigma) in $100 \mu$ reaction buffer ( $50 \mathrm{mM}$ sodium acetate, $10 \mathrm{mM}$ magnesium chloride and $2 \mathrm{mM}$ calcium chloride) for 10 minutes at $37^{\circ} \mathrm{C}$. The sections were rinsed three times in PBS at $4^{\circ} \mathrm{C}$ before the TUNEL assay was performed.

\section{Gel electrophoresis and Western blot analysis}

To control the immunohistochemical results concerning the Bcl-2 expression, ten frozen sections of $10 \mu \mathrm{m}$ thickness were cut from each of the following tissue samples: human normal heart, human spleen, atrial tissue from goat in sinus rhythm, atrial tissue from goat with CFA and goat spleen. The human tissues were both derived from an explant donor. The sections were botled lor 5 minutes in sample buffer containing $62.5 \mathrm{mM}$ Tris-HCl $(\mathrm{pH} 6.8), 8 \% \mathrm{glycerol}, 2 \%$ SDS and $0.00125 \%$ bromophenol blue. After centrifugation, the protein content of the supernatant was assessed by a BCA protein assay (Pierce, Rockford, IL, USA), and all samples were diluted with sample buffer to the same protein concentration. After addition of $10 \% 2$ mercaptoethanol (Bio-Rad, Hercules, CA, USA), the samples were boiled again for 5 minutes. One-dimensional SDS-gel electrophoresis was done using $12 \%$ Ready Gels (Biomad) in a Ready Geli cell system (Bio-Rad). Equal amounts of protein were loaded on the gels, and those were run for $15 \mathrm{~min}$ at $60 \mathrm{~V}$ and 1 hat $120 \mathrm{~V}$. Thereafter, protems were blotted on a nitrocellulose membrame (Hybond $\mathrm{C}$ pure, Amersham Life Science, Buckinghamshire, England) using a Transblot SD semi dry transfer cell (Bio-Rad).

After rinsing the membranes with $A D$, they were blocked for th at $R T$ using PBS containing 5\% non-fat dry milk (Bio-Rad) and 0.05\% Tween-20 (Polyoxyethylene-20-sorbitan monolaurate, Acros). The same buffer was used to dilute the antibodies. After overnight incubation with the primary antibody (clone $124, \mathrm{DAKO}, 1: 25$ ) at $4^{\circ} \mathrm{C}$, the blots were rinsed with PBS containing 0.05\% Tween-20, and subsequently incubated for th at RT with the secondary antibody (Donkey anti-mouse Ig, horseradish peroxidase conjugated, Amersham, 1:2000). Then the blots were extensively washed and peroxidase activity was detected by chemoluminescence (Lumi-Light plus, Boehringer Mannheim). High performance chemiluminescence film (Hyperfilm ECL, Amersham) was used for visulization of the luminescent signals. 


\section{Results}

Morphologic evaluation

In the biopsies from the group of 28 patients with CHM, an average of $27.1 \%$ of the cardiomyocytes were affected by sarcomere depletion to more than $10 \%$ and by glycogen accumulation. The atria of the 13 goats showed similar changes, in approximately $50 \%$ of the cells. In addition to these typical changes, specific alterations were noted in the nuclear morphology of cardiomyocytes derived from CHM patients. Two types of nuclei with altered morphology could be distinguished. In one type, the chromatin was evenly dispersed, closely resembling nude of embryonic/fetal cardiomyocytes (Figure 1b). The other type showed an irregular chromatin distribution, with clumps at the nuclear membrane and throughout the nucleoplasm (Figure 1c). The detailed quantification and evaluation of these nuclear changes has been described elsewhere [9]. In brief, redistribution of heterochromatin in a pattern similar to that found in fetal cardiomyocytes was seen in $67 \%$ of the affected cells (Figure 11 b). Clumping of chromatin was found in $13 \%$ of the affected cardiomyocytes. (Figure $1 \mathrm{c}$ ), while $20 \%$ of the cells showed a normal margination of chromatin (Figure la).

We found none of the features characteristic of apoptosis, such as shrinking of the cell cytoplasm accompanied by a rise in cell density, condensation of the nuclear chromatin and its segregation into sharply delineated masses against the nuclear membrane, karyorhexis or the 'budding' phenomena, or the occurrence of apoptotic bodies.

Figue : Electron microscopio detals of a nucleus with nomal heterochromatin distributron (a) and nuclei of chronic hibemating cardionnocytes. Two types of altered nuclear morphology condd be distinguished: nucle with homogeneotyly dispersed heterochromatin (b), therety resembing nude of retal cardomyocytes, and suclei with clumping of heterothomatin throughout the nucleoplasm (c). (a) $1025 x, 0.4090 x, 03785 x)$

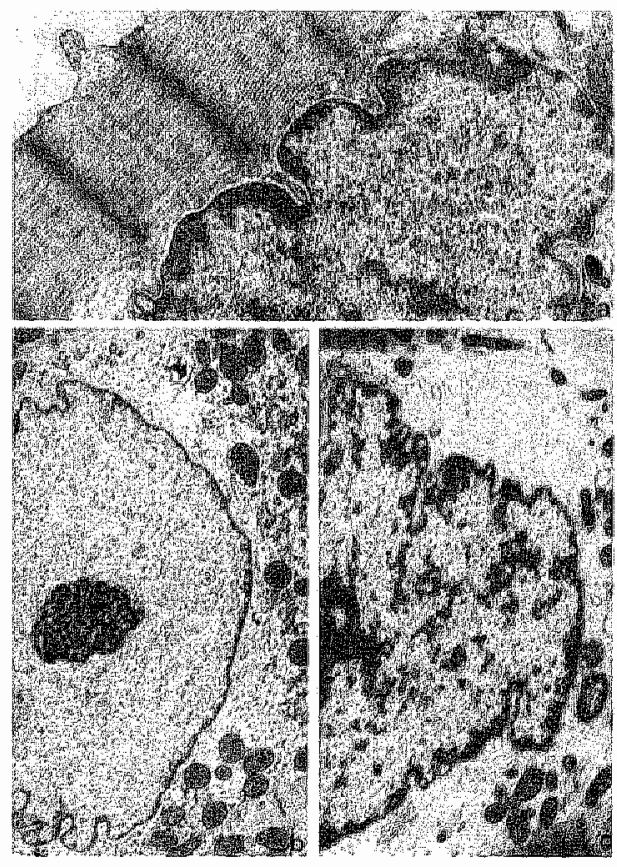




\section{Immunohistochemical evaluation}

The detection of cells with DNA nicks, thus potentially apoptotic, with the TUNEL method revealed no positive cardiomyocytes from CHM (Figure 2a), CFA (Figure 2b) or control goats. In one section of $\mathrm{CHM}$ there was one cell, probably an interstitial cell of mesenchymal origin, that showed intense staining (Figure $2 \mathrm{a}$, insert). In the sections of atria from goats with CAF or sinus rhythm, a minority of the interstitial cells - possibly fibroblasts or endothelial cells stained positive. Many thymocytes, spread throughout the guinea pig thymus, were TUNEL positive, as expected (Figure 2c). In the DNAse-treated myocardial sections from mouse, control goat and goat with CAF, most of the nuclei - both from cardiomyocytes and interstitial cells also stained positive (data not shown).

As far as the expression of the oncoprotein Bcl-2 in cardiac tissue of human CHM (Figure 2d), goats in CAF (Figure 2e) and goats in sinus rhythm is concerned, no positively stained cardiomyocytes - myolytic or normally structured - could be observed. Normal human cardiac tissue was also free of positively stained cardiomyocytes (data not shown). Occasionaly, interstitial cells (probably fibroblasts or endothelial cells) were found to be slightly stained positive for $\mathrm{Bcl}-2$ (data not shown). In the control reactions with human lymphoma tissue and human spleen, many cells stained intensely for Bcl-2 (data not shown). A similar Bcl-2 reactivity could be observed in goat spleen (Figure $2 \mathrm{f}$ ) and lymph node (data not shown).

The tumour suppressor gen product P53 was equally not detectable in cardiomyocytes or interstitial cells derived from CHM patients (Figure $2 \mathrm{~g}$ ), from normal human cardiac tissue (not shown) or from goats in sinus rhythm. Only two cells in cardiac tissue from goats in CAF displayed reaction product in the perinuclear cytoplasm, a localization not conforming with the normal nudear residence of P53 (Figure $2 h$, insert). On the basis of their topographical localization and their size, these two cells were probably cardiomyocytes. Several P53-positive nucleated keratinocytes were found in the epidermis of the UV-irradiated human skin (Figure 2i).

Proliferating Cell Nuclear Antigen (PCNA) expression could not be detected in cardiac tissue of CHM, CFA or control goats. All cells, including the affected and unaffected cardiomyocytes, were PCNA negative, in contrast to many lymphocytes in human reactive lymph node tissue (data not shown).

\section{Western blot analysis}

The expression of Bcl- 2 in cardiac tissue was also assessed using Western blot analysis. Human and goat spleen were used as positive control. The results show that there is a large constitutive expression of $\mathrm{BCl}-2$ in human spleen. However we also could detect some $\mathrm{Bcl}-2$ expression in normal human heart, however the level of expression is lower, since the signal was much less, 

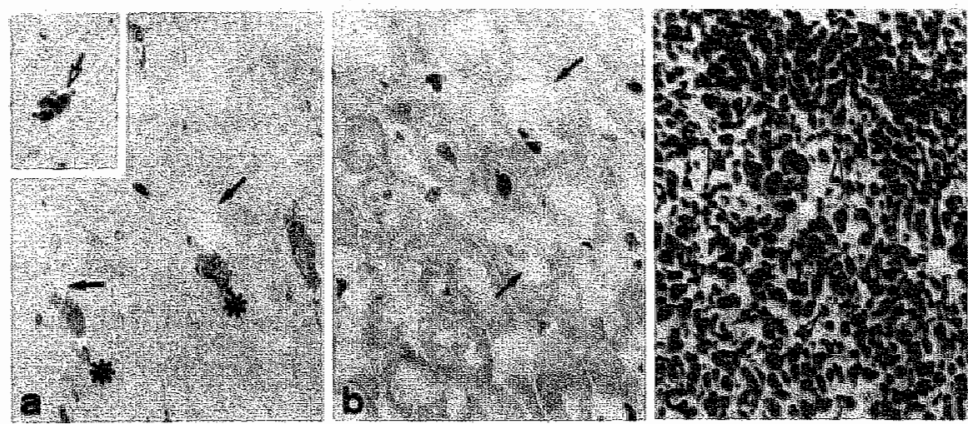

Figure 2a-c: Apoptosis detection with the TUNEL procedure: Light microscopic images of CHM (a), CFA (b) and gunea pir thym (C). None of the cardiomyocytes of CHM and CFA stained. Only one interstitial cell in CHM was tound to be positive (open arrow) (inser" of fig. 2a). The green/brown perinudear granulles consist of lipotuscin (astensks). Note he myolytic perinuclear areas (arrows), In the guinea pig thymus, used as positive control, scattered apoptotic thymocytes were found to be stained (arrowhed 5$)(c)$. (a:214x, insert $174 x, b: 214 x, c 214 x)$
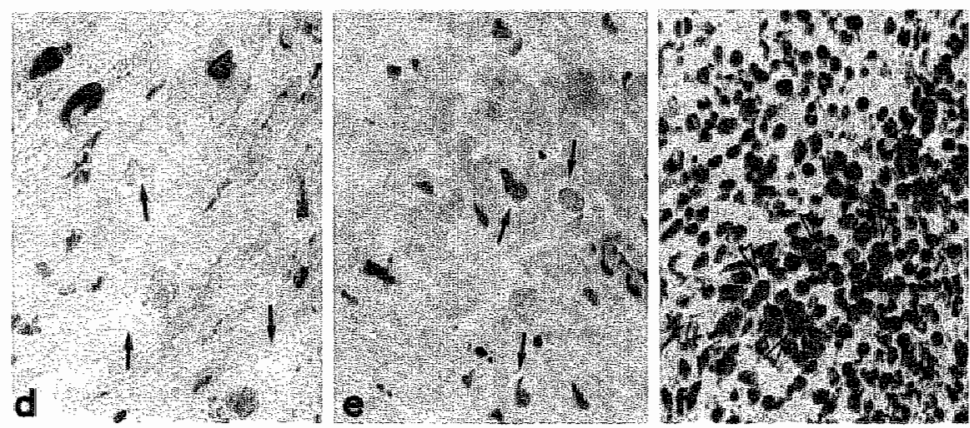

Fugute 2d-f: Light microscopic images of immunohistochemical Bd-2 detertion in (CHA (d) and CFA (e). All the cardionyocytes and inferstitial cels are negative in myocardial tissue from CHM and CFA Myolytic perintudear areas (arrows) Scattered Bcl. 2 postave cels (arrowheds) can be obseved in goat spleen tissue, used as positive control ( $)$. (4:214x, 214x, $1258 \mathrm{x})$
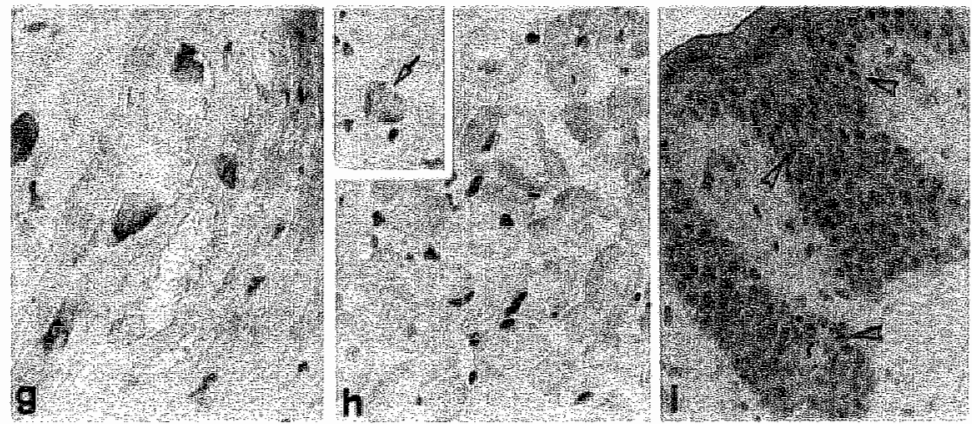

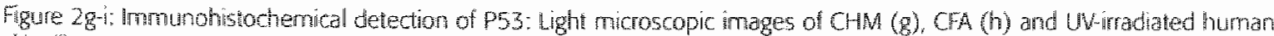
skin (G). None of the cells present in CHM was found to be stamed. Orly wo cells in CFA, of which one is shown in the inser of fig. 2h, were PS3-positwe (open arow). However P53 did not show the normal nudear distribution in this cell. Myotytic

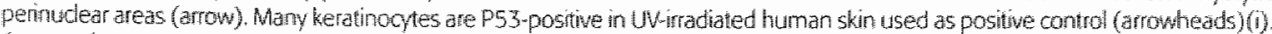
(8.214x, h:214x, insent208x, i86x) 
although equal arnounts of protein were loaded (Figure 3). Many attempts to demonstrate $\mathrm{Bcl}-2$ expression in goat tissue, did not come up with clear results. No or only faint signals could be detected in goat spleen, whereas goat heart (both from control goats as goats with CFA) was never positive (Figure 3).

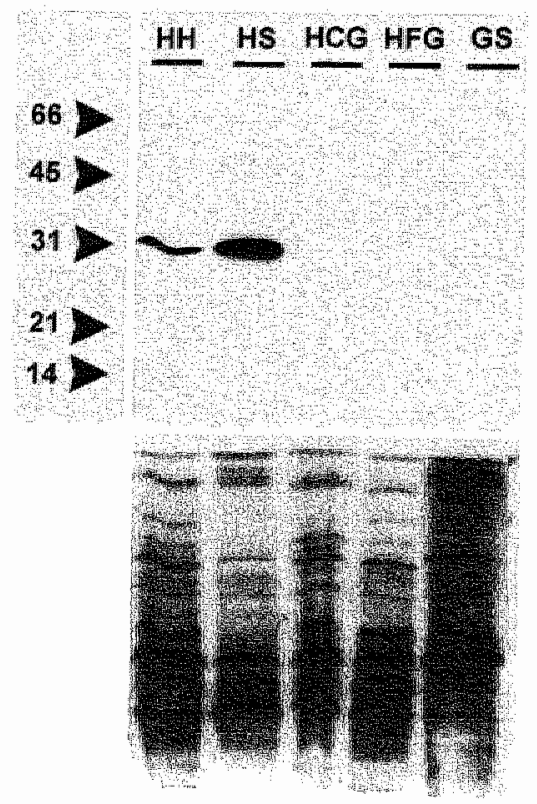

Fugure 3: Westem blot analysis of Bd-2 explession in human control heart $(\mathrm{HH})$, humben spleen (HS), cardiac muscle from goats in sinus thythm (HCO) and goats with CFA (HFC), and goat splear (GS). Significant expression of $\mathrm{BCl} 2$ in human spleen, lower expression in nomal human heart. Cubat sphern was BCl-2 negatwe, or only slightly positive, whereas cardiac muscle from the goat (both nomal and Chy goats) was always.
negative (panel a)

The protein content of al the samples was the same as deternined by Ponceau Red staining (panel b) 


\section{Discussion}

In chronic hibernating myocardium ( $\mathrm{CHM}$ ), a number of typical structural changes are seen in cardiomyocytes suggestive of dedifferentiation, i.e. a phenotype switch to an earlier developmental stage $[3,4]$, although it is uncertain whether this dedifferentiated state is stable. Some researchers, however, interpret some of the changes observed as degenerative, and believe that the process ends in cell death [10-12]. In this study, we tried to assess whether cell death via apoptosis occurs in CHM in humans and in chronic fibrillating atrium (CFA) in the goat, the only animal model available with structural changes resembling those of CHM $[6,7]$.

\section{Nuclear morphology}

When we limited our observations strictly to viable areas, thus excluding areas of infarctions or infarction border zones, morphologic evaluation of the tissue samples revealed no apoptotic phenomena. We were unable to detect any 'endstage' apoptotic cells or apoptotic bodies. Although nuclear changes were seen in some cells in the affected areas, only the minority of cardiomyocytes from $\mathrm{CHM}$ had nuclei in which the heterochromatin distribution was irregular and patchy, showing some resemblance with nuclei of degenerative cells. The origin of this altered chromatin distribution is, however, not clear. It remains doubtful whether such changes are related to an early degenerative phenomenon, because the cells display no other subcellular degenerative alterations. The ultimate condensation of chromatin, so characteristic of apoptotic nuclei was not found, nor were any nuclear fragments detected. On the contrary, many dedifferentiated (myolytic) cells showed quite the opposite of condensed chromatin, i.e. virtual disappearance of clustered heterochromatin, giving the nuclei a pale look. The latter chromatin distribution pattern strongly resembles that seen in embryonic/fetal cardiomyocytes.

\section{DNA damage and apoptosis-related proteins}

Apoptosis in the heart has been reported to play a role in postnatal morphogenesis |17|, but is also likely to be present in a variety of cardiomyopathies. With the TUNEL method, we were unable to identify any cardiomyocytes with TdT reactivity in cardiac tissue from $\mathrm{CHM}$ and CFA. DNA damage was thus probably absent in these cells. This conclusion is corroborated by that fact that TUNEL positivity was obtained in properly treated positive control tissue, such as cardiac samples after DNAse exposure and guinea-pig thymus. It is therefore unlikely that apoptosis is a frequently occurring phenomenon in CHM and CAF.

Although the exact mechanism is unknown, $\mathrm{Bcl}-2$ is considered to be a protein that protects the cell against apoptosis [1.4]. No Bcl-2 expression could be detected immunohistochemically in the cardiomyocytes from CHM, CFA and normal heart (both from human and goat). Whether Bcl-2 expression is present in normal myocardium has not yet been unambiguously 
proven $[33-37]$. Also in this study, some data are not completely in concert: we found low expression levels of $\mathrm{BCl}-2$ in the normal human heart using Western blot, but we could not detect $\mathrm{BCl}-2 \mathrm{imm}$ unohistochemically in the same tissue. We argue that the expression levels of $\mathrm{Bel}-2$ in normal human heart is too low to be detected with the immunohistochemical method used, and/ or that cardiomyocytes are not the major source of this protein. Because Bcl-2 could also not been picked up immunohistochemically in CHM, we suggest that the expression level of $\mathrm{BCl}-2$ does not increase markedly in this setting. Unfortunately we were unable to confurm this hypothesis by Western blot analysis, because of the limited size of the biopsies, and their limited availability at present. Western blot analysis of goat cardiac tissue did not come up with clear results. Goat spleen, which was shown to have a high expression level of Bcl-2 using immumohistochemistry, was not or only slightly positive on Western blot, and cardiac tissue from goats al ways negative. Therefore we hypothesize that during the process of tissue sampling (in order to prepare it for Western blot), most of the goat Bcl-2 - if not all undergoes profound changes, so that it no longer can be detected by the primary antibody. It has been described before that an increase in $\mathrm{Bcl}-2$ in cells may represent a reaction to oppose programmed cell death [37]. From the here presented results, a significant increase in Bcl-2 expression in cardiomyocytes from CHM and CFA is not likely, so one may assume that these cardiomyocytes are more prone to undergo apoptosis, if a trigger for this kind of cell death were present. However, we could not find evidence for increased apoptosis, nor increased Bcl2 levels in CHM and CFA, so it is possible that these combined results indicate that the cardionyocytes are not subjected to an apoptotic threat.

The P53 protein is known to be an apoptosis-inducing agent. When the DNA is damaged, an upregulation of P53 expression will lead to an arrest of the cell cycle, in order to provide time for DNA repair, or to induce apoptosis if DNA repair is inadequate, impossible or insufficient [15]. P53 is not expressed in adult myocardium, or only at very low levels, in contrast to embryonic/fetal cardiac lissue, where high levels of $P 53$ expression have been observed [38]. However, to our knowledge no study has yet been published in which P53 expression in cardiomyocytes was assessed by use of immunohistochemistry. We could not find any evidence for neither a substantial expression of P53 in normal cardiac tissue (from thuman and goats in sinus rhythm), nor a substantial upregulation of P53 expression in normal (unaffected) or abnormal (affected) cardiomyocytes in CFA or CHM. Thus, DNA damage and/or apoptosis induction seems very unlikely in these tissues. The absence of P53 expression, although not actually supporting the dedifferentiation hypothesis 139$]$, might be an indication of the incomplete dedifferentiation state of cardiomyocytes in CHM and CFA. Previous observations have shown that proteins present in very early stages of myocardial development, such as vimentin and the cytokeratins 8 and 18 , are absent in CHM and CFA, thereby supporting the bypothesis of incomplete dedifferentiation $[4,7]$. 
proliferating Cell Nuclear Antigen (PCNA) is a protein that is a requisite for DNA replication and DNA repair, and its detection is frequently used as a marker of cell proliferation. Inducing DNA damage leads to the upregulation of PCNA, so the absence of such an upregulation probably means that DNA damage is absent [40]. Some authors report that PCNA is also upregulated during apoptosis, even in the physiological forms of apoptosis, because the DNA strand breaks induce a DNA repair process, though a futile one [41]. Because P53 and PCNA work co-operatively in DNA repair mechanisms, their actions in the apoptotic process are probably also related. PCNA is rarely if ever immunohistochemically detectable in normal adult cardiac tissue $[42,43]$. Western and Northern blots can demonstrate very low levels of PCNA mRNA and protein, although the source of the PCNA expression - cardiomyocytes or other cell types - remains inconclusive [44]. Marino et a]. [44] also noticed high expression levels in fetal and neonatal cardiac tissue. In our study, we could not detect any PCNA in cardiac tissue from CHM, CFA or the control goats. Again, this result, together with the finding that 553 expression is also absent, indicates that DNA damage is unlikely, and that there is no cellular, or DNA proliferation in CHM and CFA.

Because of the absence of any detectable upregulation of $\mathrm{BCl}-2$ expression and TUNEL reactivity in the cardiomyocytes under study, we have to assume that in CHM and CFA, the heart muscle cells, like normal cardiomyocytes, are not prone to undergo apoptosis. This assumption is reinforced by the absence of detectable llevels of $\mathrm{P} 53$ and PCNA expression in CHM and CFA, suggesting that there is no DNA damage in these cells.

\section{Viability of hibernating myocardium}

With respect to the viability of hibernating myocardium, some reported data show that the protective mechanisms in this tissue are insufficient to retain the viability of the cardiac tisstie. We believe that at least part of the reason that the results from our study differ from those from other studies can be attributed to the patient selection criteria $[10,12]$ and, perhaps of even greater importance, the tissue selection criteria [10-12]. Our studies included strict patient selection criteria, so that pathologies other than CHM were excluded. When evaluating cardiac tissue from CHM, we took great care to exclude areas of infarction and infarct border zones histologically. It is well established that apoptosis, albeit to a limited extent, does occur in these areas $(19-22)$, and we have also been able occasionally to observe morphologically identified apoptotic bodies in infarction areas and their bonder zones (Borgers, unpublished data). We are therefore not sure that our present findings are truelly different from the data published. hitherto [12]. Although they reported finding apoptosis in human hibernating myocardium, the authors gave only a very wague description of the areas that were examined, i.e. whether or not they were in the vicinity of infarcted zones, and gave no data on the frequency of apoptosis. In addition, the ultrastructural image of an apoptotic cardiomyocyte as published in $\mid 12 !$ is 
devoid of the typical morphological characteristics of dedifferentiated cardiomyocytes, such as sarcomere depletion and glycogen accumulation. Thus we propose that dedifferentiation and apoptosis may not be consecutive phenomena but possibly occur in different cell populations. Another report [11] mentioned extensive apoptosis in a pig model of hibernating myocardium. Although concomitant infarctions might be responsible for some of the occurrence of apoptotic cells, as convincingly reported elsewhere [25], the percentages of apoptotic cells reported $(9.8 \pm 4.6 \%$ in the subendocardial region) are improbably high. With such high frequencies noted between 24 hours and 4 weeks after the induction of the coronary occlusion, no viable cells would remain after that period [45]. The low specificity of the TUNEL procedure $[46,47]$ might be responsible for the detection of artificial DNA damage in the pig model [11].

An important issue to be addressed is related to the time period these cells can survive in their dedifferentiated state. It is expected that indeed, below a certain threshold of oxygen supply, even these cells get insufficient fuel to survive. It may well be that apoptosis is the degeneration pathway that would then be involved. Nor can it be excluded that at some stage in the adaptation to ischemia, perhaps at the onset, cell loss through apoptosis occurs, but might not be noticed at later stages because of the fast resolution of the apoptotic phenomena. Furthermore it is still possible that only very few cells are undergoing apoptosis, which can only be detected when much more tissue is evaluated. The main study limitation is therefore the small size of the human cardiac biopsies. The very few apoptotic cells which can be missed, could be clinically relevant after prolonged periods of time if revascularization is delayed. However the current data stiggest that dedifferentiation of cardiomyocytes normally does not end up in apoptosis, and that the possible sporadic apoptotic cells are of no short term clinical importance.

Since all of the apoptosis-related processes and characteristic morphologic changes currently under study are absent in our tissue samples, we suggest that the hibernating state might be of prolonged duration, both in chronic hibernating myocardium and chronic fibrillating atrium. The adaptation process of cardiomyocytes in both pathologies seems to be stereotypic. It might be speculated that dedifferentiation is the best way to survive for a prolonged period of time in the altered environment imposed by either increased passive wall stress, reduced oxygen supply or both. The 'survival' state that is created by activating a 'fetal program', moreover, allows these cardiomyocytes to return to normal as soon as the blood supply is restored, indicated by the recovery of function after revascularization.

In conclusion, dedifferentiation of cardiomyocytes as seen in CHM and CFA can be considered as an adaptive principle of protection allowing cardiomyocytes to survive for a prolonged period of time in which a relative oxygen shortage, an increased wall stress or both take place. The survival of dedifferentiated cardiomyocytes could be a prerequisite for recovery of contractile function after revascularization in CHM or cardioversion in CFA. 


\section{Acknowledgments}

The author wishes to thank M. Jansen and G. Krekels for providing tissue samples needed for positive controls in this study, G. Schaart and M. Mercken for their practical suggestions in regard to the Western blotting and L. Leijssen for processing the images. Part of this study was supported by the Dutch Heart Foundation, NHS Grant 96-155.

\section{References}

1) Rahimtoola SH. The hibernating myocardium. Am Heart J 1989;117:211-21.

2] Rahimtoola SH. Hibernating myocardium: a brief article. Basic Res Cardiol 1995;90:38-40.

3] Borgers M, Thoné F, Wouters L, Ausma J, Shivalkar B, Flameng W. Structural correlates of regional myocardial dysfunction in patients with critical coronary artery stenosis: chronic hibernation? Cardiovasc Pathol 1993;2:237-45.

4) Ausma I, Schaart G, Thoné F, et al. Chronic ischemic viable myocardium in man: aspects of dedifferentiation. Cardiovasc Pathol 1995;4:29-37.

51 Wijfels MC, Kirchhof CI, Dorland R, Allessie MA. Atrial fibrillation begets atrial fibrillation. A study in awake chronically instrumented goats. Circulation 1995;92:1954-68.

61 Ausma J, Wijffels $M$, Thoné $F$, Wouters $L_{3}$ Allessic M, Borgers M. Structural changes of atrial myocardium due to sustaned atrial fibrillation in the goat. Circulation 1997;96:3157-63.

7] Ausma I, Wijffels M, van Eys G, et al. Dedifferentiation of atrial candiomyocytes as a result of chronic atrial fibrillation. Am ] Pathol 1997;151:985-97.

8] Borgers $M$, De Nollin $S$, Thoné $\mathbb{E}$, Wouters L, Van Vaeck L, Flameng W.. Distribution of calcium in a subset of chronic hibernating myocardium in man. Histochen J 1993;25:312-8.

9] Ausma J, Thoné F, Dispersyn GD, et al. Dedifferentiated cardionyocytes from chronic hibernating nyocardium are not ischemic. Mol Cell Biochem 1998;186:159-168

10] Schwarz ER, Schaper I, wom Dahl J, et al. Myocyte degeneration and cell death in hibernating: human myocardium. J An Coll Cardiol 1996:27:1577-85.

11) Chen $C_{n} M a L, L i n f e r t ~ D R$, et al. Myocardia cell death and apoptosis in hibernating myocardium. J Am Coll Cardiol 1997;30:1407-12. 


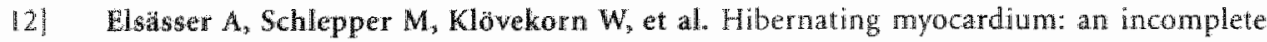
adaptation to ischemia. Circulation 1997;96:2920-31.

13) Kerr IF, Wyllie $\mathrm{AH}_{4}$ Currie AR. Apoptosis: a basic biological phenomenon with widewanging implications in tissute kinetics. Br J Cancer 1972;26:239-57.

141 Hockenbery $D$, Nunez, G, Milliman C, Schreiber RD, Korsmeyer SI. BCl.2 is an inner nitochondral membrane protein that blocks programmed cell death. Nature 1990;348:3346.

15) Lane DP.Cancer. p53, guardian of the genome. Nature 1992;358:15 -6.

16) Wyllie AH, Morris RG, Smith AL, Dunlop D. Chromatin deavage in apoptosis: alssociation with condensed chromatin morphology and dependence on macromolecular synthesis. I Pathol 1984;142:67-77.

17) James TN. Normal and abnormal consequences of apoptosis in the human heart. From postnatal morphogenesis to paroxysmal armythmias. Circulation 1994; 90:556-73.

18j Kajstura J, Mansukhani $M$, Cheng W, et al. Programmed cell death and expression of the protooncogene bcl-2 in myocytes during postmatal maturation of the heart. Exp Cell kes 1995;210:110-21.

19) Cheng W, Kajstura J, Nitahara JA, et al. Programmed myocyte cell death affects the viable myocardium after infarction in rats. Exp Cell Res 1996;226:316-27.

20) Kajstura J, Cheng W, Sarangarajan R, et al. Necrotic and apoptotic myocyte cell death in the aging heart of Fischer 344 rats. An J Physiol 1996;271:H1215-28.

21) Itoh $G$, Thmura J, Suxuki $M$, et al. DNA fragmentation of human infarcted myocardial cells demonshated by the nick end labeling method and DNA agarose get electrophoresis. Am I Pathol 1995; 146:1325-31.

22) Saraste A, Pulkki K, Kallajoki $M$, Hentiksen K, Parvinen M, Voipio-Pulkki LM. A poptosis in human acute myocardial infarction. Circulation $1997,95: 320-3$.

23) Sharov VG, Sabbah HN, Shimoyama $H$, Goussev AV, Lesch $M_{x}$ Goldstein S. Evidence of cardiocyte apoptosis in myocardium of dogs with chronic heart failure. Am J Pathol 1996; 148:14 \-9.

24] Yao M, Keogh A, Spratt P, dos Remedios CG, Kiessling PC. Elevated DNase ll levels in human idiopathic diated cardiomyopathy an indicator of apoptosis? J Mol Cell Cardiol 1996;28:95 $10 \%$.

251 Mallat Z, Tedgui A, Fontaliran F, Frank R, Durigon M, Fontaine G. Evidence of apoptosis in arthythmogenic right ventricular dysplasia. N Engl f Med 1996;335:1190-6. 
26) Narula, Haider $N$, Virnani $R$, et al. Apoptosis in myocytes in end-stage heart failure. N Engl Med 1996;335:1182-9.

27] Flameng $W$, Wouters $L$, Sergeant $P$, et al. Multivariate analysis of angiographic, histologic, and electrocardiographic data in patients with coronary heart disense. Circulation 1984:70:7-17.

28] Vanoverschelde $\mathrm{IL}_{\mathrm{N}}$ Wijn $\mathrm{W}$, Depre $\mathrm{C}_{\mathrm{n}}$ et al. Mechanisms of chronic regional postischemic dysfunction in humans. New insights from the study of noninfarcted collaterall-dependent myocardium. Circulation 1993;87:1513-23.

291 Maes A, Flameng W, Nuyts I, et al. Histological alterations in chronically hypoperfused myocardium. Correlation with PET findings. Circulation 1994;90:735-45.

301 Gavrieli Y, Sherman Y, Ben-Sasson SA. Identification of programmed cell death in situ via specific labeling of nuclear DNA fragmentation. I Cell Biol 1992;119:493-501.

311 Jansen MPHM, Machiels BM, Hopman AHN, et all. Comparison of A-and Butype lamin expression in reactive lymph nodes and nodular sclerosing Hodgkins-disease. Mistopathology 1997;31:304-312.

32] Krekels G, Voorter C, Kuik F, Verhaegh M, Ramaekers F, Neumann M. DNA-protection by sunscreens - p53 immunostaining. Eur II Dermatol 1997; 7:259-262.

33] Hockenbery DM, Zutter M, Hickey W, Nalnm M, Korsmeyer SJ. BCL2 protein is topographically restricted in tissues characterized by apoptotic cell death. Proc Nat Acad Sci USA 1991;88:69615.

34 McDonnell TJ, Beham A, Sarkiss M, Andersen MM, Lo P. Importance of the Bel-2 tamily in cell death regulation. Experientia 1996:52:1008-17.

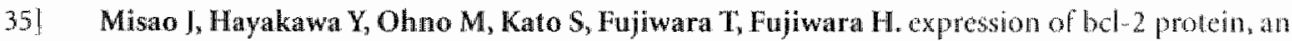
inhibitor of apoptosis, and Bax, an accelerator of apoptosis, in ventricular myocytes of human hearts with myocardial infanction. Circulation 1996;94:1506-12.

36] Olivetti $G$, Abbi R, Quani F, et al. Apoptosis in the failing human heart. N Engl I Med $1997,336: 113141$.

37) Anversa P, Olivetti G, Leri A, Liu X, Kajstura I. Myocyte cell death and ventricular remodeling. Curr Opin Nephrol Hypertens 1997:6:169-176.

38] Kim KK, Soonpaa MH, Daud AI, Koh GY, Kim IS, Field LJ. Tumor suppressor gene expression during normal and pathologic myocardial growth. I Biol Chem 1994;269:22607-13.

39] Nees $M$, Homann $N$, Discher $H$, et al. Expression of mutated p53 occurs in tumor-distant epithelia of head and neck cancer patients: a possible molecular basis for the development of multiplc tumors. Cancer Res 1993;53:4189-96. 
40) Sawio M, Stivalla LA, Bianchi L, Vannini V, Prosperi E. Involvement of the proliferating cell nuclear antigen (PCNA) in DNA repair induced by alkylating agents and oxidative damage in human fibroblasts. Carcinogenesis 1998;19:591-6.

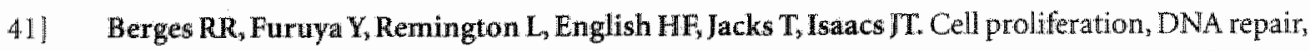
and 53 function are not required for programmed death of prostatic glandular cells induced by androgen ablation. Proc Natl Acad Sci USA 1993;90:8910-4.

42] Hall PA, Levison DA, Woods AL, et al. Proliferating cell nuclear antigen (PCNA) immunolocalization in paraffin sections: an index of cell proliferation with evidence of deregulated expression in some neoplasms. I Pathol 1990;.62:285-94.

43] Matturri L, Biondo B, Colombo B, Lavezzi AM, Rossi L. Significance of the DNA synthesis in hypertrophic cardiomyopathies. Basic Res Cardiol 1997;92:85-9.

44] Marino TA, Cao W, Lee J, Courtney R. Localization of proliferating cell nuclear antigen in the developing and mature rat heart cell. Anat Rec 1996;245:677-84.

45] Colucci WSC. Apoptosis in the heart. N Engll Y Med 1996;335:1224-6.

46] Allen RT, Hunter WJ 3rd, Agrawal DK. Morphological and biochemical characterization and analysis of apoptosis. J Pharmacol Toxicol Methods 1997:37:215-228.

47) Collins IRI, Harmon BV, Gobe GC, Kerr JF. Internudeosomal DNA cleavage should not be the sole criterion for identifying apoptosis. Intl J Radiat Biol 1992;61:451-453. 
Chapter 3

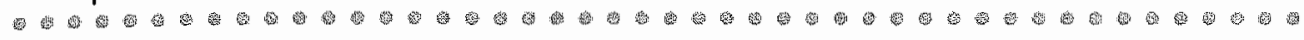

\title{
Changes in ultrastructural calcium distribution in goat atria during atrial fibrillation.
}

\author{
Jannie Ausma, Gerrit D. Dispersyn, \\ Hans Duimel, Fred Thoné, Luc Ver Donck, \\ Maurits A. Allessie, Marcel Borgers.
}

published in: 
It has been suggested that $\mathrm{Ca}^{2}$ content of atrial cardiomyocytes is increased at the onset of atrial fibrillation (AF). Whether this phenomenon is transient is currently unknown. Therefore, in this study the time-related changes in $\mathrm{Ca}^{2}$ location in atrial myocytes from goats with chronic AF have been investigated.

The distribution of calciuna was assessed with the electron microscope using the cytochemical phosphate-pyroantimonate and oxalate-pyroantimonate methods in atrial biopsies from goats in sinus rhythm and goats with 1 -16 weeks of burst-pacing-induced AF.

In atrial nyocytes from control goats in sinus rhythm, a normal $\mathrm{Ca}^{2}$ distribution was observed, with regular deposits along the sarcolemma (an average of 3.4 deposits per $\mu \mathrm{m}$ at a regular distance). The number of sarcolemma-bound $\mathrm{Ca}^{2}$ deposits substantially increased after $l$ and 2 weeks of atrial fibrillation, $A$ fter this period the amount of $\mathrm{Ca}^{2}$ precipitate decreased at 4 and 8 weeks, and became below control level at 16 weeks. A similar timerelated redistribution of $\mathrm{Ca}^{2+}$ occurred in mitochondria. Whereas mitochondria from control goats displayed very few $\mathrm{Ca}^{2}$ deposits (average 4.0 deposits per $\mu^{2}$ ), their number markedly increased after 1 and 2 weeks of atrial fiballation, which indicates cellular Ca ${ }^{2+}$ overload. Froin 4 weeks, $\mathrm{Ca}^{2}$ deposits reached control levels and were below control level after 16 weeks of atrial fibrillation (2.5 deposits per $\mu^{2}$ ).

Our findings are consistent with the previously observed $\mathrm{Ca}^{24}$ overload early after the onset of atrial fibrillation. The present study shows that this overload persists for at least 2 weeks, after which the cardiomyocytes apparently adapt to a new $\mathrm{Ca}^{2 *}$ homeostasis, thereby avoiding $\mathrm{Ca}^{2}$-overload. This protection against $\mathrm{Ca}^{\text {t}}$-overload co-occurs with dedifferentiation like cellular remodeling: 


\section{Introduction}

Atrial fibrillation (AF) is a common arrhythmia in man, and patients with paroxysmal AF often progress to sustained AF. After cardioversion the electrical and contractile function of the atria are impaired and recurrences of AF are frequent. Apart from progressive changes due to the underlying heart disease as seen in patients. AF itself causes progressive electrophysiological changes, like shortening of the atrial refractory period, the atriall fibrillation cycle length and fragmentation of the wavefronts [1,2]. It has been established that in chronically instrumented goats AF begets AF [1]. In humans, subsequent to electrical remodeling, subcellular changes occur in atrial myocytes of these patient during chronic $\mathrm{AF}|3|$. We described a variety of structural changes in experimentally induced chronic AF in goat atrial myocytes, with as the main features depletion of contractile elements and accumulation of glycogen $[4,5]$. Recently we studied the time course of structural changes during AF in goats after $1-16$ weeks of AF [6]. The structural changes appeared to develop progressively, the earliest changes having been noted after 1 week of AF.

It has been proposed that atrial contractile dysfunction occurs after short-term and chronic AF $[7,8]$. Contractile dysfunction after chronic AF is most likely related to the structural alterations in atrial myocytes and a possible explanation for the atrial dysfunction after shortterm $\mathrm{AF}$ might be that cytosolic $\mathrm{Ca}^{2+}$, but not $\mathrm{Ca}^{2+}$ transients, increases due to the high rate of atrial activation. Fast succeeding action potentials inhibit a proper sarcoplasmic reticulum $\mathrm{Ca}^{2+}$ re-uptake, resulting in elevated cytosolic $\mathrm{Ca}^{2+}$, possibly altering the excitation-contraction coupling [9-13]. Alternatively, the presence of rellative ischemia during $A F$ may account for the increased intracellular $\mathrm{Ca}^{2+}$. Whether the $\mathrm{Ca}^{2+}$-overload is transient or sustained after $\mathrm{AF}$ has not been investigated so far. It was the aim of this study to elucidate whether the increased, intracellular calcium level during acute AF is transient and whether subcellular modifications during chronic AF are accompanied by a re-setting of $\mathrm{Ca}^{2}$. levels in the various $\mathrm{Ca}^{2+}$-handling compartments. Accordingly, the time-related changes in ultrastructural $\mathrm{Ca}^{21}$ location have been investigated cytochemically in atria from goats with 0 to 16 weeks of atrial fibrillation.

\section{Material and Methods}

\section{Animals}

A total of 36 female goats with a mean ( $($ SD) weight of $61( \pm 13) \mathrm{kg}$ were used in this study. of these, 6 goats were kept in sinus rhythm and used as controls. The other goats were subjected to respectively $1,2,4,8$ or 16 weeks of atrial fibrillation (6 goats for each group). Animal 
handling was carried out according to the Dutch Law on Animal Experimentation (WOD) and The European Directive for Protection of Vertebrate Animals Used for Experimental and Other Scientific Purposes.

\section{Chronic atrial fibrillation model}

Anesthesia in the goats was induced with Nesdonal $(15 \mathrm{mg} / \mathrm{kg})$ and maintained by ventilation with halothane (1-2\%) and a mixture of $\mathrm{O}_{2}$ and $\mathrm{N}_{2} \mathrm{O}$. The goats were instrumented with a

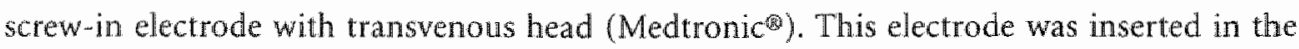
right atrium via the jugular vein. The lead was connected to an Itrel-II-pacemaker (Medtronic implanted in a subcutanous pocket in the neck of the animal. One week after surgery AF was induced by switching on the pacemaker, which produced $50 \mathrm{H} z$ bursts lasting $2 \mathrm{~s}$ each at intervals of Is at 4 times the threshold voltage. At the onset, AF was self-terminating within seconds, whereas over the next few days AF episodes became longer and finally were no longer selfterminating [1]. Gradually, the interburst interval could be prolonged to a maximum of 30 min in order to maintain sustained AF. At the onset, an external ECG was monitored for a few hours, and over the next 2 weeks daily monitoring of the ECG was performed to check the persistance of AF. After 2 weeks, the chance of self-termination of AF had becomes very low and, the goats were inspected weekly by external ECG monitoring (Fig. 1).
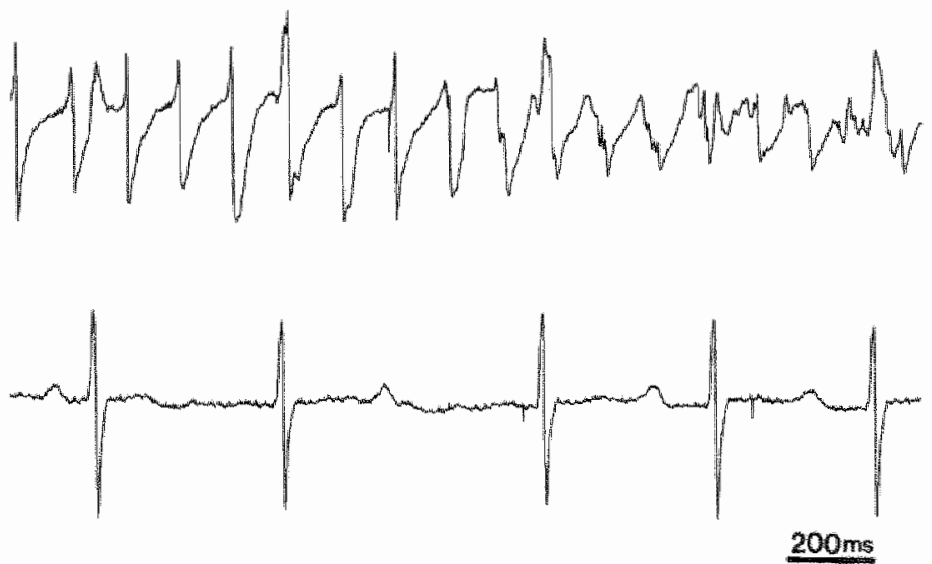

rigure 1: Electrocardiographic recondings from g goat with 2 weeks of atrial fibritatum.

a) Monitoring of an atrial signal from the right atrial free wall with an average atrial fibrillation cyce length of $110 \mathrm{~ms}$. This short atrial forllation oyde length is characteristic for sustaned atrial fibrillation.

b) Suface olectrocdiogram recorded from the same goat with sustained atrial fibrilation at the same time. Note the absence of the P-wave and the irregular ventricular thythm, charcateristics of atrial fibribation. 


\section{Tissue processing}

At the end of the experiment, the goats were anesthetized with Nesdonal $(15 \mathrm{mg} / \mathrm{kg})$ and by ventilation with halothane $(1-2 \%)$ and a mixture of $\mathrm{O}_{2}$ and $\mathrm{N}_{2} \mathrm{O}$. Five min before the goats were killed $5000 \mathrm{U}$ heparine was given intravenously to avoid blood coagulation, and to ensure optimal perfusion fixation of the hearts. For the localization of intracellular $\mathrm{Ca}^{2 *}$ with the oxalate-pyroantimonate (OPA) procedure, small parts $\left(4 \mathrm{~mm}^{3}\right)$ of both right and left appendages were removed from the intact heart and immediately fixed by immersion in potassium oxalate-buffered $3 \%$ glutaraldehyde $(\mathrm{pH} 7.4$ ) for at least 24 h at room temperature [14].

To perform a morphological evaluation by light- and electron microscopy and to locate $\mathrm{Ca}^{3+}$ by means of the phosphate-pyroantimonate (PPA) method, the heart was removed and fixed within a few seconds by retrograde perfusion with 2 liter $3 \%$ glutaraldehyde at room temperature, buffered with potassium phosphate to $\mathrm{pH} 7.4$. Subsequently, parts of the left and right atrial free walls were divided into small blocks ( $4: \mathrm{mm}^{3}$ ) and kept for at least $24 \mathrm{~h}$ in the same fixative at room temperature [15].

\section{Morphological evaluation}

For morphological assessment, the fixed tissue blocks were washed with $90 \mathrm{mM}$ potassium phosphate containing. $7.5 \%$ sucrose, postfixed with $2 \%$ osmium tetroxide in $50 \mathrm{mM}$ veronal acetate buffer for $1 \mathrm{~h}$, dehydrated through graded ethanol series, and routinely embedded in the epoxy-resin Epon.

For electron microscopy, ultrathin sections were cut from each sample, counterstained with uranyl acetate and lead citrate, and examined in a Philips CM 100 microscope.

\section{Calcium distribution studies}

\section{Phosphate-pyroantimonate procedure}

Phospholipid-bound calcium was located with the phosphate-pyroantimonate (PPA) technique, as previously described and validated by Borgers et al. [15,16]. By this method a precipitate of phospholipids, phosphate and calcium can be identified as electron dense antimonate precipitate [17]. Vibratome sections ( $100 \mu \mathrm{m}$ thick) were cut from the fixed tissue samples and stored in phosphate-buffered $3 \%$ glutaraldehyde supplemented with $1.4 \%$ sucrose at $4^{\circ} \mathrm{C}$. The sections were rinsed in $90 \mathrm{mM}$ potassium phosphate with $7.5 \%$ sucrose for $15 \mathrm{~min}$ at $4^{\circ} \mathrm{C}$, and immersed in a mixture of $1 \%$ osmium tetroxide and $2 \%$ potassium pyroantimonate for $2 \mathrm{~h}$ at $4{ }^{\circ} \mathrm{C}$, followed by dehydration in graded series of ethanol and embedding in Epon. 


\section{Oxalate-pyroantimonate procedure}

The oxalate-pyroantimonate (OPA) procedure, as described by Borgers et al. [1.8], was used to locate part of the exchangeable calcium pools (i.e. the fraction of $\mathrm{Ca}^{2+}$ which is recruitable for normal cellular processes). By this method a precipitation of calcium with oxalate and conversion into an electron dense antimonate precipitate occurs $[19,20]$. In brief, vibratome sections ( $100 \mu \mathrm{m}$ thick) were cut from the fixed tissue samples and stored in oxalate-buffered $3 \%$ glutaraldehyde supplemented with $1.4 \%$ sucrose at $4^{\circ} \mathrm{C}$. The sections were rinsed with $90 \mathrm{mM}$ potassium oxalate containing $7.5 \%$ sucrose for $15 \mathrm{~min}$ at $4^{\circ} \mathrm{C}$ and postfixed in $1 \%$ osmium tetroxide containing $2 \%$ potassium pyroantimonate, dehydrated in graded series of ethanol and embedded in Epon. Ultrathin sections, either unstained or briefly counterstained with uranyl acetate and lead citrate, were examined by electron microscopy.

\section{Morphometrical analysis of calcium precipitates}

The amount of $\mathrm{Ca}^{2+}$ deposits in mitochondria and at the sarcolemma was evaluated by computer based morphometrical analysis of electron microscopic pictures. A minimum of 16 electron micrographs at each timepoint of AF, at a magnification of $8900 \mathrm{x}$, were scanned with a Hewlett Packard Scanlet $4 \mathrm{c}$ scanner from different samples in randomized and blinded fashion. On the micrographs the area of mitochondria and the contour length of the sarcolemma were evaluated morphometrically with a planimetric image processing software. Calcium precipitates in the mitochondria or associated with the sarcolemma were expressed as the number of deposits per $\mu \mathrm{m}^{2}$ area of mitochondria and per $\mu \mathrm{m}$ contour length of sarcolemma respectively. Minimal total area of mitochondria evaluated was $2.42 \times 10^{6} \mu \mathrm{m}^{2}$ for each timepoint of AF. Minimal total length of sarcolemma evaluated as $246 \mu \mathrm{m}$ for each timepoint of AF.

\section{Statistical Analysis}

Data are expressed as mean $上$ standard deviation. For statistical comparison of mitochondrial or sarcolemma-associated $\mathrm{Ca}^{2+}$ deposits variance analysis was carried out followed by the student t-test for unpaired data. For all comparisons an $\mathrm{P}<0.05$ was considered indicative of statistically significant difference.

\section{Results}

Morphological changes during AF

Light- and electron microscopy was performed to verify whether subcellular changes characteristic of chronic AF as described by Ausma et al. $\{4\}$ were present in the series of 
animals under study. Indeed such alterations had occurred, the most obvious of which being the depletion of sarcomeres in the perinuclear region of the cardiomyocytes. The cytoplasmic space resulting from this myolysis became filled with glycogen (Fig. 2a, b). Mitochondria
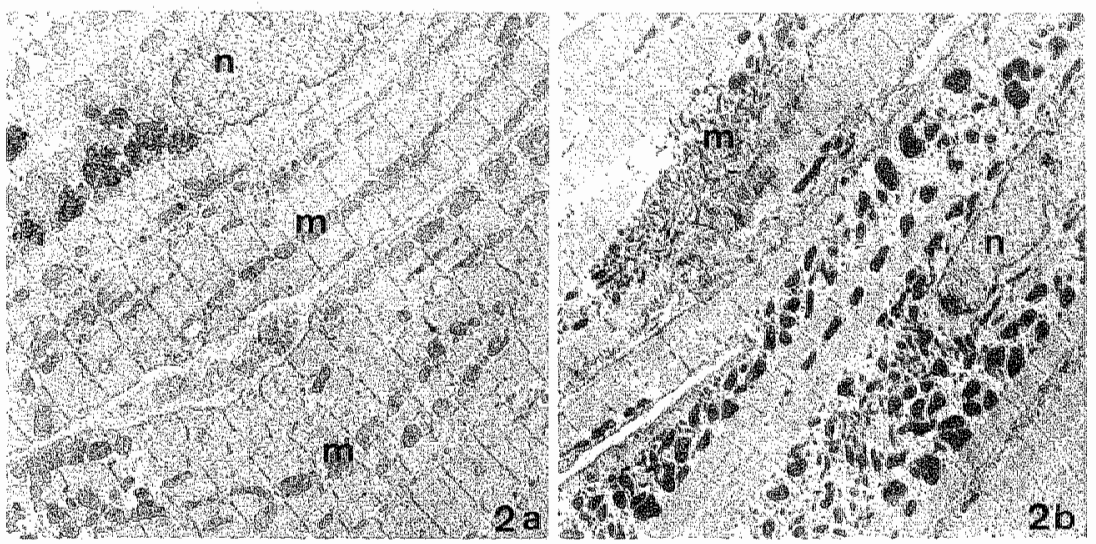

Figure 2: Worphological changes after chronic atrial fibrillation.

a) Elertron microscope picture of atrial cardiac tissue of a goat in sinus rhythm. All cellular structures, such as sarcoplasmic reticulum and mitochondria ( $m$ ), are nomal. (n=nucless). (2090x)

b) Electron microscope picture of goat atria after $B$ weeks of chronic atrial fibrillation. Several abnormalities can be noted, the normal dense sarcomenc structure is not in place, the number of sarcomeres ane reduced, and the alignment is lost. Several mitochondria have an abnomal elongated 5hape (m). The cardiomyovoytes also display glycogen accumulation. (n=muclews). (2090x)

\begin{tabular}{|c|c|c|c|}
\hline & PPA & OPA & Morphology \\
\hline $\begin{array}{l}\text { Duration } \\
\text { of AF }\end{array}$ & 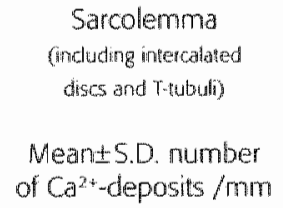 & $\begin{array}{l}\text { Mitochondria } \\
\text { MeantS.D. number } \\
\text { of } \mathrm{Ca} \mathrm{a}^{2+} \text {-deposits/mm? }\end{array}$ & $\begin{array}{l}\text { \% Affected anial myocytes } \\
\text { (cells > 10\% myoliss) }\end{array}$ \\
\hline O week & $3.37 \pm 0.43$ & $3.97 \pm 1.19$ & $8.2 \pm 4.7$ \\
\hline 1 week & $5,03 \pm 044$ (P<0,001) & $9,32 \pm 2,44(P<0,001)$ & 16.42172 \\
\hline 2 weeks & $4.64 \pm 1.29(P<0.05)$ & $6.32 \pm 1.24(P<0.001)$ & $20.2 \pm 9.8$ \\
\hline 4 weeks & $304 \pm 0.54(P-0.052)$ & $4061132(P=0.837)$ & $232498(1<005)$ \\
\hline 8 weeks & $3.14 \pm 0.46(P=0.301)$ & $5.65 \pm 0.96(P<0.001)$ & $45.9 \pm 12.4(P<0.05)$ \\
\hline 16 yeaks & $196+0.74$ ( $<<0.001)$ & $245+101$ (P<0,001) & $51,8+83(P<0,05)$ \\
\hline
\end{tabular}

Toble 1: Quantification of calcium deposits at the sarcolemma and in mitochondrat from atriol mocyes of fords with

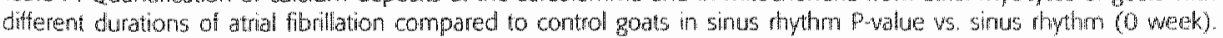

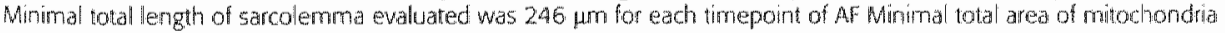
evaluated was $2.42 \times 10^{5} \mu m^{2}$ for each time point of $\mathrm{AF}$. 

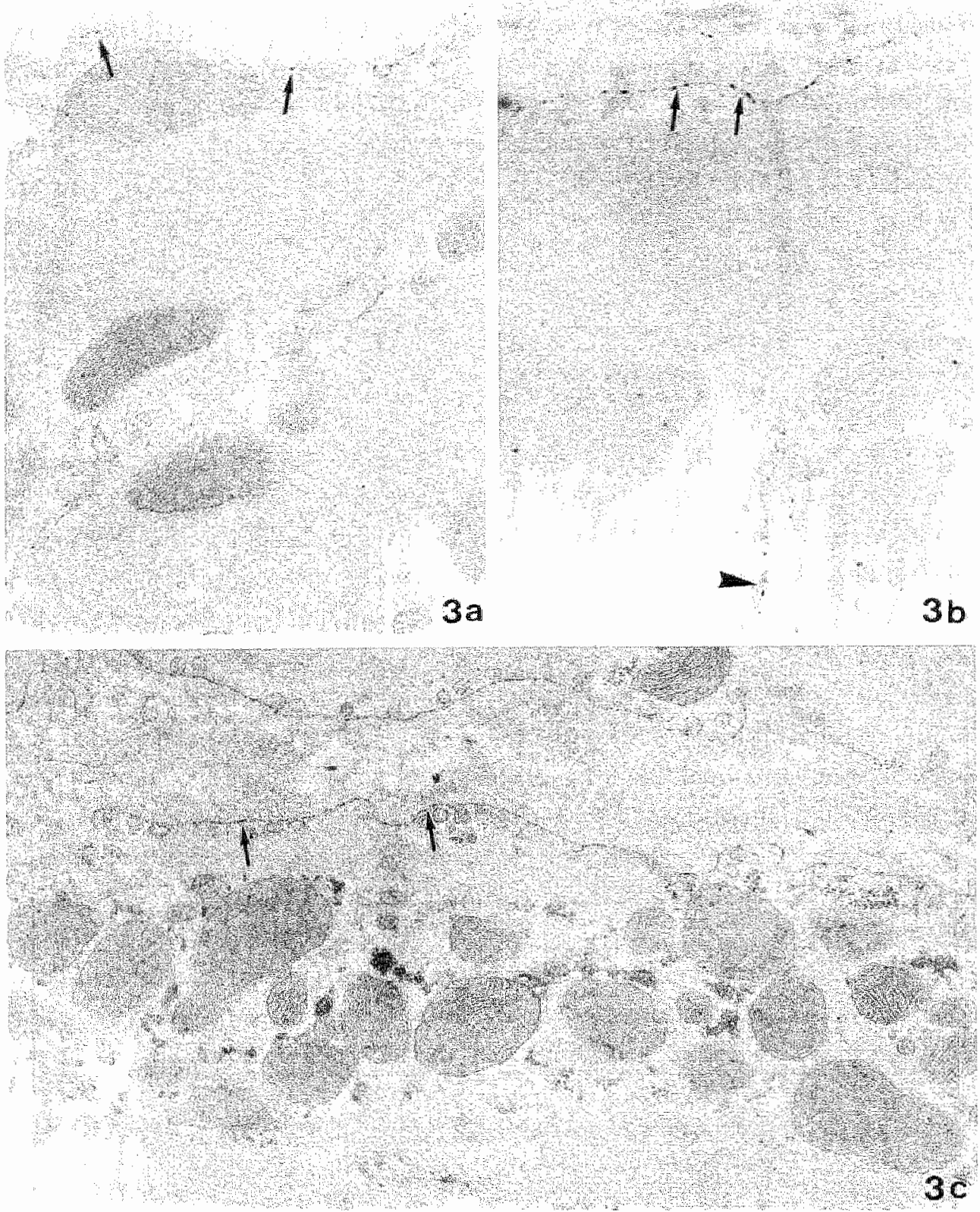

Figure 3: Uitastuctural detection of phospholipid-bound $\mathrm{Ca}^{2 \mathrm{~s}}$ with the phosphate pyroantimonate technique.

a) Electron microscopic detall of more or less regularly spaced Ca" deposits at the sarcolemma (errows) and at the $T$. lubules (arrowhead) of a cardiomyocye from atrial vissue of a control goat in sinus thythm. (19785x)

b) A manked increase in Ca" deposits can be noted at the sacolemma (arrows) of atrial cardianyocytes and at the T. tubules (arrowhead) after 1 weak of chronic atrial fibrillation: (21430x)

c) The number of $\mathrm{Ca}^{2+}$ deposits at the sarcolemma (arrows) of atrial cardiomyocytes returned to the control levels after 16 weeks of chronic atrial fibrittition. (20350x) 


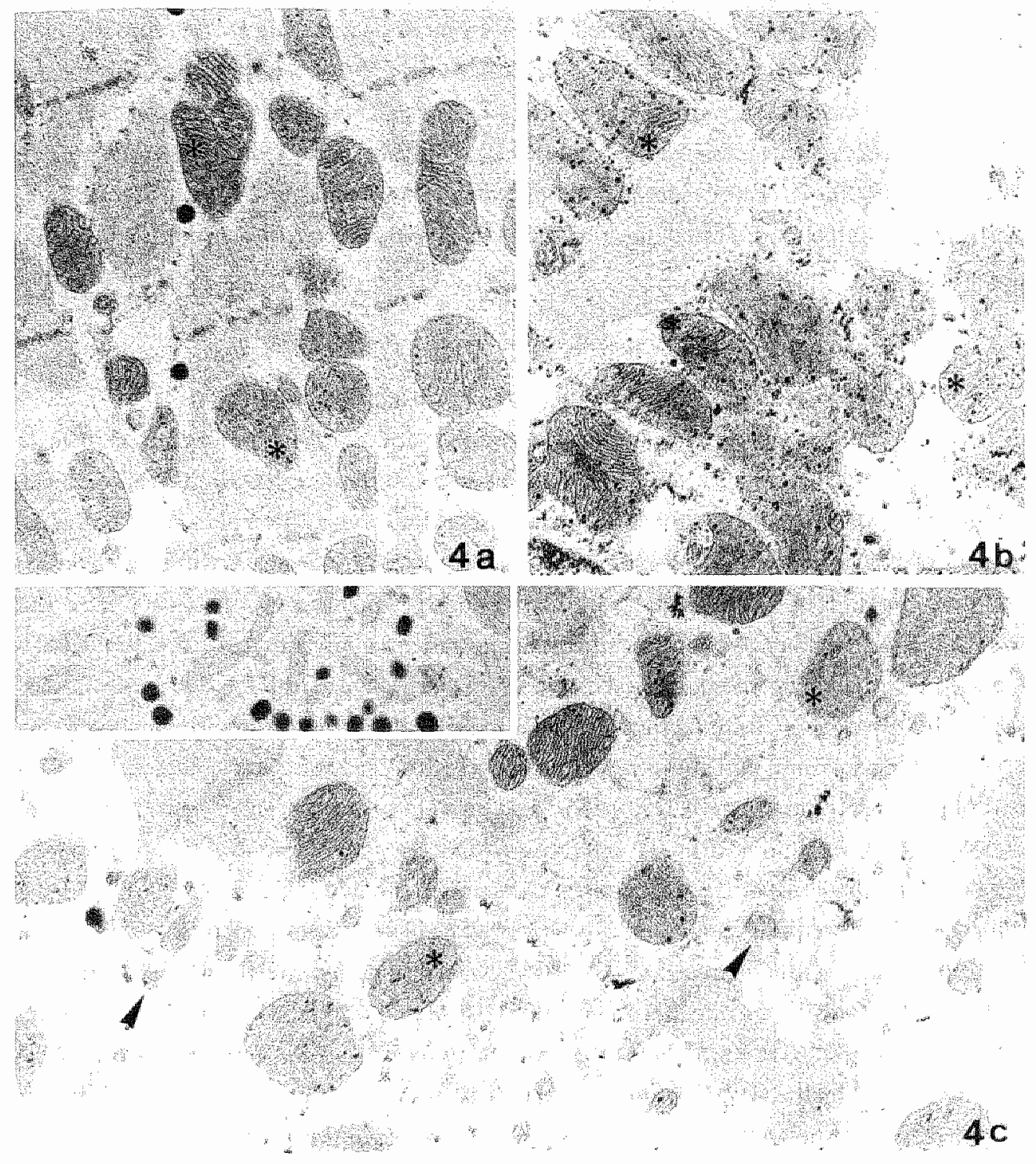

Figure 4: Ultrastructural detection of exchangeable $\mathrm{Ca}^{2+}$ with the oxalute pyoantimonate technique.

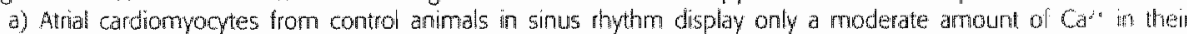
mitochondrita (asterisks). (20010x)

b) The arrount of $\mathrm{Cs}^{2+}$ deposits in the mitochondna of atrial cardiomyocytes from goats after 1 week of chronic atrial fibrillation had increased significanty (asterisks), which suggests tor a Cat owerload. (21990x)

c) The level of $\mathrm{Ca}^{3 *}$ deposits in the normal mitochondria (asterisks) and small mitoohondria (arrowheads) of atrial cardiomyocytes atter 16 weeks of chronic atrial fibrilation was lower than normat. Insert: Abnomally shapted elongated mitochondria, part of them show $C^{2 *}$ precipitate. (20010x, insert: $16860 x$ ) 
underwent changes in size and shape, characterized by elongation and reorientation of their cristae. Nuclei showed a homogeneous distribution of their heterochromatin. This change appeared from 4 weeks and was most pronounced at 8 and 16 weeks, involving up to $40 \%$ of the cardiomyocytes in the free left and right atrial walls (Table 1). Definite signs of ischemic cell change or cellular degeneration, such as the formation of cytoplasmic vacuoles, intracellular clarifications, mitochondrial swelling, nuclear pyknosis and the formation of contraction band necrosis, were not observed.

\section{Calcium distribution}

\section{Distribution of calcium in atrial myocytes from goats in sinus rhythm}

When the subcellular calcium distribution was assessed with the PPA technique, ellectron dense $\mathrm{Ca}^{2+}$ precipitates (around $20 \mathrm{~nm}$ thick) were mainly found along the inner leaflet of the sarcolemma, the sarcolemma-derived vesicles, T-tubules and intercalated disks. In the cardiomyocytes from the right and left artial free walls of goats in sinus rhythm 3.37 deposits/ $\mu \mathrm{m}$ were present (Fig. 3a and Table I). A limited number of deposits was seen in a minority of mitochondria. With the OPA-procedure, a moderate amount of precipitated $\mathrm{Ca}^{2+} 3.97$ deposits/ $\mu \mathrm{m}^{2}$ was confined to the mitochondrial matrix of cardiomyocytes from the right and left atrial appendages from goats in sinus rhythm (Fig. 4a and Table I). Vesicles, not belonging to the organized sarcoplasmic reticulum, were not loaded with $\mathrm{Ca}^{2+}$ precipitate. The euchromatin part of the nuclei contained few $\mathrm{Ca}^{2+}$ deposits.

\section{Time course of changes in calcium distribution during $A F$}

With the PPA-technique it was observed that the number of $\mathrm{Ca}^{2+}$ deposits along the sarcolemma, including T-tubules and intercalated disks of the atrial myocytes from left and right atrial free walls, was substantially greater after 1 and 2 weeks of $A F, 5.03(P<0.001$ vs. sinus rhythm) and 4.64 ( $P=0.018$ vs. sinus rhythm) deposits/um, respectively (Fig. 3 b and Table l). Mitochondrial $\mathrm{Ca}^{2}$, as assessed by the OPA technique, was elevated at the onset of AF, indicative of cellular $\mathrm{Ca}^{2+}$-overload, as shown in Fig. 3b. Such a marked increase in mitochondrial $\mathrm{Ca}^{2+}$ was most pronounced at 1 and 2 weeks of AF, 9.32 and 6.32 deposits/ $\mu m^{*}$, respectively (for both $\mathrm{P}<0.001$ vs. sinus rhythm) (Table I). The cellular $\mathrm{Ca}^{2+}$-overload was not accompanied by structural signs of damage to mitochondria such as matrix swelling and cristae disruptions.

After this period of excessive $\mathrm{Ca}^{2+}$-overload, a normalization of the calcium distribution pattern took place. From 4 weeks the number of $\mathrm{Ca}^{2+}$ deposits at the saroolemma, the $\mathrm{T}$-tubules and the intercalated disks decreased, reaching control levels. After 16 weeks of AF the level was below control, 1.96 deposits/ $/ \mathrm{m}(\mathrm{P}<0.001$ vs. sinus rhythm) (Fig. $3 c$ and Table I). The mitochondrial $\mathrm{Ca}^{2+}$ levels returned to control values after 4 weeks of $\mathrm{AF}^{2} \mathrm{Ca}^{2++}$ deposits in 
mitochondria were virtually absent from the atrial myocytes from the left and right atria after 16 weeks of AF, 2.45 deposits/um ( $P<0.001$ vs. sinus rhythm) (Fig. 4c and Table I). In atrial myocytes with abnormal. shaped smal! mitochondria the amount of $\mathrm{Ca}^{2+}$ deposits was comparable with normal structured mitochondria in the same atrial myocyte. As for the $\mathrm{Ca}^{2+}$ precipitates confined to the euchromatin of nuclei, there were no obvious differences between $\mathrm{SR}$ and $\mathrm{AF}$ hearts at any time of fibrillation.

\section{Discussion}

Antimonate-based methods have been used extensively to locate $\mathrm{Ca}^{2+}$ in the heart $[14,21-24]$. PPA- and OPA are reliable methods for electron microscopic visualization of $\mathrm{Ca}^{2+}$ at the sarcolemma, nuclei, cytoplasmic membranes and mitochondria. However, we realize that assessment of $\mathrm{Ca}^{2 *}$ in tissues by these methods might not provide an accurate account of the overall $\mathrm{Ca}^{2+}$ load since the information on $\mathrm{Ca}^{2+}$ distribution, as dealt with in this paper, is restricted to a subset of the important subcellular $\mathrm{Ca}^{2+}$ compartments. Structural assessment of $\mathrm{Ca}^{2+}$ at subcellular sites, such as the sarcoplasmic reticulum, is not possible by these antimonate methods because $\mathrm{Ca}^{2+}$ residing in the sarcoplasmic reticulum is so tightly bound to $\mathrm{Ca}^{2+}$ binding proteins that it cannot be precipitated by oxalate and phosphate and hence can not be visualized by the applied cytochemical procedure. Taking these limitations into account, we still think that a reliable estimation of redistributional changes of $\mathrm{Ca}^{2+}$ can be made with these methods. Especially, these methodologies may give some clues as to whether more or less $\mathrm{Ca}^{2+}$ is handled at the sarcolemma under pathophysiological conditions and whether mitochondrial $\mathrm{Ca}^{2+}$ overload occurs, as documented for ischemia/reperfusion $[14,16,20,25$ 277 .

$\mathrm{Ca}^{2+}$ redistribution at the onset of $\mathrm{AF}$

The data presented in this paper make it clear that sarcolemma-bound $\mathrm{Ca}^{2+}$ increases markedly up to 2 weeks of AF and tends to regress towards normal levels from 4 weeks of AF. A similar increased $\mathrm{Ca}^{2+}$ deposition in atrial cells was described after $30 \mathrm{~min}$ of $\mathrm{AF}$ in pigs and in ventricular cells after $48 \mathrm{~h}$ of rapid ventricular pacing in dogs $[28,29]$. In the latter study, the cellular $\mathrm{Ca}^{2+}$-overload induced by overdrive pacing was reversible. There is evidence from various studies that the $\mathrm{Ca}^{2+}$-overload occuring at the onset of $\mathrm{AF}$ can be reduced by the $\mathrm{Ca}^{2+}$ antagonist verapamil $[9,10,12]$.

Electrical pacing of cardiomyocytes in culture resulted in raised $\mathrm{Ca}^{2 *}$ levels at the sarcolemmat 
in comparison with unstimulated quiescent cells $[30]$. AF induces an increased influx of $\mathrm{Ca}^{2 *}$ $[9,10,28]$, which in our experiments might be reflected by elevated levels of $C^{2+}$ precipitate. The loss of the sarcolemma"s ability to bind $\mathrm{Ca}^{2+}$ is considered a crucial event in the development of irreversible injury to cardiomyocytes [16]. When hearts were subjected to mild ischemia followed by reperfusion, transient $\mathrm{Ca}^{3+}$-shifts were accompanied by ultrastructural signs of reversible injury $[26,27]$, whereas after prolonged ischemia, the Ca ${ }^{2+}$ overload was not transient. Similar observations on transient and permanent $\mathrm{Ca}^{2 *}$ shifts were made in anoxia-exposed cultured cardiomyocytes [25]. Mitochondrial scavenging of $\mathrm{Ca}^{2 \cdot}$ occurs after ischemia followed by reperfusion as a rescue reaction whose purpose is to avoid $\mathrm{Ca}^{2 *}$-overload $[16,26,27]$. It is still not known whether mild ischemia plays a role in the AF induced electrophysiological and structural changes in the atria. Reported data on the presence of atrial ischemia during AF are conflicting. Some data suggest that atrial ischemia does occur during chronic AF [31], while other data did not support such a relation [32,33]. Moreover, atrial blood flow measurements are scarce. White et al. (1982) established that in dogs, oxygen consumption in the atrial tissue increases two- to three-fold immediately after the induction of AF, resulting in a marked reduction of the flow reserve during atrial fibrillation. Recently, layachandran et al. [35] showed that in dogs the atrial blood flow was reduced by $78 \%$ after 4 weeks of pacing-induced AF. Clear evidence of oxygen deficit was not mentioned in the latter study.

Although the pattern of $\mathrm{Ca}^{2+}$ distribution at the onset of $\mathrm{AF}$ strongly resembles that after acute reversible ischemia [16], a causal relationship has not been unambiguously proved. If atrial ischemia occurs during the early phase of AF, it is most likely a mild form of ischemia that does not lead to irreversible damage of the cardiomyocytes. Moreover, preliminary metabolic studies performed in our series of goats showed that depletion of high energy phosphates does not occur after 1 and 2 weeks of AF suggesting that severe ischemic damage is absent [36].

\section{Topographical resetting of $\mathrm{Ca}^{2+}$ after chronic atrial fibrillation}

At the onset of $\mathrm{AF}$, high intracellular $\mathrm{Ca}^{2+}$ concentrations might influence the expression levels of ton-channels. It has been determined that the number of L-type Ca ${ }^{2+}$ channels and their conductance is decreased [37]. In our study the amount of $\mathrm{Ca}^{2+}$ decreased again after 4 weeks

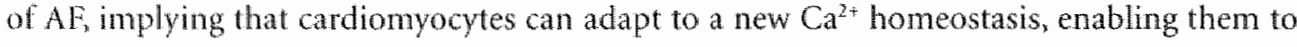
overcome the detrimental $\mathrm{Ca}^{2+4}$-overload. However, it cannot be excluded that at later stages of $\mathrm{AF}$ (>8 weeks) the cellular $\mathrm{Ca}^{2+}$ load remains elevated, but that the $\mathrm{Ca}^{2 *}$ buffering function is taken over by a higher content of $\mathrm{Ca}^{2+}$ binding proteins and therefore no longer visualized with the applied techniques. This homeostatic resetting coincides with a structural adaptation of the cardiomyocytes characterized by the depletion of contractile filaments, accumulation of glycogen, the depletion of sarcoplasmic reticulum, an altered nuclear chromatin distribution, 
and the presence of numerous small mitochondria. Such a structural remodeling is believed to constitute a switch towards a fetal phenotype of the cardiomyocytes, as deduced from the reexpression of various proteins present in neonatal cells $[4,5]$. Although, the exact mechanism of this dedifferentiation is not known, a transient $\mathrm{Ca}^{24}$-overload may be involved in this process. It can also be conjectured that at the onset of AF, cellular $\mathrm{Ca}^{2+}$-overload triggers the structural remodeling. Elevated levels of intracellular $\mathrm{Ca}^{2+}$ are known to activate proteolysis, resulting in increased breakdown of myofilaments, which in turn is responsible for decreased contractility. It is expected that a loss of contractile proteins and sarcoplasmic reticulum, leading to at depressed $\mathrm{Ca}^{2+}$ transient, will negatively influence contractility. After 8-16 weeks of sustained $\mathrm{AF}$, this is reflected by a diminished $\mathrm{Ca}^{2+}$-deposition at the sarcolemma, and the virtual absence of $\mathrm{Ca}^{2+}$ in mitochondria. The structural remodeling in atrial myocardium after chronic $\mathrm{AF}$ can therefore be held responsible for the delay in recovery of contractile function after cardioversion [4].

The dedifferentiated cardiomyocytes from goats with chronic AF resemble those from humans with chronic hibernating myocardium [38]. We have previously shown that the dedifferentiated cardiomyocytes in the setting of chronic hibernating myocardium have mitochondria free from $\mathrm{Ca}^{2+1}$ and also that they have a well-preserved $\mathrm{Ca}^{2+}$ distribution along the sarcolemna $[15,39]$. We therefore hypothesize that dedifferentiation of cardiomyocytes during $\mathrm{AF}$ is an effective protective mechanism, rendering the cells more resistant to ischemia and/or intracellular $\mathrm{Ca}^{2+}$-overload.

\section{Conclusion}

Our findings suggest that $\mathrm{Ca}^{2+}$-overload occurs in atrial myocytes carly after the induction of atrial fibrillation. This $\mathrm{Ca}^{2+}$-overload persists for at least 2 weeks, after which cardiomyocytes apparently adapt to a new $\mathrm{Ca}^{2+4}$-homeostasis. A relationship between the transient $\mathrm{Ca}^{2+}$-overload, atrial contractile dysfunction and electrical remodeling is proposed. Cellular adaptation, i.e. dedifferentiation, during chronic AF can be regarded as a protective adaptation against detrimental $\mathrm{Ca}^{2 *}$-overload.

\section{Acknowledgements}

The authors would like to thank Theo van der Nagel and Ruud Kruger for technical assistance. This study was in part was supported by the Dutch Heart Foundation (grant NHS 96-155) and the Universiteitsfonds Limburg SWOL. 


\section{References}

1) Wiffels MCEF, Kirch of CIHI, Dorland R, Allessie MA. Afrial fibrillation begets atrial fibrillation. A study in awake chronically instrumented goats. Circulation 1995;92: 1954-1968

21 Konings KTS, Kirchhof CJHI, Smeets JLRM, Wellens HJ, Penn OC, Allessie MA. High-dersity mapping of electrical induced atrial fibrillation in humans. Circulation 1994;89: 1665-1680.

3) Mary-Rabinel, Albert A, Pham TD, Hordof A, Fenoglio J, Malm JR, Rosen MR. The relationship of heman atrial cellular electrophysiology to clinical function and ultrastructure. Circ Res 1983;52:188-199.

4.] Ausma J, Wijffels $\mathbf{M}$, Thoné $F_{y}$ Wouters $\mathbb{L}$, Allessie $\mathbf{M}$, Borgers $\mathbf{M}$. Structural changes of atrial myocardium due to sustained atrial fibrillation in the goat. Circulation 1997;96: 3157-3163.

51 Ausma ل, Wijffels M, Van Eys $\mathrm{G}_{2}$ Koide M, Ramaekers $\mathrm{F}_{3}$ Allessie M, Borgers M. Dedifferentiation of atrial cardiomyocytes as a result of chronic atrial fibrillation. Am J Pathol 1997;151: 985-997.

6] Ausma J, Lenders MH, Mast F, Allessie MA, Ramaekers F, Wouters L, Thoné F, Borgers M. Time course of structural changes due to atrial fibrillation in the goat. Circulation 1998;98: I-683.

71 Manaing W, Silverman D, Katz S, Riley $\mathbf{M}_{*}$ Came P, Doherty R, Munson I, Douglas P. Impaired Jefi atrial mechanicalfunction after cardioversion: relation to the duration of atrial fibrilation. I Am Coll Cardiol 1994:23:135-140.

8) Manning WJ Leeman De, Gotch PJ, Come PC. Pulsed evaluation of atrial mechanical function after electrical cardioversion of atrial fibrillation. J Am Coll Cardiol 1989;13:617-623.

9! Leistad E, Aksnes, Verburg E, Christensen G. Atrial contractile dysfunction after short-rem atrial fibrillation is reduced by verapamil, but increased by BAY -K 8644 . Circulation 1996; 93: $1747-1.754$.

10. Tieleman RG, De Langen CDJ Van Gelder IC, de Kam PJ, Granjean J, Bel WJ, Wijffels MCEF, Allessie MA, Crijns HIGH. Verapamil reduces tachycardia-induced electrical remodeling of the atria. Circulation 1997; $95:$ 1945-1953.

1. 1) Tïeleman RG, Van Gelder IC, Crijns HJ, de Kam PI, Van den Berg MP, Haaksma J, Van der Woude HJ, Allessie MA. Early recurrences of atrial fibrillation after electrical cardioversion: a result of fibrillation induced electrical remodeling of the atria? I An Coll Cardiol 1998;31:167173.

12] Goette A, Honeycutt C, Langberg JI. Electrical remodeling in attrial fibrillation. Time course and mechanisms. Circulation 1996; 94: 2968-2974t.

13. Daoud EG, Knight BP, Weiss R, Bahu M, Paladino W, Groyal R, Man KC, Strickberger SA, Morady E. Effect of verapamil and procainamide on atrial fibrillation-induced electrical remodeling in humans, Circulation 1997;96; 1542*1550. 
14] Flameng $W$, Daenen $W$, Borgers $M$, Thone $F$, Xhonneux $R$, Van de Water $A$, Van Belle $H$. Cardioprotective effects of lidoflazine during 1 hour nomothermic ischemia. Circulation 1981;64: $796-707$.

15] Borgers M, De Nollin S, Thoné F, Wouters L, Van Vaeck L, Flaneng W. Distribution of calcium in a subset of chronic hibernating myocardium in man. Histochem I 1993;25:312-318.

16] Borgers M, Liu G-S, Xhonneux R, Thoné F, Van Overloop P. Changes in ultrastructure and Cat distribution in the isolated working rabbit heart after ischemia. Am I Pathol 1987; 126:92-102.

17] Boskey AL, Posner AS. Optimal conditions for Ca-acidic phospholipid-PO, formation. Calcif Tiss Int 1982; 34: S1-S7.

18] Borgers M, De Brabander M, Van Reempts J, Wouters F, Jacob WA. Intranucleat microtubules in lung mast cells of guinea pigs in anaphylactic shock. Lab Invest 1977; 37: 1 8.

19] Wick SM, Hepler PK. Selective localization of intracellular $\mathrm{Ca}^{2+}$ with potassium antimonate. I Histochem Cytochem 1982; 30: 1190-1204.

20] Konrad T, Beier $K_{\text {, }}$ Kusterer $K$, Juchem $\mathbf{R}$, Usadel $K H$, Angermuller $S$. The effect of verapamill on mitochondrial calcium content in normoxic, hypoxic and reoxygenated rat liver. Histochem $]$ $1997 ; 29,309-315$.

21) Borgers M, Thoné F, Verheyen A, ter Keurs HEDJ. Localization of calcium in skeletal and cardiac muscle. Histochem J 1984: 16:295-309.

22) Liu G-S, Ravens U, Sadony V, Vandeplassche G, Borgers M. Functional and structural impairment in human, rat and guinea-pigatrial muscle in response to in vitro calcium overload: a cytochemical study on cellular calcium distribution. J Mol Cell Cardiol 1991;23:795-805.

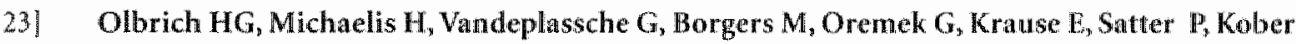
G, Mutschler $E_{y}$ Kaltenbach M. Ultrastructural calcium distribution and myocardial calcium content in human idiopathic dilated cardiomyopathy. Cardiovase Pathol 1993;2: 127-136.

24. Czarnowska E, Karwatowska-Prokopczuk E, Kurzydlowski K. Ultrastrictural study of calcium shift in ischemic/reperfused rat heart under treatment with dimethylhionsea, diltingem and amiloride. Basic Res Cardiol 1998; 93: 269-275.

25] Borgers M and Piper HM. Calcium shifts in anoxic cardiac myocytes. A cytochemical study. J Mol Cell Cardiol 1986; 18:439-448.

26) Vandeplassche $G$, Thoné $F$, Hermans $C$, Borgers M. Ultrastructural damage and $\mathrm{Ca}^{2+}$-shifts in the canine myocardium subjected to regional incomplete ischemia. Basic Res, Cardiol 1990; 85: 384-391. 
27) Wandeplassche $\mathrm{G}_{*}$ Lu HR, Wouters L, Flameng W, Borgers M. Normothermic ischemic cardiac arrest in the isolated working rabbit heart: effects of dl-nebivolol and atenolol. Basic Res Cardiol $1991 ; 86: 21-31$.

28] Leistad $\mathbb{E}_{*}$ Borgers $M$, Christensen $G$. Atrial contractile dysfunction after short-term atrial fibrillation can be explained by changes in intracellular calcium, but not by atrial ischemia. Circulation $1996 ; 94: 1-386-387$.

291 De Pauw M, Borgers M, Heyndrickx GR. Ultrastructural calcium distribution in cardiac myocytes after 48 h of rapid pacing in dogs. Circulation 1996; 94: I-604.

30] Ver Donck L, Verellen G, Geerts H, Borgers M. Lysophosphatidylcholine-induced Ca ${ }^{2+}$-overload in isolated cardiomyocytes and effect of cytoprotective drugs. I Mol Cell Cardiol 1992;24:977988.

31) Smetnev AS, Bunin I, Nargizian AB, Petrovskii PF, Vakhliaev VD. Characteristics in the metabolism in the myocardium of patients with auricular fibrillation. Kardiologia 1983; 23: 7073.

32. Lau CP, Leung WH, Wong CK, Cheng CH. Haemodynamics of induced atrial fibrillation: a comparative assessment with sinus rhythm, atrial and ventricular pacing. Eur Heart I 1990; 11: $219 \cdot 224$.

33] Wijffells MCEF, Kirchhof CIHI, Dorland R, Power J, Allessie MA. Flectrical remodeling due to atrial fibrillation in chronically instrumented conscious goats. The role of neurohumoral changes, ischemia, atrial stretch, and high rate electrical activation. Circulation 1997; 96:3710-3720.

34 White CW, Kerber RE, Weiss HR, Marcus ML. The effects of atrial fibrillation on atrial pressurevolume and flow relationships. Circ Res 1982;151: 205-215.

35 Jayachandran $\mathrm{V}$, Winkle W, Sih Hy, Zipes DP, Olgin JE. Chronic atrial fibrillation from rapid atrial pacing is associated with reduced atrial blood flow: a positron emission tomography study. Circulation 1998; $98: \mathbb{1 - 2 0 9}$.

36] Ausna J, Coumans W, Duimel M, Allessie MA, Van der Vusse GJ, Borgers M. Do high energy phosphates and mitochondrial enzyme activity change during prolonged atrial fibrillation? Circulation 1999; 100:1-11.

37) Yue L, Feng J, Gaspo R, Wang Z, Nattel S. Ionic remodeling underlying action potential changes in a canine model of atrial fibrillation. Circulation 1997; $81: 512-525$.

38 Borgers $M$, Thoné $\mathbb{F}$, Wouters L, Ausma I, Shivalkar B, Flameng W. Structural correlates of regional myocardial dysfunction in patients with critically coronary artery stenosis: chronic hibernation? Cardiovasc Pathol 1993;2: 237-245

391 Ausma I, Thoné F, Dispersyn GD, Flameng W, Vanoverschelde JL, Ramaekers FCS, Borgers M. Dedifferentiated cardiomyocytes from chronic hibernating myocardium are ischemia-tolerant. Mol Cell Biochem 1998;186: 159-168. 
Chapter 4

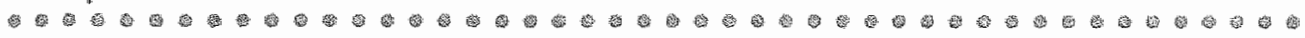

\title{
PET reversed mismatch in an experimental model of subacute myocardial infarction.
}

\author{
Liesbet Mesotten, Gerrit D. Dispersyn, Alex \\ Maes, Mirek Zietkiewicz, Joham Nuyts, Guy \\ Bormans, Tijbbe de Groot, Marcel Borgers, \\ Luc Mortelmans, Willem Flameng
}

published in: 
Rationale: The aim of this study was to evaluate the relationship between flow/metabolism, histology and functional follow-up in a sheep model of subacute myocardial infarction.

Methods: In 8 juvenile sheep, a myocardial infarction was induced by Intracoronary injection of macrobeads. Left ventricular function was evaluated using echocardiography. ${ }^{13}$ NH, ${ }^{8}$ FDG positron emission tomnography (PET) was perforned at 6 weeks and 16 weeks after embolization. In 5 sheep, a dynamic $11 \mathrm{C}$-acetate study was performed. In each animal, two regions of interest were defined on the polar map, corresponding to the embolized and the nonembolized region. After the final measurements the hearts were processed for histological evaluation.

Resulls: PET revealed a moderately decreased flow and oxidative metabolism In the embolized region at 6w, without significant changes at follow-up. At 6 weeks, ${ }^{18}$ FDG uptake in the embolized area was more severely decreased as compared to the flow index in the embolized area $(\mathrm{p}<0.05)$. At 16 weeks, "RDG metabolism had significantly recovered ( $<0.05$ ). Serial echocardiograply showed a persistent decrease of global and regional left ventricular function. Histology revealed a mix of microinfarcted and viable tissue in the embolized region.

Conclusions. In this model of subacute myocardial infarction a PET ' reversed mismatch' pattern was observed, with partial recovery of ${ }^{8} \mathrm{FDG}$ uptake at follow-up. The histological counterpart of this PET pattern appears to be patchy necrosis. 


\section{Introduction}

Myocardial infarction appears to be one of the most common sources of left ventricular dysfunction [1]. Positron emission tomography (PET) is known to accurately identify viable myocardium in patients with impaired left ventricular function $[2-4]$. A stable reproducible and simple experimental animal model of myocardial infarction is needed to study the basic mechanisms leading to ischemic cardiomyopathy. It is known that thrombolytic agents may promote polymorphonuclear leukocytes activation [5]. Regional plugging of myocardial microvasculature by polymorphonuclear leukocytes may induce microinfarctions and thus contribute to the no-reflow phenomenon. The aim was to mimic this by injection of macrobeads and to evaluate the effect on perfusion and metabolism. Our center developed a sheep model of subacute myocardial infarction by single coronary microembolization [6]. The choice of sheep is based on their similarity to human coronary anatomy, with a very small number of collaterals. In this study PET flow/metabolism results were compared with histology and functional follow-up in an experimental sheep model of subacute myocardial infarction.

\section{Material and Methods}

Animal preparation

In 8 juvenile sheep (female, weight 60-65 $\mathrm{kg}$ ), subacute myocardial infarction was induced by selective intracoronary injection of a suspension of polymer macrobeads (Bangs Laboratories, Inc., Carmel, IN, USA; mean diameter $99(\mathrm{~m})$. All animals were treated and cared for in accordance with the National Institute of Health Guide for the Care and Use of Laboratory Animals (NIH Publication no.85-23, revised 1996). Sheep were premedicated with ketamine $\mathrm{HCl}(15-20 \mathrm{mg} / \mathrm{kg}$ IM). Anesthesia was induced with halothane (up to $4 \%$ ) and sodium pentobarbital ( $5 \mathrm{mg} / \mathrm{kg}$ ), the animals were intubated and ventilated through an Engström 200 ventilator with a mixture of $\mathrm{O}_{2}$ and $\mathrm{N}_{2} \mathrm{O}(50-60 \%$ and $50-40 \%)$. Anesthesia was maintained with halothane $0.8-1.6 \%$ and fentanyl $0.2-0.4 \mathrm{mg}$ IV. Postoperative analgesia was provided with piritramide $(20 \mathrm{mg}$ subcutaneously). Procedures were performed in closed-chest animals by insertion of a Sones catheter into the carotid artery. Injections were given selectively $(36,3 \pm 5,2$ $m$ ) into the left anterior descending $(L A D, n=2)$ or left circumflex $(C x, n=6)$ coronary artery under fluoroscopic guidance. The embolization solution was prepared by suspending $0.1 \mathrm{~g}$ of macrobeads in $5 \mathrm{ml}$ of physiological saline and $5 \mathrm{ml}$ of contrast medium. The mean number of macrobeads in $1 \mathrm{ml}$ suspension was $1.85 \times 10^{4}$. Injection was always followed by severe ECG changes (ST-segment elevations) and drop in arterial blood pressure. 


\section{Echocardiography}

All anmals underwent transthoracic two-dimensional echocardiography (Sonotron Vingmed CFM 725 , Horten Norway $2.5 \mathrm{MHz}$ probe) to assess global and regional myocardial function at baseline, 1 day, $1,6,10$ and 16 weeks (w) after the procedure. The measurements were performed on spontaneously breathing animals sedated with ketamine $\mathrm{HCl}(15-20 \mathrm{mg} / \mathrm{kg} \mathrm{IM})$. All parameters were measured at the mid-papillary level in the short-axis parasternal view [7]. Previous measurements of myocardial blood flow using the colored microspheres technique [8] in sheep estimated the regions supplied by the respective coronary arteries. The LAD region was estimated to belimited to the anteroseptum and anterior free wall, whereas the Cx region was defined as posterior and inferior wall areas.

\section{Positron emission tomography}

Myocardial blood flow and glucose metabolism was measured with PET at $6 \mathrm{w}$ and. $16 \mathrm{w}$ after embohzation. Additionally regional myocardial oxygen consumption was studied in 5 sheep at 6 w and in 5 sheep at 16w. A whole-body positron emission tomograph (model ECAT EXACT HR +; CTI Siemens, Knoxville, TN) with 32 detector rings allowing the acquisition of 63 planes with an interplane spacing of $2.4 \mathrm{~mm}$ was used. A small cyclotron (Cyclone 10/5; Ion Beam Applications, Louvain-la-Neuve, Belgium) and auxilliary chemical equipment were used to produce ("C)-acetate ("C-acetate), 2-["F]-fluoro-2-deoxy-D-glucose ("FDG) and nitrogen13-labeled ammonia $\left({ }^{13} \mathrm{NH}_{3}\right)$.

After positioning the sheep in the whole-body tomograph, a 15-minute transaxial transmission scan using three ${ }^{68}$ Ge rod sources for photon attenuation correction was performed.

\section{Image acquisition}

"NH ${ }^{\prime \prime}$ "FDG

$555 \mathrm{MBq}$ of ${ }^{13} \mathrm{NH}_{3}$ in $5 \mathrm{ml}$ saline followed by a $2 \mathrm{ml}$ flush of saline was slowly infused at a constant rate of $10 \mathrm{ml} / \mathrm{min}$. Acquisition was started simultaneously with the injection of ${ }^{13} \mathrm{NH}_{3}$, 22 dynamic frames were recorded ( $12 \times 10 \mathrm{sec}, 4 \times 30 \mathrm{sec}, 3 \times 2 \mathrm{~min}, 1 \times 3 \mathrm{~min}, 1 \times 7 \mathrm{~min}, 1 \times 10 \mathrm{~min}$ ). Glucose metabolic studies were performed using the hyperinsulinemic euglycemic clamp technique $[9,10]$. The dose of injected insulin was similar in all sheep $(69 \pm 8 \mathrm{IU} / \mathrm{h}) .370 \mathrm{MBq}$ of "FDG was injected after stabilization of the glucose level between 85 and $95 \mathrm{mg} \%$ and not earlier than 50 minutes after " $\mathrm{NH}_{3}$ injection to allow for decay. Twenty-two dynamic frames were recorded ( $8 \times 15 \mathrm{sec}, 4 \times 30 \mathrm{sec}, 2 \times 1 \mathrm{~min}, 2 \times 2 \mathrm{~min}, 6 \times 10 \mathrm{~min})$. 


\section{${ }^{11} \mathrm{C}$-acetate}

In 5 sheep at $6 \mathrm{w}$ and $16 \mathrm{w}$, a dynamic "C-acetate study was performed between the "NH and the ${ }^{15} \mathrm{FDG}$ study. $740 \mathrm{MBq}$ of "C-acetate, diluted with saline $0.9 \%$ to a volume of $5 \mathrm{ml}$ was injected in a bolus not earlier than 50 minutes after ' $\mathrm{NH}_{3}$ injection to allow for decay. Twentyfour dynamic frames were recorded $(8 \times 15 \mathrm{sec}, 4 \times 30 \mathrm{sec}, 2 \times 1 \mathrm{~min}, 10 \times 2 \mathrm{~min}) .{ }^{18}$ FDG was injected not earlier than 60 minutes after ${ }^{11} \mathrm{C}$-acetate injection.

\section{Image processing}

${ }^{13} \mathrm{NH}_{3} /{ }^{18} \mathrm{FDG}$

The first 19 frames of the perfusion studies and the 22 frames of the metabolic studies were reconstructed using a Hanning filter with a cut-off frequency of 0.3 . A summed frame of both the perfusion study and the metabolic study was constructed using frame 18-22. The long axis of the left ventricle was indicated manually on the summed frame. The myocardial image was resampled into 16 radial slices. The radial slices were delineated using an algorithm developed in our department $[4,11]$. The delineation was used to construct a polar map [12].

For the metabolic studies, the creation of radial slices, delineation, polar maps and regional time activity was done in exactly the same way as for the flow studies. A region of normal tracer uptake was manually defined on the ${ }^{13} \mathrm{NH}_{3}$ polar map and copied to the ${ }^{\text {IFDG }}$ map. The mean values of that region were used as reference values: $100 \%{ }^{13} \mathrm{NH}_{3}$ uptake and $100 \%{ }^{18} \mathrm{FDG}$ uptake respectively.

In each sheep, two regions of interest were defined on the polar map of the summed frame. The first, representing nonembolized myocardium consisted of the area perfused by the nonembolized coronary artery. The second region was drawn over the area perfused by the embolized coronary artery. Flow and metabolic indices were computed for the polar maps. $A$ flow index was calculated as the ratio of ${ }^{13} \mathrm{NH}_{3}$ uptake in the embolized or the nonembolized region and the ${ }^{13} \mathrm{NH}_{3}$ uptake in the region with the highest uptake (reference region). A metabolic index was defined as the ratio of glucose utilization in the embolized or nonembolized region and that in the reference zone. Regions were defined as PET viable when the flow index was $>0.8$ ('match normal') or when the ratio of metabolic and flow index was $>1.2$ ('mismatch'). Regions were defined as PET nonviable when the flow index was $<0.8$ and when the ratio of metabolic and flow index was <1.2 [4,13].

Regions with a ratio of metabolic and flow index $<0.8$ were defined by the new concept of "reversed mismatch" indicating a more pronounced decrease of glucose metabolism as compared to flow.

A three-compartment model was applied to calculate absolute blood flow values and Patlak graphical analysis to estimate glucose utilization values $[14,15,16]$. 


\section{"C-acetate}

Polar maps of every frame were constructed in the same way as for the ${ }^{1 \mathrm{NH}}$ and ${ }^{\mathrm{B}} \mathrm{FDG}$ images. For each study, the embolized and the nonembolized region were used as defined in the analysis of the ${ }^{13} \mathrm{NH}_{3}$ and ${ }^{16} \mathrm{FDG}$ images. Oxidative metabolism was assessed using a 3 compartment model [17]. In this model, rate constant $k_{2}$ is proportional to the oxygen consumption.

\section{Histopathology of myocardial tissue}

Sheep were sacrificed by intravenous injection of saturated $\mathrm{KCl}$ after the PET scan at $6 \mathrm{w}(\mathrm{n}=2)$ and at $16 \mathrm{w}(n=6)$. The heart was immediately fixed by perfusion with $3 \%$ glutaraldehyde in $0.09 \mathrm{M} \mathrm{KH}_{2} \mathrm{PO}_{4}(\mathrm{pH} 7.4)$. Different biopsies of the embolized and nonembolized region were taken based on the results of the three-dimensional polar map. Using this method, myocardial samples could easily be selected with a high accuracy. The samples were postfixed in $2 \% \mathrm{OsO}_{4}$ in weronal acetate buffer , dehydrated and routinely embedded in epon epoxy resin. For light microscopy, semithin sections ( $2 \mu \mathrm{m}$ ) were cut and stained with periodic acid schiff and toluidine blue. Ultrathin sections $(50 \mathrm{~nm})$ were briefly counterstained with uranium acetate and lead citrate, before visualization in a Philips CM 100 electron microscope.

\section{Statistical analysis}

Results are given as mean values \pm standard deviation. Statistical significance was indicated by $p$ values $<0.05$. Differences between groups were inwestigated by using Student $t$ tests for paired data. For evaluation of the relationship between normalized flow and percentage fibrosis linear regression plots were used.

\section{Results}

A subacute myocardial infarction was induced by intracoronary injection of macrobeads in 8 sheep. Six weaks after embolization the sheep were examined by echocardiography $(n=8)$, "NH $y^{\mid N F D G ~ P E T ~}(n=8)$ and "C-acetate PET $(n=5)$. Two sheep were sacrificed at that time (histological evaluation, $\mathrm{n}=2$ ).

Examinations were repeated 16 w after embolization (echocardiography $(n=6),{ }^{13} \mathrm{NH}_{3} / 8 \mathrm{FDG}$ PET ( $n=6)$, "C-acetate PET $(n=5)$ and histological evaluation $(n=6))$.

\section{PET imaging}

Flow indices, absolute blood flow, metabolic indices, absolute glucose utilization and acetate oxidative metabolism in the nonembolized and the embolized region at $6 \mathrm{w}$ and $16 \mathrm{w}$ are summarized in Table 1. 


\begin{tabular}{|c|c|c|c|c|c|c|c|c|c|c|c|c|c|c|c|c|c|c|c|c|c|c|}
\hline & \multicolumn{11}{|c|}{ GWEEKS } & \multicolumn{11}{|c|}{16 WEES } \\
\hline & \multicolumn{5}{|c|}{ NONEMSOL } & \multicolumn{5}{|c|}{ EMBOL } & \multirow{2}{*}{ 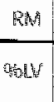 } & \multicolumn{5}{|c|}{ MONEMBOLL } & \multicolumn{5}{|c|}{ EMBOL } & \multirow{2}{*}{$\frac{\text { Mat }}{\text { Mon }}$} \\
\hline 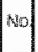 & Nith & $\mathrm{BF}$ & $\mathrm{FOC}$ & G) & $A C$ & $\mathrm{NH}_{3}$ & $B F$ & FDC & Gu & $A C$ & & NHI & $\mathrm{EF}$ & $F D_{A}$ & $\mathrm{Gu}$ & $\mathrm{AC}$ & $\mathrm{Ning}_{*}$ & $\mathrm{BF}$ & $\mathrm{FDO}$ & Gu & $\mathrm{AC}$ & \\
\hline 1 & 101 & 69 & 95 & 57 & & $9 ?$ & 79 & 77 & 43 & & 34 & & No & data 6 & sacrifter & $\mathrm{ad} 6 \mathrm{w}$ & cets ant & ar en & nboles: & ffion) & & \\
\hline 2 & 0 & 7 & 95 & 69 & & 71 & 71 & 5 & $\mathrm{~F}_{4}$ & & 40 & 96 & 90 & 89 & $n$ & & 73 & 41 & 73 & 48 & & 11 \\
\hline 3 & 91 & 67 & 109 & 59 & & 52 & 36 & 39 & 21 & & 47 & 91 & 83 & 104 & $5 \sqrt{3}$ & 0,18 & 33 & 55 & 58 & 25 & 0,13 & 1 \\
\hline 4 & 89 & s: & 86 & 52 & 018 & 68 & 37 & 52 & 23 & 6, 64 & 23 & 90 & 86 & 88 & 76 & 0,15 & 60 & 57 & 73 & 43 & 013 & \\
\hline 5 & 87 & 73 & 96 & 57 & 0,19 & 82 & 63 & 63 & 34 & 0,15 & 33 & 92 & 65 & $9 \times$ & 78 & 0.16 & 84 & 62 & 74 & 58 & 0,14 & 14 \\
\hline 6 & 90 & 78 & 1ar: & 75 & 60 & 69 & 72 & 38 & 26 & $(0) 16$ & 4 & & & (n) & AG & 16 & diks arne & eem & bolita & (Won & & \\
\hline 7 & 95 & 87 & 96 & 42 & 0,22 & 73 & 72 & 54 & 23 & 0,18 & 15 & 86 & 9 & 91 & 57 & 0,28 & 68 & 64 & 72 & 52 & 0,27 & 1 \\
\hline 8 & 9 & 64 & 6) & 88 & 021 & 85 & 62 & 6) & 54 & 10,20 & 7 & a7 & 109 & 64 & 16 & 1726 & 81 & 9 & 73 & 64 & 124 & 7 \\
\hline
\end{tabular}

Table 1: Flow indices, obsolute blood flow values, metabolic indices, absolute glucose utilization and acetate oxidative metabolism values in the embolized and nonembolized region Gw and 16 w after embolization. NONEMBOL = nonembolzed region, EMBOH=: embolized region, $\mathrm{NH}_{3}=$ mean nomalized ${ }^{\mathrm{N}} \mathrm{NH}$, uptake $(0 \%)$, BF $=$ absolute blood flow $(\mathrm{m} / \mathrm{min}$ per $100 \mathrm{~g})$, $\mathrm{BDC}=\mathrm{mean}$

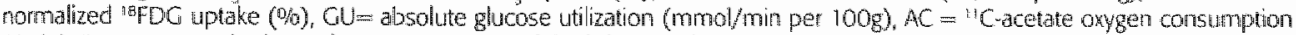
$(/ \mathrm{min})$. RM = reversed mismatch. \% $\mathrm{LV}=$ area of the left wentricle.
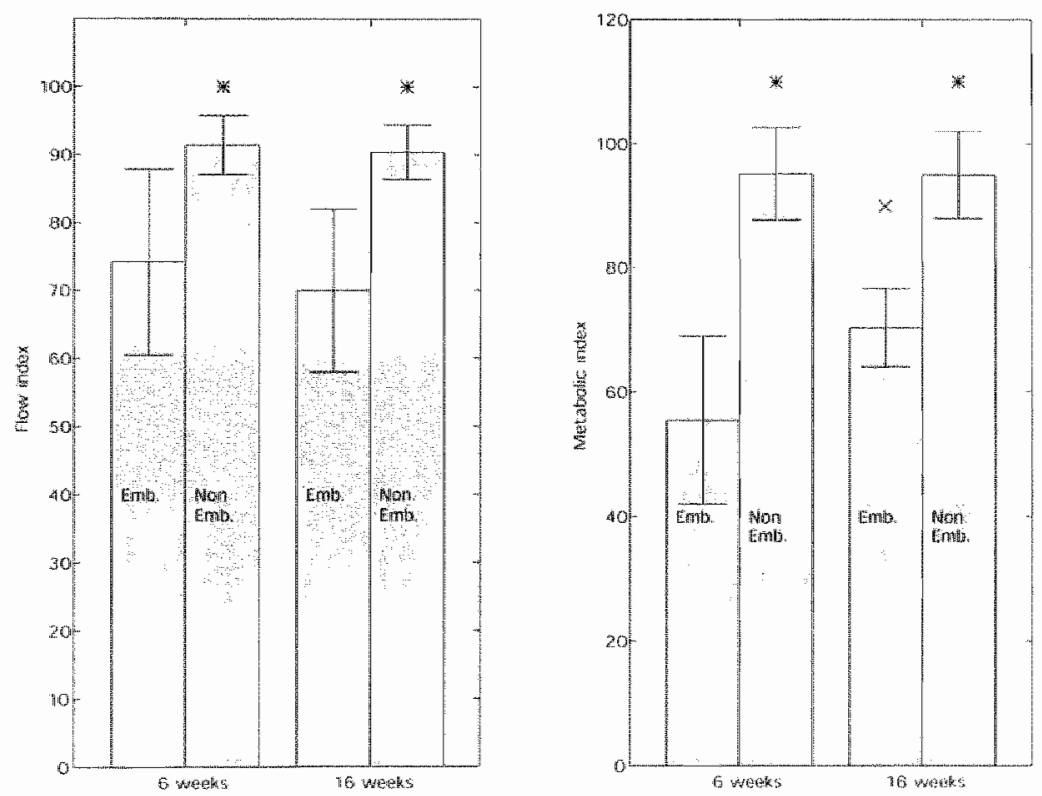

Figure 1: Comparison of flow and metabolic indices fow and 16 w after embolization in the embolized and the nonembolized region. A significant difference in flow index and metabolic index was found between the embolized region and the nonembolized region (* $\mathrm{p}<$ 0.05 ). The llow index remained stable owel time in any region A significant recovery of the metabolic index was tound in the embolized region $(x p<0.05)$ ( emb = embolized region, nonefnb = nonembolized region) 
${ }^{13} \mathrm{NH}_{3}$ " $\mathrm{FDG}$ results

Blood Flow

Flow indices at $6 \mathrm{w}$ and $16 \mathrm{w}$ are plotted on Figure la. In the embolized areas, PET revealed a decreased flow index at both 6 w and 16w. The flow index in the embolized area was significantly lower as compared to the nonembolized area $(6 \mathrm{w}: 74 \pm 14 \%$ vs. $91 \pm 4 \%, \mathrm{p}<0.05$, 16w: $70 \pm 12 \%$ vs. $90 \pm 4 \%, \mathrm{p}<0.05$ ). The flow index did not change significantly over time in any region.s

Absolute blood flow values were also calculated: $62 \pm 17 \mathrm{ml} / \mathrm{min}$ per $100 \mathrm{~g}$ in the embolized region both at $6 \mathrm{w}$ and $16 \mathrm{w}$ and $70 \pm 10 \mathrm{ml} / \mathrm{min}$ per $100 \mathrm{~g}$ at $6 \mathrm{w}$ and $85 \pm 14 \mathrm{ml} / \mathrm{min}$ per $100 \mathrm{~g}$ at $16 \mathrm{w}$ in the nonembolized region respectiwely. The absolute blood now values did not change significantly over time.

A.
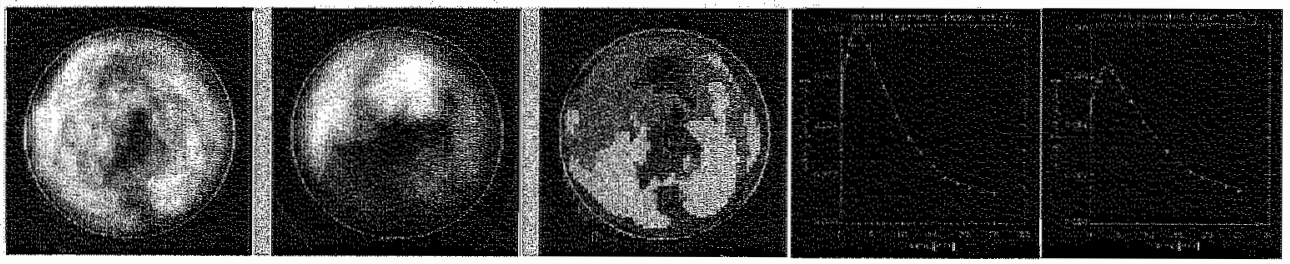

(A) Polar map of a sheep 6w after embolization. Nomal flow and nomal metabolism in the LAD region. The interpretation shows PET match normal (vable) represented in green. Decreased flow index and more severely decreased metabolic index in the $C x$ region. The interpretation shows a PET reversed mismatch, represented in gray. The two different colors of gray represent the different flow indices. Flow index in the nom-embolized region is $87 \%$, in the embolized region $82 \%$. The metabolic index in the non-embolized reguon $96 \%$ in the embolized region $63 \%$. Oxygen consumption valtues in the nonembolized region: $0.19 / \mathrm{min}_{\text {in }}$ in the embolized region $0.15 / \mathrm{min}$.

13.
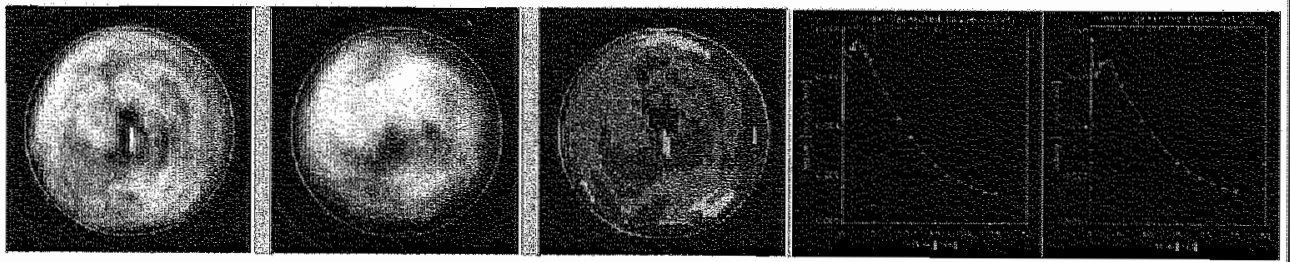

(B) Polar map of the same sheep 16 w after embolization. Nomal flow and nomal metabolism in the LAD region. Recovery of ${ }^{2} \mathrm{FO}$ uptake is noticed in the $\mathrm{Cx}$ region. Flow index in the non wembolized region is $92 \%$, in the embolized region $34 \%$. The melabolic index in the non embolized region $94 \%$, in the embolized region $740 \%$. Oxygen consumption (/min) values in the non-embolized region: $0.16 / \mathrm{m}$ in, in the embotized region $0.14 / \mathrm{min}$

Figure 2: Polar map of $\mathrm{NH}_{3}$, ${ }^{10} \mathrm{FDG}_{4}$, the interpretation and curves of "Cacetate oxidative metabolism. The hirst map of every case

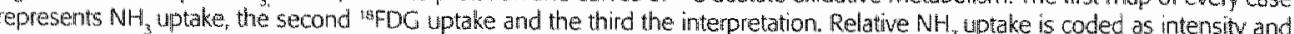
the combined patron in color. The cuves represent the "C-acetate measured tirne activity curve (t) and hted model (solid ine) for the non-embolized region and for the embolized region. 


\section{Metabolism}

Metabolic indices at $6 \mathrm{w}$ and $16 \mathrm{w}$ are plotted on Figure $1 \mathrm{~b}$. At $6 \mathrm{w}$ the metabolic index in the embolized area was significantly decreased as compared to the nonembolized region ( $55 \pm 13 \%$ vs. $95 \pm 7 \%, \mathrm{p}<0.05$ ). At $16 \mathrm{w}$, the metabolic index in the embolized region had significantly recovered from $55 \pm 13 \%$ to $70 \pm 6 \%$ ( $\mathrm{p}<0.05$ ), but was still significantly lower as compared with the metabolic index in the nonembolized region $(70 \pm 6 \%$ vs. $95 \pm 7 \%$, $\mathrm{p}<0.05)$. No difference was measured between the metabolic index in the nonembolized region at $6 \mathrm{w}$ and $16 \mathrm{w}$ (Figure $1 \mathrm{a}+\mathrm{lb}$ ).

Absolute glucose distribution was calculated: $32 \pm 11$ (mol/min per $100 \mathrm{~g}$ at $6 \mathrm{w}$ and $49 \pm 13$ ( $\mathrm{mol} / \mathrm{min}$ per $100 \mathrm{~g}$ at $16 \mathrm{w}$ in the embolized region and $63 \pm 15(\mathrm{~mol} / \mathrm{min}$ per $100 \mathrm{~g}$ at $6 \mathrm{w}$ and $70 \pm 10(\mathrm{~mol} / \mathrm{min}$ per $100 \mathrm{~g}$ at $16 \mathrm{w}$ in the nonembolized region. Significant recovery of absolute glucose utilization was observed at $16 \mathrm{w}$ in the embolized region $(\mathrm{p}<0.05)$.

\section{Comparison between myocardial flow and metabolism}

At $6 \mathrm{w},{ }^{18} \mathrm{FDG}$ uptake was more severely decreased as compared to the flow indices in the

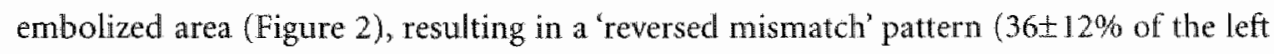
ventricle) (Table 1). At $16 \mathrm{w},{ }^{18} \mathrm{FDG}$ metabolism had partially recovered, giving rise to a change in a 'PET match' pattern. Reversed mismatch regions were still present in $6 \pm 6 \%$ of the left ventricle (Table 1 ).

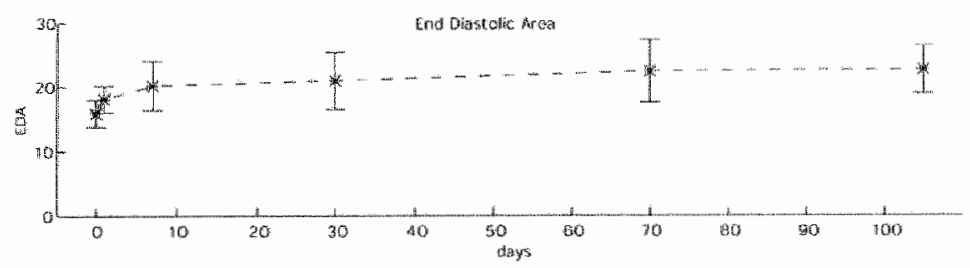

Figure 3: Folown-up of left westritibur function based on the echo resulis.
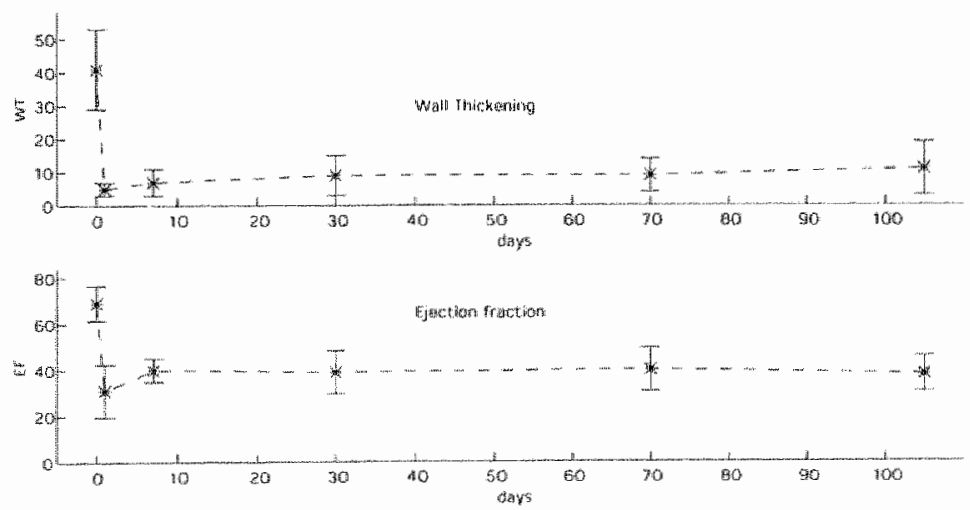


\section{"Cracetate results}

Oxidative metabolism as measured with $k_{2}$ was significantly lower both at $6 \mathrm{w}$ and $16 \mathrm{w}$ in the embolized region compared to the nonembolized region (6w: $0.16 \pm 0.04 / \mathrm{min}$ vs. $0.2 \pm 0.03$ / $\min _{3} \mathrm{p}<0.05,16 \mathrm{w}: 0.18 \pm 0.06 / \mathrm{min}$ ws. $\left.0.2 \pm 0.06 / \mathrm{min}, \mathrm{p}<0.05\right)$. In the nonembolized region $\mathrm{k}_{2}$ was identical at $6 \mathrm{w}$ and $16 \mathrm{w}(6 \mathrm{w}: 0.2 \pm 0.03 / \mathrm{min}, 16 \mathrm{w}: 0.2 \pm 0.06 / \mathrm{min})$. No significant difference was noticed in the oxidative metabolism in the embollized region between $6 \mathrm{w}$ and $16 \mathrm{w}$.

\section{Left ventricular function}

Changes in left ventricular function in the embolized region at baseline, 1 day, $1 \mathrm{w}, 6 \mathrm{w}, 10 \mathrm{w}$ and $16 \mathrm{w}$ after embolization are summarized in Table 2 and Figure 3 . The end-diastolic left ventricular area was significantly increased at $6 \mathrm{w}$ after embolization as compared to baseline (baseline: $\left.16 \pm 2 \mathrm{~cm}^{2}, 6 \mathrm{w}: 21 \pm 5 \mathrm{~cm}^{2}, \mathrm{p}<0.05\right)$ and did not change significantly until the end of the followup period ( $\left.16 \mathrm{w}: 22 \pm 4 \mathrm{~cm}^{2}\right)$. The ejection fraction was significantly decreased at $6 \mathrm{w}$ (baseline: $69 \pm 8 \%, 6 \mathrm{w}: 38 \pm 9 \%, \mathrm{p}<0.05)$ and no significant changes were noticed at $16 \mathrm{w}(1.6 \mathrm{w}: 37 \pm 8 \%)$. The contractility of the embolized region expressed as wall thickening dropped (baseline: $40 \pm 12 \%, 6 \mathrm{w}: 9 \pm 6 \%)$ and remained stable until $16 \mathrm{w}(16 \mathrm{w}: 12 \pm 9 \%)$. A persistent hypokinesis of the embolized region was noticed.
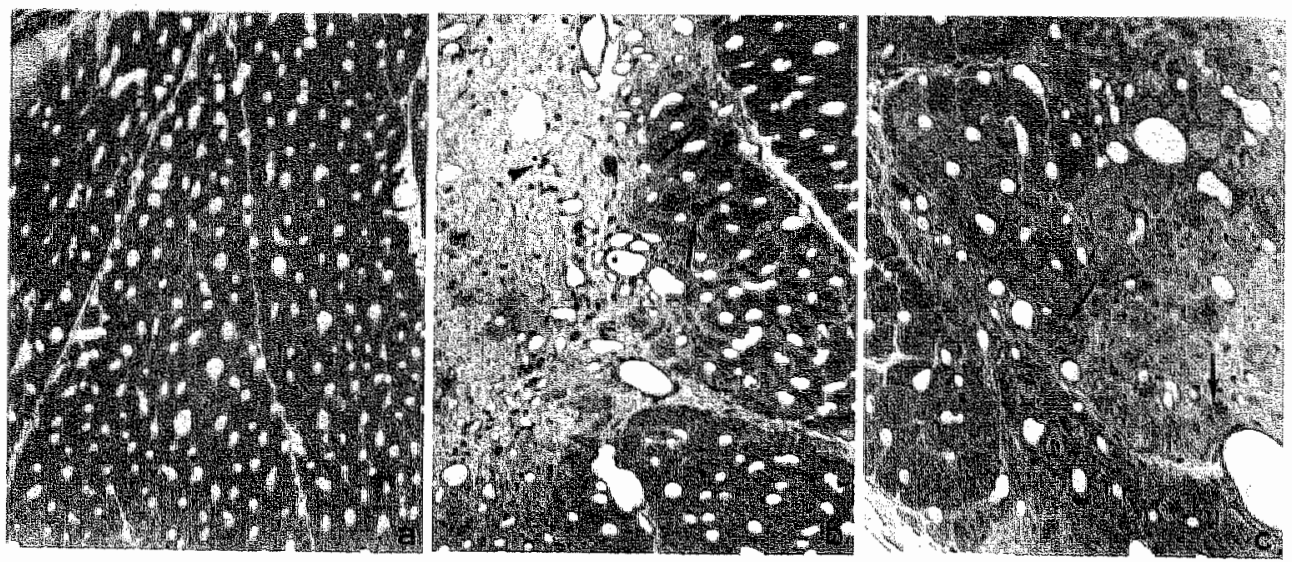

Figure 4. Light microscopic pictures of a nomal nonembolized tegion (a) and embolzed regions at 6w (b) and $16 \mathrm{w}$ (c). Fibrotic areas are prominent in the embolized regions. At 5 w infilrated interstutial cells are present (arrowhead) and less collagern deposition hawe occurred so far, in contrast to the fibrotic areas at 16 . Cardiomyocyres with sarcomere depletion and gycogern accumulation can be seen in the microintarcion border zones (arrows) (a:180x, b.130x, c:130x) 

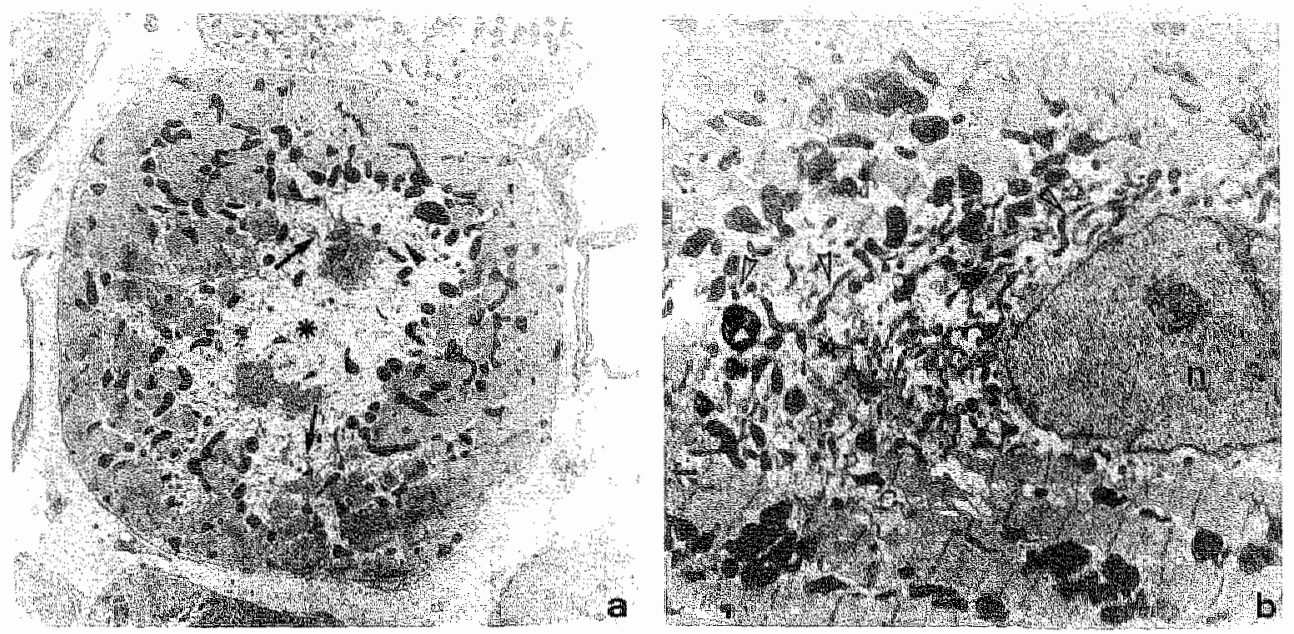

Figure 5: Electron microscopic pictures of cardionyocres with ultastructural changes found in the embolized region, bordering the microinfarctions: (a) Sarcomere depletion (asterisk) is accompanied by ghoogen accumulation (arrowheads). Only remianis of organized sarcoplasmic reticulum are present (arrows). (b) Nuclear heterochomatin is homogeneously dispersed $(n)$ and numerous mitochondria are abmomally small and/or elongated (open amow). (a:1930x, b:35.70x)

\section{Histology}

Histology revealed transmural a mix of microinfarcted and viable tissue in the reversed mismatch regions at 6 w that evolved to the match pattern at 16 w (Figure 4+5). No significant difference was observed between the amount of microinfarcted tissue in the reversed mismatch

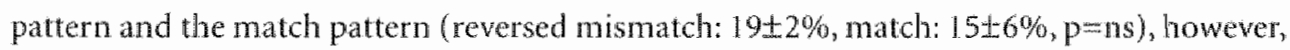
in those regions at $6 \mathrm{w}$ the collagen deposition was not yet as pronounced as at $16 \mathrm{w}$. The percentage fibrosis in the embolized region (17 $3 \%$ ) was significantly higher compared to the nonembolized region $(4 \pm 2 \%, p<0.05)$. A significant inverse correlation exists between the percentage fibrosis in the nonembolized and embolized region and the perfusion measurements with ${ }^{13} \mathrm{NH}_{3}(\mathrm{r}=-0.7 \times \mathrm{p}<0.05)$.

Viable cardiomyocytes, both remote areas and closely surrounding the microinfarctions were dearly nonischemic as can be shown ultrastructurally by the presence of intramatricial asmophilic granules in the mitochondria [18]. However, subcellular alterations could be found in cardiomyocytes bordering the microinfarctions, such as sarcomere depletion, glycogen accumulation, nuclear heterochromatin distribution and the appearance of numerous aberrantly shaped mitochondria. Nevertheless these cells showed no degenerative changes like cellular swelling, cytoplasmic vacuolization or membrane disruption. 


\begin{tabular}{|l|lll|lll|lll|}
\hline \multirow{2}{*}{ No. } & \multicolumn{2}{|l|}{ EDA $\left(\mathrm{cm}^{2}\right)$} & & \multicolumn{2}{|l|}{ WT $(\%)$} & \multicolumn{3}{|l|}{ EF (\%) } \\
\cline { 2 - 9 } & BS & $6 \mathrm{~W}$ & $16 \mathrm{~W}$ & BS & $6 \mathrm{~W}$ & $16 \mathrm{~W}$ & BS & $6 \mathrm{~W}$ & $16 \mathrm{~W}$ \\
\hline 1 & 15 & 15 & $*$ & 33 & 14 & $*$ & 79 & 50 & $*$ \\
2 & 15 & 18 & 19 & 33 & 13 & 17 & 63 & 34 & 39 \\
3 & 17 & 27 & 27 & 21 & 3 & 0 & 75 & 26 & 27 \\
4 & 17 & 24 & 24 & 48 & 1 & 6 & 68 & 46 & 47 \\
5 & 17 & 17 & 17 & 47 & 10 & 6 & 67 & 49 & 44 \\
6 & 12 & 21 & $*$ & 52 & 3 & $*$ & 79 & 28 & $*$ \\
7 & 19 & 24 & 21 & 36 & 13 & 20 & 64 & 38 & 32 \\
8 & 15 & 22 & 23 & 58 & 17 & 20 & 59 & 37 & 3 \\
\hline
\end{tabular}

Table 2: Echocardiographic resilts. EDA = end-diastolic left ventricular area,

WT $=$ wall thickening fraction, EF $=$ LV ejection fraction, $B S=$ baseline, $6 \mathrm{~W}=6$ weeks, $16 \mathrm{~W}=16 \mathrm{weeks} *$, no data (sacifliced $6 \mathrm{w}$ after embolization)

\section{Discussion}

PET results

A PET viable pattern consisting of hypoperfusion with relatively preserved ${ }^{13} \mathrm{FDG}$ uptake (PET mismatch) or normal flow and metabolism (PET match normal) is an indicator of viability. A combined reduction of both parameters (PET match necrosis) suggests necrosis (transmural or nontransmural). Areas of reversed mismatch can sometimes be noticed in myocardial areas with decreased function [19]. The significance of this pattern is a matter of debate at present. In previous acute experiments, the same phenomenon of decreased glucose uptake was found 2 days postischemia [20]. Glucose uptake values returned to baseline by 7 days. Oxygen consumption was normal both at 2 and 7 days after ischemia. In another study with pigs, "FDG retention in acutely stunned myocardium was lower than in the remote regions 2 hours after the ischemia [21]. Twenty-four hours following reperfusion ${ }^{18} \mathrm{FDG}$ uptake in these reperfused regions was normal or enhanced compared to the remote regions.

In dogs, the glucose metabolic rate in normal myocardium underwent larger changes immediately after reperfusion [22]. Three hours after the LAD occlusion an increase of the glucose uptake in remote myocardium was noticed compared to the baseline study. Twenty- 
four hours post reperfusion, glucose metabolic rate was decreased in remote myocardium. In rats the addition of $B$-hydroxybutyrate, or lactate significantly decreased the uptake of ${ }^{1 *} \mathrm{FDG}$ as compared to glucose uptake [23]. In the same experiment after the addition of insulin the glucose uptake increased without a significant increase of ${ }^{16} \mathrm{FDG}$. In this study the other competing substrates and insulin are suddenly added to a perfusate of isolated working heart. Glucose is the only energy substrate and insulin is not available. This is an unphysiological and non steady state condition where the ${ }^{\mathrm{s}} \mathrm{FDG}$ model might not be valid. In contrast, during physiological and steady state conditions in humans insulin increases ${ }^{18} \mathrm{FDG}$ uptake severalfold [24].

Although these animal models show some similarities to our study, the main difference is that in these studies acute situations were described. In our sheep model, the first PET scan was performed after $6 w^{18}{ }^{18} \mathrm{FDG}$ uptake was severely depressed in the embolized region at that time. This suggests that after a myocardial infarction ${ }^{18} \mathrm{FDG}$ uptake in viable cells does not recover quickly either due to the use of other substrates than glucose. Only $16 \mathrm{w}$ after embolization ${ }^{19} \mathrm{FDG}$ had recovered significantly.

A study in patients with a subacute myocardial infarction showed a similar pattem of reduced glucose metabolism after thrombolytic therapy in the infarct area [25]. The selective embolization of one coronary artery in our animal model might be comparable to what happens after thrombolysis. Thrombolysis might result in very small particles spreading diffusely to the small vessels. These small particles may then very well cause similar microinfarctions as observed in the animal model.

\section{Histology}

A typical pattern of 'patchy necrosis' with a mixture of fibrotic and viable myocardium was observed in the reversed mismatch region. This finding confirms previous findings suggesting that regions with decreased FDG uptake and relatively preserved flow would consist of a mixture of fibrotic myocardium and viable tissue [19].

Several abnormally structured cardiomyocytes were found in the regions bordering the microinfarction in both 'match' and 'reversed mismatch' regions. "Those cells showed sarcomere depletion, glycogen accumulation, nuclear heterochromatin redistribution and aberrantly shaped mitochondria, changes that can also be noted in chronic hibernating myocardium [4]. The nature of possible triggers causing these ultrastructural changes is not clear, but the presence of altered mechanical load and the occurrence of chronic or repetitive relative underperfusion might play a role. 


\section{Function}

Left ventricular dilatation and depression of global function were accompanied by persistent hypokinesis of the embolized region. No changes in global and regional left ventricular function were obserwed between 6 wnd 16 w.

Another recent study of our group [26] showed recovery of function from the intact subepicardial layers 3 months after a subendocardial infarction. In our sheep model the injected macrobeads spread to both epi- and endocardium, resulting in diffuse microinfarctions in all layers of the myocardial wall. It is possible that due to this diffuse pattern of microinfarctions; the integrity of the myocardial contractile apparatus is too severely disrupted to allow recovery of left ventricular function despite the presence of viable cells.

\section{Study limitations}

The number of animals included in this study is small, mainly because of the laborious study protocol. However, by analyzing the differences in flow and metabolism between the embolized and the nonembolized region statistically significant results were obtained.

In the model intracononary injection of macrobeads results in patchy necrosis of myocardium probably without any reflow. The regions between the necrotic areas have no ischemic burden at all. This is very different to the injury caused by subacute myocardial infarction in humans in which ischemia leads to myocardial necrosis. The injury might be patchy but the tissue between the necrotic areas is typically chronically or repeatedly ischemic. Furthermore, the epicardiallendocardial difference does not exist in the present model.

No plasma substrates and insulin levels were measured during the study protocol.

\section{Conclusion}

From the results of this model of subacute myocardial infarction, we conclude that a PET reversed mismatch' pattern with a lower metabolic index in relation to the flow index can be observed $6 \mathrm{w}$ after embolization. This is probably due to the use of alternative substrate. The histological counterpart of this PET pattern appears to be 'patchy necrosis'. Decreased function was observed in these areas atready from the tirst day after the procedure without significant recovery at follow-up. At later time points, the reversed mismatch pattern shows recovery of PDG uptake and an evolution into a 'PET match' pattern. 


\section{References}

1] Bourassa MG, Gurne O, Bangdiwala SI, et al. Natural history and patterns of current practice in heart failure. IAm Coll Cardiol 1993; 22:14A-19A.

2] Tillisch J, Brunken $\mathbf{R}$, Marshall $\mathbf{R}$, et al. Reversibility of cardiac wall notion abnormalities predicted by positron tomography. N Engl J Med 1986; 314:884-888.

3] Schellbert HR. Positron emission tomography for the assessment of myocardial wiability. Circulation 1991; 84 (suppl): 122-131.

4] Maes A, Flameng W, Nuyts J, et al. Histological alterations in chronically hypoperfused myocardium: correlation with PET findings. Circulation 1994; 90:735-745.

5. Hansen P. Role of neutrophils in myocardial ischemia and reperfusion. Circulation 1995;91:1872. 1885.

6! Zietkiewicz M, Perek B, Meyns B, et al. Chronic heart lailure model induced by corenary embolization in sheep. Int J of Artif Organs 1999; 22:499-504.

7) Chen C, LiL, Chen LL, Prada JV, et al. Incremental doses of dobutanine induce a biphasic response in dysfunctional left ventricular regions subtending coronary stenoses. Circulation 1995; 92:756766.

81 Wieland W, Wouters PF, Van Aken H, Flameng W. Measurement of organ blood flow with coloured microspheres: a first time-saving improvement using automated spectrophotometry. Proceedings of computers in cardiology $1993 ; 691-694$.

9) Knuuti JM, Nuutila P, Ruotsalainen U, et al. Euglycemic hyperinsulinemic clamp and oral glucose load in stimulating myocardial glucose utilization during positron emission tomography. I Nucl Med 1992; 33:1255-1262.

10) Defranzo RA, Tobin JD, Andres R. Glucose damp fechnique: a method for quantifying insulin secretion and resistance. Am I Physiol 1979;237.E214-223.

11] Nuyts J, Suetens P, Oosterlinck A, De Roo M, Mortelmans L. Delineation of LCl images using global constraints and dynamic programming. IEEE Trans med imaging 1991; 10:489-498.

12] De Land sheere $C_{\text {, Raets }}$ D, Pierard L. Regional myocardial perfusion and glucose aptake: clinical experience in 92 cases studied with positron tomography, In: Schmidt HAE, Chambron J, editors. Nuclear Medicine: Quantitative analysis in imaging and function. Stuttgart: Schattaue Verlag, $1990: 245-247$.

13) Maes A, Wan de Werf $F_{x}$ Nuyts J, Bormans $G_{3}$, Desmet W, Mortelmans L. Imparied myocardial tissue perfusion early after success ful thrombolysis. Impact on myocardial flow, metabolism and function at late follow-up. Circulation 1995, 92:2072-8. 
14] Muxik $O$, Beanlands RS, Hutchins GD, Mangner T], Nguyen $N$, Schwaiger $M$. Validation of nitrogen-13-ammonia tracer knetic model for quantification of myocardial blood flow using PET. INuCl Med 1993; 34:83-9 .

15] Paflak CS, Blasberg $\mathbb{R G}_{x}$ Fenstermacher ID. Graphical evaluation of blood-to-brain transfer constants from multiple-time uptake data. J Cereb Blood Flow Metab 1983; 3:1-7.

161 Patlak CS, Blasberg RG. Graphical evaluation of blood-to-brain transfer constants from multiple -time uptake data generalizations. I Cereb Blood Flow Metab 1985;5:584-590

17. Buck $A$, Wolpers $H$, Hutchins $G$, et al. Effect of carbon-11 -acetate recirculation on estimates of myocardial oxygen consumption by PET. I Nucl Med 1991; 32:1950-1957.

18] Vandeplassche G, Hermans $C$, Thone F, Borgers $M$. Stunned myocardium has increased mitochondrial NADH oxidase and ATPase activities. Cardioscience 1991; 2:47-53.

19] Perrone-Filardi P. Bacharach S, Dilsizian $V_{n}$ et al. Clinical significance of reduced regional myocardial glucose uptake in regions with normal blood how in patients with chronic coronary artery disease. JACC 1994; 23:608-616.

20) Baldwin D, McFalls $E$, Jaimes D, Fashingbauer $P$, Nemzek $\mathbb{T}_{*}$ Ward $\mathbb{H}$. Myocardial glucose metabolism and ATP levels are decreased two days after global ischemia. Jounal of surgical research $1996 ; 63: 35-38$.

21) McFalls EO, Ward $\mathbf{H}$, Fashingbauer $\mathbf{P}$, Gimmestad $\mathbf{G}$, Palmer B. Myocardial blood flow and FDG retention in acutely stunned porcine myocardium. JNM 1995; 36:637-643.

22] Buxton D, Schelbert H. Measurement of regional glucose metabolic rates in reperfused myocalldium. Am I Physiol 1991; 261: :-12058-H2068.

23) Hariharan R, Bray M, Ganim R, Doenst T, Goodwin G, Taegtmeyer H. Fundamental linitations of $[18 \%] 2-$ deoxy-2-fluoro-d-glucose for assessing myocardial glucose uptake. Circulation $1995 ; 91: 2435-2444$.

24] Maki M, Luotolahti $M$, Nuutila $P$, et al. Glucose uptake in the chronically dysfunctional but viable myocardium. Circulation 1996;93:1658-1666.

25. Gropler RI, Siegel B, Sampathkumaran et al. Dependence of recovery of contractile function on mainteneance of oxidative metabolism after myocardial infarction. IACC 1992;19:989-997.

26] Bogaert I, Maes A, Van de Werf F, et al. Functional recovery of subepicardial myocardial tissue in transmural myocardial infarction after successful reperfusion. Circulation 1999;99:36-43. 
Chapter 5

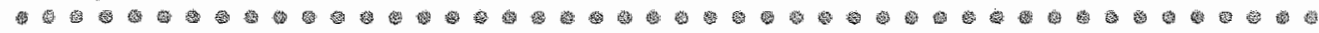

Dissociation of cardiomyocyte apoptosis and dedifferentiation in infarct border zones.

Gerrit D. Dispersyn, Liesbet Mesotten, Bart Meuris, Luc Mortelmans, Willem Flameng, Frans C.S. Ramaekers, Marcel Borgers 
Background: Cardiomyocyte apoptosis is known to occar in infarct border zones. In these areas; cardionyocyte dedifferentiation as seen in hibernating myocardium can also be observed. The ain of the study is to determine whether dedifferentiated cardionyocytes represent a population of cells stably surviving or undergoing apoptosis.

Methods: Mieroinfarctions were induced in sheep $(\mathrm{n}=8)$ by a single selective intracoronary injection of polymer macrobeads into LAD or CX coronary artery, The sheep were sacrificed when cardiac function was stably decreased $(\mathrm{EF} 37 \pm 6 \%$, mean $\pm \mathrm{SEM})$, but not earlier than six weeks after embolization. Transinural biopsies were taken from embolized and remote areas, based on the results of flow measurements with PET. Cells were classified as dedifferentialed when sarconere content was depleted by $>10 \%$ and glycogen content increased. Apoptosis was detected using the TUNEL inethod and activated caspase 3 inmunolabeling on frozen sections. From each region, a mean of 3400 cardiomyocytes was evaluated. Dedifferentiated cardiomyocytes were identified by morphology and by immunohistochemical evaluation of dedifferentiation related expression patterns of desmin, titin, cardiotin and $\alpha$-smooth nuscle actin.

Resilts: Cardionyocyte apoptosis was detected in both the infarction border zones and remote areas. Dedifferentiated cardionayocytes accounted for up to $30 \%$ of the cell population in enbolized areas and were almost exclusively not apoptotic.

Conchision In errbolization induced microinfarcted tissue, dedifferentiated cardionyocytes are preferentially spared to undergo apoptosis. Therefore, If is hypothesized that dedifferentiated eardionyocytes and apoptotic cardionyocytes represent two different cell populations. The dedifferentiated cells can be considered as stably surviving cells. 


\section{Introduction}

It is generally accepted that apoptosis occurs in several cardiac disease states. A well-known paradigm is the occurrence of cardiomyocyte apoptosis in acute pathophysiological conditions, as in acute myocardial infarction. Indeed, in this setting cardiomyocyte apoptosis has been demonstrated in both experimental [1-4] and clinical settings [5-8], and is believed to play an important role in the outcome. Considerable attention has also been paid to the role of apoptosis in more chronic situations and although a causal relationship is far from proven, apoptosis has been consistently linked with heart failure [9-11]. Nevertheless, the role of cell death in more intermediate adaptive processes like chronic hibernating myocardium is still obscure. Hibernating myocardium was originally described as a protective mechanism of the heart in which it downregulates its function to cope with oxygen shortage caused by a chronic or repetitive underperfusion accompanied by a limited flow reserve [13-15], Although hibernating myocardium retains its ability to respond to inotropic challenges and shows recovery of function after revascularization, this recovery can take a few months to 1 year in a subset of patients with chronic hibernating myocardium [16]. It has been suggested that structural remodeling, which can be found in chronic hibernating myocardium, is at least partially responsible for this delayed recovery of function [17]. These structural changes are characterized by both cellular and extracellular features [18]. It has been shown that the subcellular changes actually represent dedifferentiation of the cardiomyocytes, giving rise to cardiomyocytes with structural hallmarks of fetal heart cells $[18,19]$. The recovery of function after revascularization is suggestive of the reversibility of the dedifferentiation, although direct evidence is still missing. Several indirect observations have suggested that dedifferentiated cardiomyocytes represent an adaptive state, enabling the cardionyocytes to survive under unfavorable circumstances [20]. However, apart from subcellular changes, an increase in the amount of extracellular matrix has also been observed in chronic hibernating myocardium |21,22]. This observation, plus the finding that the recovery of function after revascularization is often incomplete, leaves us with two important questions. First, is cardiomyocyte cell death through apoptosis involved in chronic hibernating myocardium, and secondly, if so, does cardiomyocyte dedifferentiation ultimately lead to cardiomyocyte degeneration? The hitherto limited research into apoptosis. in an attempt to answer the first question came up with discrepant findings. Some reported data suggest that apoptosis is an important feature of chronic hibernating myocardium $|23,24|$, while others claim that in this setting apoptosis does not occur, or only to a very limited extent [25]. Two major problems are involved when trying to resolve this issue. First of all, there is the difficulty of accurately detecting low rates of apoptosis which, however, can definitely be of clinical importance after a prolonged period of time |26|. Secondly, especially with regard to the second question, if apoptosis is truly present, then dedifferentiated cardiomyocytes and 
apoptotic ones might still represent wo different cell populations, leaving the possibility that dedifferentiation does not lead to apoptosis per se [27]. In an attempt to answer the latter question, infarct border zones represent a particularly interesting area for investigation. Indeed, it has been shown that in an animal model in which microinfarctions were induced by intracoronary microembolization, not only was cardiomyocyte apoptosis detected but ultrastructural evidence for cardiomyocyte dedifferentiation was also found $[10,28]$. In the present investigation we used the embolization model to investigate whether cardiomyocyte dedifferentiation and a poptosis could occur in the same or in different cell populations, thereby cataloguing cardiomyocyte dedifferentiation as an adaptive or maladaptive phenomenon. These findings may contribute to answering the clinically important question whether or not patients with hibernating myocardium should undergo revascularization without delay.

\section{Methods}

Animal preparation and functional follow-up

In 8 juvenile sheep (female, weight $60-65 \mathrm{~kg}$ ) heart failure was induced by selective intracoronary injection of a suspension of polymer macrobeads, as previously described [29]. In brief, procedures were performed in closed-chest animals by insertion of a Sones catheter into the carotid artery. Injections were given selectively into the left anterior descending ( $L A D, n=2)$ or left circumflex ( $\mathrm{Cx}, \mathrm{n}=6$ ) coronary artery under fluoroscopic guidance. The embolization solution was prepared by suspending $0.1 \mathrm{~g}$ of macrobeads (Bangs Laboratories, Inc., Carmel, Ind., USA; mean diameter $99 \mu \mathrm{m}$ ) in $5 \mathrm{ml}$ of physiological saline and $5 \mathrm{ml}$ of contrast medium. The nean number of macrobeads in $1 \mathrm{ml}$ suspension was $1.85 \times 10^{4}$. Injection was always followed by severe ECG changes (ST segment elevations) and a drop in arterial blood pressure. All animals underwent transthoracic two-dimensional echocardiography (2D-echo, Sonotron Vingmed CFM 725, Horten, Norway, with $2.5 \mathrm{MHz}$ probe) to assess global and regional myocardial function at baseline, 1 day, 1 week and 6 weeks (w) after the procedure. The measurements were performed on spontaneously breathing animals sedated with ketamine HCl (15-20 mg/kg IM). All parameters were measured at the mid-papillary level in the shortaxis parasternal view [29]. All echocardiographic measurements were performed by two observers who were blinded to each other's results.

\section{Positron emission tomography}

Myocardial blood flow and glucose metabolism were measured with PET at $6 \mathrm{w}$ after embolization as previously detailed [17]. A whole-body positron emission tomograph (model: 
ECAT EXACT HR +, CTI Siemens, Knoxville, Tenn.) was used with 32 detector rings was used. Blood flow was measured using $555 \mathrm{MBq}$ of ${ }^{13} \mathrm{~N}$-ammonia $\left({ }^{13} \mathrm{NH}_{3}\right) .22$ dymamic frames were recorded immediately after injection of the tracer. Total acquisition time was 30 min. "The glucose metabolic studies were performed using the hyperinsulinemic euglycemic clamp technique. $370 \mathrm{MBq}$ of ${ }^{18} \mathrm{~F}$-fluorodeoxyglucose ( ${ }^{18} \mathrm{FDG}$ ) was injected after stabilization of the glucose level between 85 and $95 \mathrm{mg} \%$ and twenty-two dynamic frames were recorded with a total acquisition time was 70 min. Both perfusion and metabolic studies were reconstructed and delineated as previously described [17].The delineation was used to construct a polar map [17]. A region of normal tracer uptake was manually defined on the ammonia polar map. The mean value of that region was used as reference value, which is $100 \%$ ammonia uptake. The same region was used as reference region on the ${ }^{18} \mathrm{FDG}$ polar map.

In each sheep, two regions of interest were defined on the polar map. The first, representing nonembolized myocardium, consisted of the area perfused by the nonembolized coronary artery. The second region was drawn over the area perfused by the embolized cononary artery. Flow and metabolic indices were computed for the polar maps. A flow index was calculated as the ratio of ${ }^{13} \mathrm{NH}_{3}$ uptake in the embolized or nonembolized region and the ${ }^{13} \mathrm{NH}_{3}$ uptake in the region with the highest uptake (reference region). A metabolic index was defined as the ratio of glucose utilization in the embolized or the nonembolized region and that in the reference zone.

\section{Tissue processing}

Sheep were sacrificed by intravenous injection of saturated $\mathrm{KCl}$ after cardiac function was stably decreased; however, not earlier than 6 after embolization. The whole heart was taken out and different transmural biopsies of the embolized and the nonembolized region were immediately taken, based on the results of the three-dimensional polar map. Using this nethod, myocardial samples could easily be selected with a high accuracy from both the affected (embolized) and normal (nonembolized) regions. For immunohistochemistry, tissue samples were immediately frozen in isopentane precooled with liquid nitrogen and stored at $-70^{\circ} \mathrm{C}$. For the immunohistochemical detection of $\alpha$-smooth muscle actin, tissue samples were fixed for $20 \mathrm{~min}$ in cold $\left(4^{\circ} \mathrm{C}\right) 3 \%$ glutaraldehyde in $0.09 \mathrm{M} \mathrm{KH}_{2} \mathrm{PO}_{4}\left(\mathrm{pH}^{2} 7.4\right)$ prior to freezing. For morphological evaluation, tissue samples were fixed in $3 \%$ glutaraldehyde, postfixed with $2 \%$ $\mathrm{OsO}_{4}$, delhydrated and embedded in epoxy resin. Semi-thin sections were stained with Periodic Acid Schiff (PAS) and toluidine blue. Cells were classified as dedifferentiated when the sarcomere content was depleted by $>10 \%$ and the glycogen content increased. 


\section{Immunohistochemistry}

For immunohistochemistry, $5 \mu \mathrm{m}$ frozen sections were cut and stored at $-20^{\circ} \mathrm{C}$ until use. Apoptosis detection in these sections was performed using the TUNEL method and activated caspase-3 detection. The TUNEL method was performed using the Apoptag peroxidase in situ detection kit (Intergen, Purchase, NY, USA), following the manufacturers instructions.

Activated caspase- 3 was detected on aur-dried frozen sections fixed with $4 \%$ paraformaldehyde in PBS. After fixation, the sections were rinsed in PBS and incubated for one hour in a $0.3 \mu \mathrm{g} /$ $\mathrm{ml}$ solution of anti-activated caspase-3 (R\&D Systems, Minneapolis, USA) with $1 \%$ bovine serum albumin (BSA) and $0.3 \%$. Triton X-100 in PBS. The sections were rinsed in PBS prior to incubation for $45 \mathrm{~min}$ with a FITC labeled goat anti-rabbit antibody (Southern Biotechnology Associates, Birmingham -Ala., USA). F-actin was stained using BODIPY@ 558/568 phalloidin (Molecular Probes, Leiden, the Netherlands). Nuclei were stained with $0.2 \mu \mathrm{M}$ TO-PRO®-3 iodide (Molecular Probes). The sections were rinsed and mounted in Slow Fade (Molecular Probes). For the assessment of cardiomyocyte dedifferentiation, the following monoclonal antibodies were used, which were previously described [19]. 9D10 against the I-band (at the A-I junction) of titin, RD30I against the tail domain of desmin, R2G against cardiotin, and $\alpha$-SM-1 (Dako, Glostrup, Denmark) against $\alpha$-smooth muscle actin. Titin, desmin and cardiotin were labeled using the following procedure: frozen sections were air-dried and then pretreated with $0.5 \%$ Triton X-100 for 5 min, followed by a wash in PBS. Undiluted antisera (with the exception of 9D1.0: diluted 1:10) were applied on the sections for one hour. After rinsing in PBS, the sections were incubated for 45 min with a Cy3-labeled goat anti-mouse antibody (Jackson ImmunoResearch, West Grove, USA). F-actin was stained using phalloidin-FITC ( $4 \mu \mathrm{M}$, Sigma). The sections were mounted in Slow Fade (Molecular Probes). For the detection of $\alpha$-smooth muscle actin in frozen glutaraldehyde fixed samples, air-dried frozen sections were trealed with $0.5 \%$ Triton X-100 for 15 min at room temperature and washed with PBS. After $15 \mathrm{~min}$ incubation in $1 \mathrm{mg} / \mathrm{ml} \mathrm{NaBH}_{4}$ in PBS and preincubation in $0.1 \%$ BSA in PBS, the sections were incubated overnight with the primary antibody at room temperature. After washing with PBS, incubation for $45 \mathrm{~min}$ was performed with an alkaline phosphatase conjugated rabbit anti-mouse Ig (Dako). Vector Blue (Vector Laboratories Burlingame, USA) was used to detect alkaline phosphatase activity. The combination of TUNEL and $\alpha$-smooth muscle detection was performed on frozen glutaraldehyde fixed samples by subsequently following both procedures and postponing the peroxidase and alkaline phosphatase activity detection until the end. 
Statistical analysis

Results are given as mean \pm SEM. Statistical significance is indicated by p values $<0.05$. Differences between groups were investigated by using unequal variance t-testing.

\section{Results}

Function, flow and metabolism

Embolization induces left ventricular functional changes. Compared with baseline ejection, fraction was significantly but stably decreased 6 weeks after embolization (38\%土3 vs. 69\%土3). The flow indeces and metabolic indices assessed with PET imaging were significantly decreased in the embolized areas compared with the non-embolized areas at 6 weeks ( $74 \pm 5 \%$ vs. $91 \pm 2 \%$, $\mathrm{p}<0.05$ and $55(5 \%$ vs. $95 \pm 3 \%, \mathrm{p}<0.05)$. Transmural biopsies were taken from embolized (decreased flow and metabolic indices) and nonembolized areas (normal flow and metabolic indices) based on the polar map views.

\section{Morphological evaluation}

In the embolized areas, a mix of microinfarcted and viable tissue could be observed, whereas nonembolized areas were devoid of microinfarctions (Figure 1). In the embolized areas, dedifferentiated cardiomyocytes could be identified and they displayed perinuclear sarcomere depletion and PAS positive glycogen accumulation. These dedifferentiated cardiomyocytes accounted for up to $30 \%$ of the cardiomyocyte population in the embolized areas $(8 \pm 2 \%)$, whereas they were virtually absent in nonembolized areas.
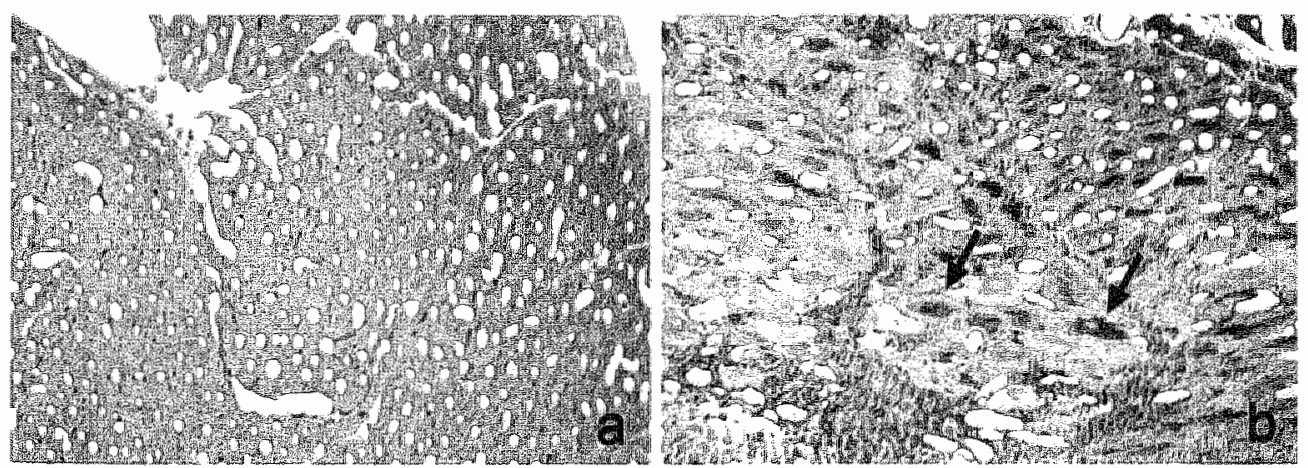

Figure 1: Light microscopical appearance of periodic acid Schiff and uoludine blue staned sections of microembolized sheep heart. Non-mbolized areas (a) vere completely nomal, whereas embolized reghons showed a mix of micrintacted and wable issue, the latter being characterzed by numerous cardiomyocyes with perinuclear sarcomere depletion and gycogen accumulätion (arrows) (a:100x, b:100x) 


\section{Dedifferentiation markers}

Immunohistochemical identification of cardiomyocyte dedifferentiation was performed by analysis of protein expression patterns of titin, desmin, cardiotin and $\alpha$-smooth muscle actin (Figure 2). In the non-embolized areas all the cardiomyocytes displayed normal, cross-striated patterns of titin and desmin and the normal expression of cardiotin in longitudinal arrays. Desmin was present in high quantities at the intercalated disks. None of these cardiomyocytes expressed $\alpha$-smooth muscle actin. In the embolized areas, however, abnormal expression patterns could be identified. In cells displaying perinuclear sarcomere depletion (dedifferentiated cardiomyocytes), the normal cross striated patterns of titin and desmin were partially lost. Titin showed in regions of decreased staining intensity an unorganized pattern. Desmin showed a mainly perinuclear filamentous pattern in dedifferentiated cells, and was no longer detected at the intercalated disks. Longitudinally oriented cardiotin arrays were less obvious or even completely lost in dedifferentiated cardiomyoctes. Re-expression of $\alpha$-smooth muscle actin was detected in the dedifferentiated cardiomyocytes of the embolized areas (Figure 5a).

\section{TUNEL}

Analysis of the number of cardiomyocytes showing nuclear DNA fragmentation was performed by TUNEL (Figure 3). Cardiomyocyte DNA fragmentation was detected in both embolized and nonembolized areas. The number of TUNEL positive cardiomyocytes tended to be higher in the embolized areas compared with the nonembolized areas, but this difference was not statistically significant $(0.12 \pm 0.04 \%$ vs. $0.07 \pm 0.03, p=N S)$. In the embolized area, the dedifferentiated cardiomyocytes, recognized by their perinuclear sarcomere depletion, were almost exclusively TUNEL negative and accounted for only $4.9 \%$ (representing 2 cells) of the TUNEL positive cardionyocytes in the embolized areas (Table 1).

TUNEL positive cardiomyocytes

\begin{tabular}{|c|c|c|c|c|c|}
\hline & \multirow[t]{2}{*}{ mean $\pm \operatorname{SEM}(\%)$} & \multicolumn{2}{|c|}{$\begin{array}{l}\text { contribution of } \\
\text { normal cells }\end{array}$} & \multicolumn{2}{|c|}{$\begin{array}{l}\text { contribution of } \\
\text { dedifferentiated cells }\end{array}$} \\
\hline & & number & $\%$ & number & $\%$ \\
\hline embolized area & $0.12 \pm 0.04$ & 39 & 95.1 & 2 & 4.9 \\
\hline remote area & $0.07 \pm 0.03$ & 10 & 100 & 0 & 0 \\
\hline
\end{tabular}



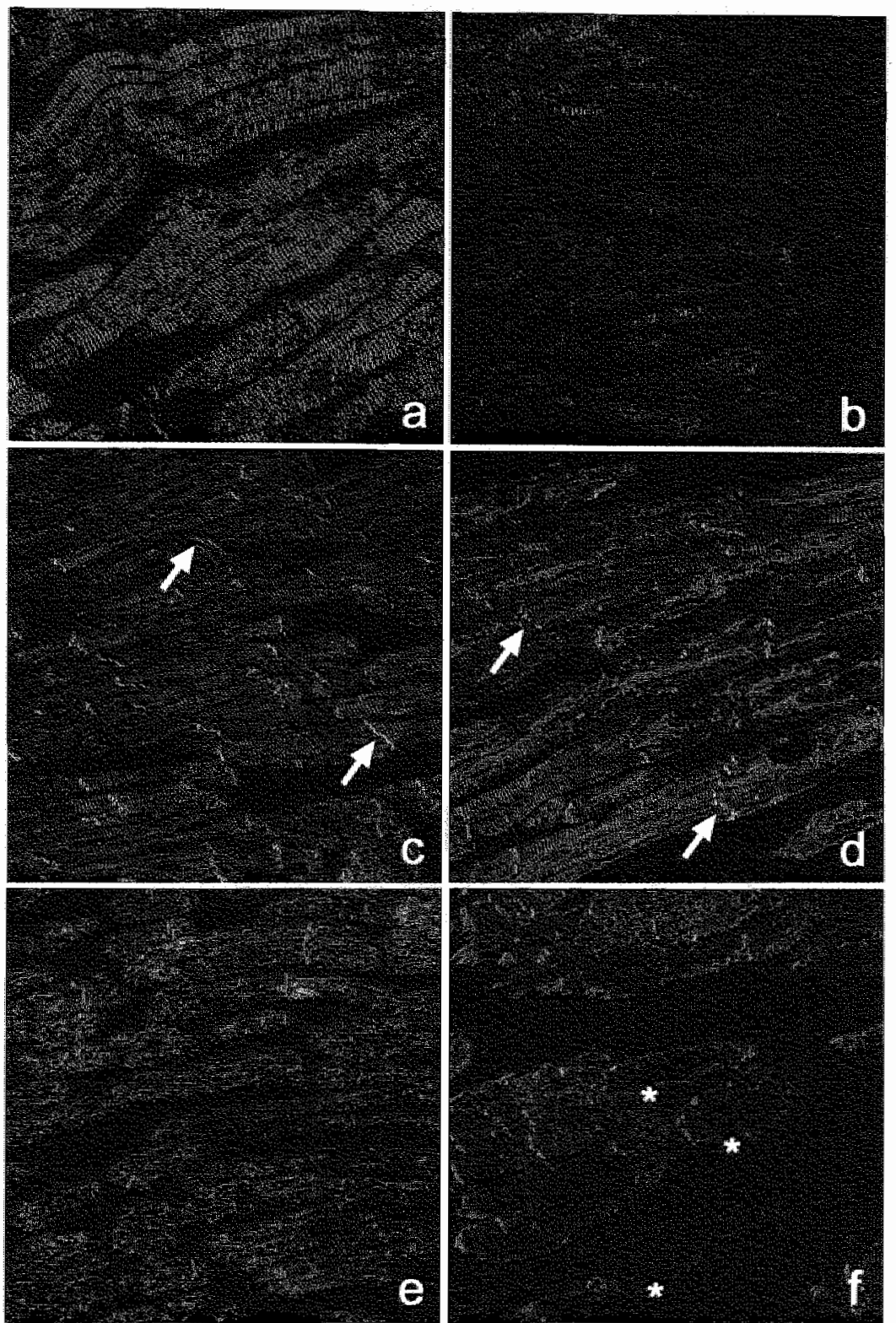

Figure 2: Immumohistochemical detection of protein expression patterns of titim (ab) desmin (c,d) and cardiotin (e, $)$ in ron-mbolized $(a, c, e)$ and embolized $(b, d, f)$ myocandial tissue. In non-embolized regions, titin shows a nomal cross striated pattern (a) which however is severely losil in dedfferentated cardianyocytes in embolized regions (b). Desmin (in red) chows nomat cross striations in nor-entbolized areas, and is presen in high amounts at the intercalated disk (colocalization with factin staned green

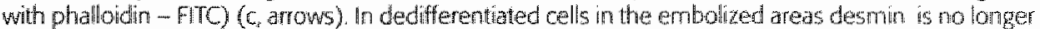
detectable at the intercalated disks (no longer a colocalization with factin) (d, anows) and cross strialin is partially lost and replaced by u unorganized filamentous pattern, manfly in the perinuclear areas. The nomal longitudinally orientated cardiotin arays (nn red) in non-embolized areas (e) car mo longer be detected in dedifferentiated cardiomyocytes witl perinudear sarcomere depletion (t, asterisks). (a:300x,b.290x, c.225x, a:230x, e.225x:180x) 

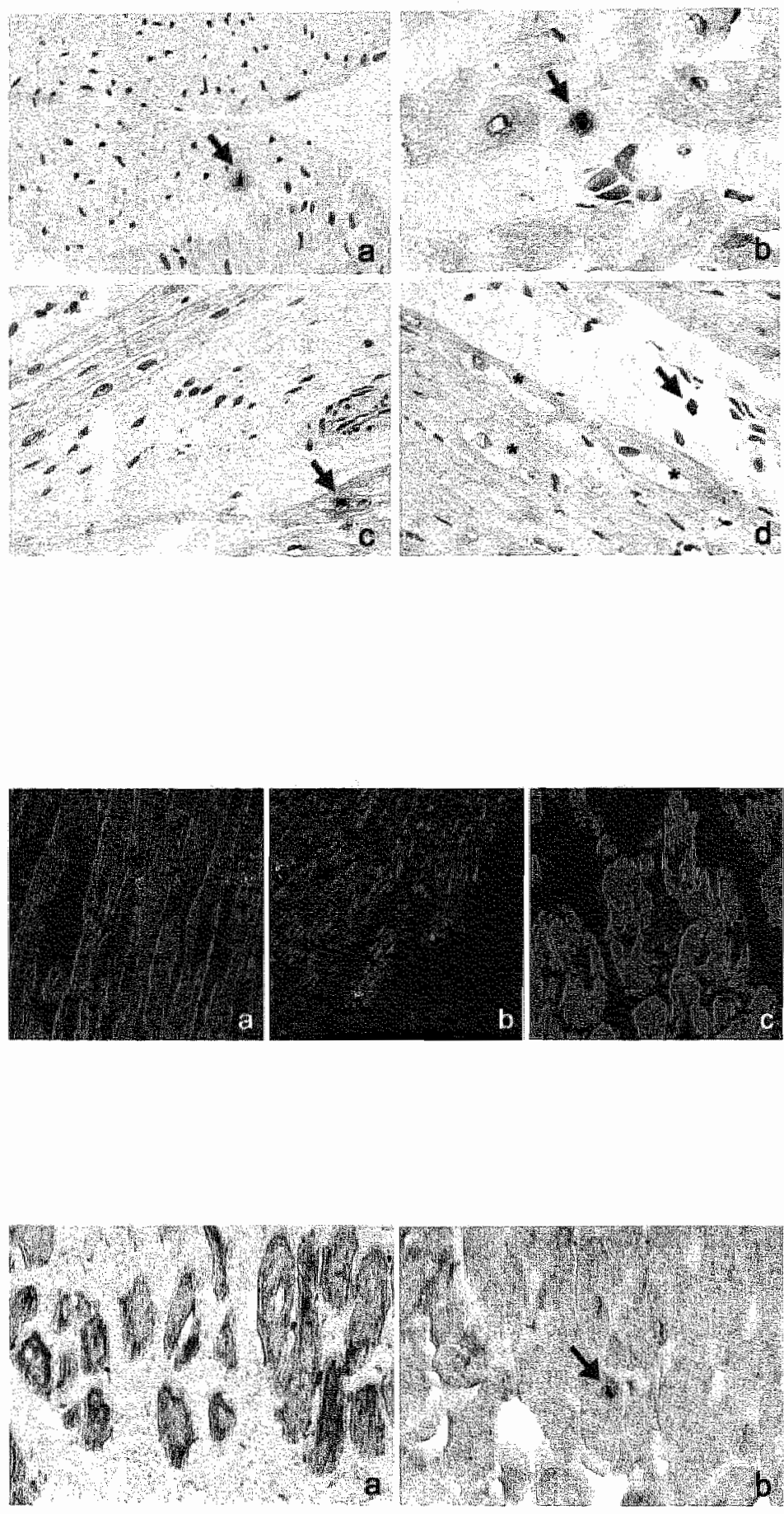

Figure 5: Combined detection of or snooth muscle actin and DNA fragmentation. A re-expression of ax-snooth muscle actin was detected in dediferentiated cardiompocyles in the embolized areas ( $a$ in blue). None of these a smooth muscle artin expressing cardiomyocyles was TUNEL postive Conversely, all TUNEL positive cardiomyocytes ( $b$, arrow) were negative for (o-smooth muscle actin. (a: $140 x, b: 285 x)$ 
Activated caspase-3

Immunohistochemical detection of activated (cleaved) caspase- 3 in cardionyocytes, confirmed the existence of apoptotic cardiomyocytes in both the embolized and nonembolized regions (Figure 4). Fluorescent labeling of the nuclei with TO-PRO-30 showed fragmented nuclei in several instances in both activated caspase-3 cardiomyocytes and interstitial cells (data not shown). The number of activated caspase-3 positive cardiomyocytes in both regions was similar, as found with the TUNEL method. Again, the difference in the number of activated caspase-3 positive cardiomyocytes between embolized and nonembolized regions was not statistically significant $(0.13 \pm 0.09 \%$ vs. $0.04 \pm 0.02 \%, \mathrm{p}=\mathrm{NS})$.

\section{Combined detection of TUNEL and $\alpha-$ smooth muscle actin}

Since $\alpha$-smooth muscle actin re-expression is a characteristic feature of cardiomyocyte dedifferentiation, its detection was performed and combined with the assessment of DNA fragmentation to investigate whether or not TUNEL positive cardiomyocytes in embolized areas are dedifferentiated (Figure 5). We found that none of the $\alpha$-smooth muscle actin reexpressing cardiomyocytes were TUNEL positive. Conversely, all the TUNEL positive cardiomyocytes were found to be negative for $\alpha$-smooth muscle actin.

\section{Discussion}

In this study we focused on the important question whether degener ative cardiomyocytes and dedifferentiated cardiomyocytes represent the same cell population, i.e. does cardiomyocyte dedifferentiation - as seen in chronic hibernating myocardium - eventually culminate in cell death through apoptosis? This connotation was put forward by Schwarz ef al.|23|, who found evidence for apoptotic cardiomyocytes in patients with chronic hibernating myocardium. In an earlier study, we were not able to confirm their findings, and concluded that apoptosis in chronic hibernating myocardium, if at all present, would occur to a very limited extent |25/. However, to investigate whether cardiomyocyte dedifferentiation finally leads to apoptosis, too limited tissue (needle biopsies from patients with chronic hibernating myocardium) is available. Therefore we used an animal model of microembolization induced microinfarctions, similar to a model in which it was already shown that cardiomyocyte apoptosis occurs and in which ultrastructural changes suggestive for cardionyocyte dedifferentiation were found $[10,28]$. Using immunohistochemical detection of protein expression patterns of different proteins previously investigated in chronic hibernating myocardium | 19], we could ascertain that the previously reported ultrastructural changes in viable cardiomyocytes from embolized regions were characteristic for cellular dedifferentiation. The typical changes in the protein 
expression pattern of titin, desmin, cardiotin and the re-expression of $\alpha$-smooth muscle actin, were previously reported in patients with chronic hibernating myocardium [19] and a goat model of chronic atrial fibrillation $[30]$, both pathologies in which no evidence for cardiomyocyte apoptosis could be found by us [25]. In the present study, cardiomyocyte dedifferentiation was only detected in the embolized areas and not in the non-embolized regions. Nevertheless evidence for cardiomyocyte apoptosis could be found in both of these regions, in accordance with a previous investigation [10]. Both the TUNEL method and activated caspase3 labeling resulted in comparable apoptotic rates. More importantly however, we found a clear dissociation between TUNEL positive cardiomyocytes and dedifferentiated cardiomyocytes in the embolized regions. With a few exceptions, all of the cardiomyocytes with dedifferentiation hallmarks, like perimuclear sarcomere depletion (myolysis) and re-expression of $\alpha$-smooth muscle actin, were TUNEL negative. Aimé-Sempé et al. [31], however, reported that almost $50 \%$ of the myolytic cardiomyocytes in human chronic fibrillating and dilated right atria, showed TUNEL positive nuclei, suggesting that at least part of these dedifferentiated cardiomyocytes were apoptotic. Nevertheless, the vast majority of these nuclei were enlarged and only weakly stained for TUNEL and DNA ladders could not be detected, making it more likely that dedifferentiated cardiomyocytes show a high level of transcription. Unfortunately the study did not mention a relationship between $\mathrm{BCl}-2$, Bax, caspase-3 expression and cellular dedifferentiation hallmarks, although in general they observed a decreased Bcl-2 expression and an increased caspase-3 expression.

The finding of a coexcistence of dedifferentiated and degenerated cardiomyocytes in both a dog model of microembolization [10] and in patients with chronic hibernating myocardium (with significant fibrosis) [24] lead to the hypothesis that cardiomyocyte dedifferentiation ultimately results in cell degeneration. However, the current findings suggest that cardiomyocyte dedifferentiation and degeneration through apoptosis are not related perse. Indeed a significant number of apoptotic cardiomyocytes would otherwise be expected in animal model of chronic atrial fibrillation in which approximately $50 \%$ of the cells were found to be dedifferentiated [30\}. Nevertheless, no evidence for the occurrence of cardiomyocyte apoptosis could be found in this model [25]. Based on these findings and on the current data, it can be hypothesized that dedifferentiated cardiomyocytes are unlikely to undergo apoptosis, but instead that dedifferentiated cardiomyocytes and apoptotic ones represent two different cell populations. Moreover, an inverse relationship might be true. It was reported earlier that dedifferentiated cardiomyocytes are more ischemia tolerant, i.e. better protected against ischemic insults compared with normally structured cardionyocytes [20]. Therefore, cardiomyocyte dedifferentiation might be regarded as an adaptive response of the cardiomyocytes to a more unfavorable environment. 
On the other hand, when considering the situation in patients, not only cell survival but also cell function is crucial. Similar to the micromembolization model, border zones of small infarcts as present in patients may comprise a considerable number of dedifferentiated cells, akin to those in chronic hibernation [18,32]. Although the viability of these cells seems not to be compromised because of the virtual absence of degenerative structural changes, either apoptotic or necrotic, we do not know whether dedifferentiation is reversible after prolonged cell survival. Hence, speedy revascularization is advised in order to subserve the possible redifferentiation of the fetal cardiomyocyte phenotype, which is identical to what has been concluded for chronic hibernating myocardium [16].

In conclusion, we report a dissociation between dedifferentiation and apoptosis in an animal model of microembolization induced microinfarctions. We conclude that cardiomyocyte dedifferentiation is not an early stage of a degenerative pathway and can therefore be considered as an adaptation enabling the survival of the cells.

\section{Acknowledgements}

This study was in part supported by 'Universiteitsfonds Limburg / SWOL'.

\section{References}

1) Gottlieb RA, Burleson KO, Kloner RA, et al. Reperfusion injury induces apoptosis in rabbit cardiomyocytes. I Clin Invest. 1994; 94:1621-1628.

2] Cheng W, Kajstura J, Nitahara IA, et al. Pyogrammed cell death affects the viable myocardium after infarction in rats. Exp Cell Res. 1996;226:316-327.

3) Fliss $\mathbf{H}$ and Gattinger D. Apoptosis in ischemic and reperfused rat myocardium. Circ Res. 1996 ; 79:949-956.

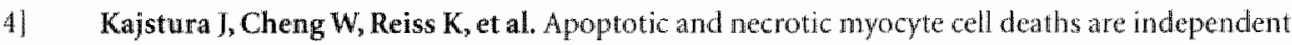
contributing variables of infarct size in rats. Lab Imest. $1996 ; 74: 86 \% 107$.

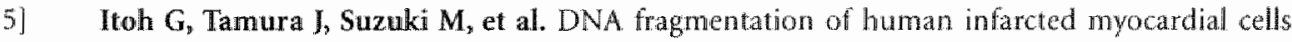
demonstrated by the nick end labelling method and DNA agarose gel electrophoresis. Am J Pathol. $1995 ; 146: 1325-1331$. 
Misao J, Hayakawa $Y$, Ohno M, et al. Expression of bcl-2 protein, an inhibitor of apoptosis, and Bax, an accelerator of apoptosis, in ventricular myocytes of human hearts with myocardial infarction. Circulation. 1996:94:1506-1512.

7) Olivetti $G$, Quaini F, Sala $R$, et al. Acute myocardial infarction in humans is associated with activation of programmed myocyte cell death in the surviving portion of the heart. $J$ Mol Cell Cardiol. 1996: 28:2005-2016.

8) Saraste A, Pulkki K, Kallajoki M, et al. Apoptosis in human acute myocardial infarction. Circulation. $1997 ; 95+320-323$.

9) Narula J, Haider $\mathbf{N}$, Virmani $R$, et al. Apoptosis in myocytes in end-stage heart failure. $N$ Engl I Med. 1996; 335:1182-1189.

10] Sharov VG, Sabbah HN, Shimoyama H, et al. Evidence of cardiocyte apoptosis in myocardium of dogs with chronic heart vailure. Am J Pathol. 1996; 148:141 149

111 Olivetti G, Abbi R, Quaini F, et al. Apoptosis in the failing human heart. N Engl I Med. 1997; $336: 131-1141$

12) Guerra S, Leri A, Wang $\mathrm{X}$, et al. Myocyte death in the failing human heart is gender dependent. Circ Res. 1999; 85:856-866.

131 Rahimtoola SH. A perspective on the three large multicenter randomized clinical trials of coronary bypass surgery for chronic stable angina. Circulation. 1985;72 (suppl V):V123-V135.

14] Rahimtoola SH. The hibernating myocandium. Am Heart J. 1989;117:211-221.

15) Braunwald E, Rutherford ID. Reversible ischemic left ventricular dysfunction: evidence for the hibernating myocardium. Am Coll Cardiol. 1986:8:1467-1470.

16. Kloner RA, Bolli R, Marban E, Reinlib L, Braunwald E. Medical and celladar implications of stumming, hibernation, and preconditioning: an NHLBI workshop. Circulation. 1998; 97:18481867

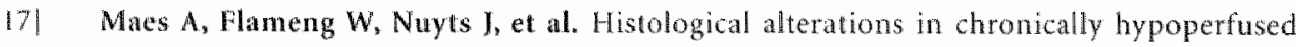
myocardium: correlation with Plet findings. Circulation. 1994;90:735-745.

18] Borgers $\mathbf{M}$. Thone $\mathbf{F}$, Wouters $\mathbf{L}$, et al. Structural correlates of regional myocardial dysfunction in patients with critical coronary stenosis: chronic hibernation? Cardiovasc Pathol. 1993;2:237 245.

19| Ausma J, Schaart G, Thone fr, et al. Chronic ischemic viable myocardium in man: aspects of dedifferentiation. Cardiovasc Pathol. 1995; 4:29-37. 
201 Ausma J, Thoné F, Dispersyn GD, etal. Dedifferentiated cardionyyocytes from chronic bibernating myocardium are ischemia-tolerant. Mol Cell Biochem. 1998; 186:159-168.

21) Ausma J, Cleutjens I, Thoné $F$, et al. Chronic hibernating myocardium: interstitial changes. Mol Cell Biochem. 1995; 147:35-42.

22] Elsässer A, Schlepper $M$, Zimmermann $\mathbb{R}$, al. The extracellular matrix in hibernating myocardium - a significant factor causing structural defects and cardiac dysfunction. Mol Cell Biochem. 1998; 186:147-158.

23] Schwarz ER, Schaper I, vom Dahl ), et al. Myocyte degeneration and cell death in hibernating human myocardium. J An Coll Cardiol. 1996; 27:1577-1585.

24] Elsässer A, Schlepper $M$, Klovekorn WP, et al. Hibernating myocardium: an incomplete adaptation to ischemia. Circulation. 1997: 96:2920-2931.

25] Dispersyn GD, Ausma J, Thoné F, et al. Cardiomyocyte remodelling during myocardial hibernation and atrial fibrillation: prehude to apoptosis? Cardiovasc Res. 1999; 43:947-957

26] Schaper J, Elsässer A, Kostin.S. The role of cell death in theart failure. Circ Res. 1999; 85:867-869.

27] Dispersyn GD, Borgers M, Flameng W. Apoptosis in chronic hibernating myocardium: sleeping to death? Cardiovasc Res. 2000; 45:696-703.

281 Sharov VG, Sabbah HN, Ali AS, et al. Abnormalities of cardiocytes in regions bordering fibrous scars of dogs with heart failure. Int J Cardiol. 1997; 60:273-279

29! Zietkiewicz M, Perek B, Meyns B, et al. Chronic heart falure model induced by coronary embolization in sheep. Int J Artif Organs. 1999;22:499-504.

301 Ausma I, Wijffels $M$, van Eys $G$, et al. Dedifferentiation of atrial cardiomyocytes as a result of chronic atrial fibrillation. Am / Pathol. 1997:151:985-997.

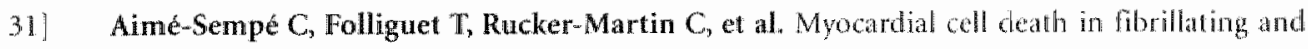
dilated human right atria. In Coll Cardiol 1999; 34:1577-1586.

321 Mesotten $\mathrm{L}_{\text {, }}$ Maes A, Herregods $\mathrm{MC}_{\text {, }}$ et al. PET reduced glucose uptake relative to perfusion patten early after acute myocardial infarction trealed with thrombolytic therapy (abstract). Circulation $2000 ; 102$ (suppl II): $\mathbb{1 1 - 7 7 0 .}$ 
幽

92 
Chapter 6

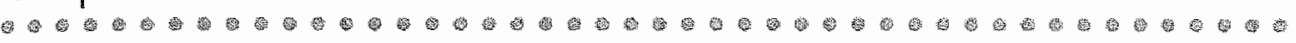
Hibernation-like dedifferentiation in cardiomyocytes cocultured with fibroblasts.

Gerrit D. Dispersyn, Eva Geuens, Luc Ver Donck, Frans C.S. Ramaekers, Marcel Borgers 
Objectives: Litle is known alout the causal factors which incuce the typical structural changes accompanying cardiomyocyte dedifferentiation in vivo such as in chronic hibeinating myocardium. For identifying important factors involved in cardionyocyte dedifferentiation, as seen in chronic hibernation, an in vitho model mimicking those morphological changes, would be extrennely helpful.

Methods: Adult rabbit cardiomyocytes were co-cultured with cardiac fibroblasts. The typical dhanges induced by this culturing paradigm were investigated using morphonetry, electron microscopy and inmunocytochemical analysis of several structural proteins, which were used as dedifferentiation narkers, i.e. titin, desmin, cardiot in and $\alpha$-smooth muscle actin.

Results: Close apposition of fibroblasts with adult rabbit cardiomyocytes induced hibernation-like dedifferentiation, similar to the typical changes seen in chronic hibernation in wivo. Both changes in ultrastructure and in the protein expression pattern of dedifferentiation markers as seen in chronic hibernating myocardium were seen in the co-cultured cardiomyocytes.

Conchsionn Hibernation-like changes can be induced by co-culturing adult rabbit cardionyocytes with fibroblasts. This cellular model can be a valuable tool in identifying and characterizing the pathways involved in the dedifferentiation phenotype in vivo, and already suggests that many of the structural changes accompanying dedifferentiation are not per se dependent on a decreased oxygen availability: 


\section{Introduction}

Patients with viable hypocontractile myocardium and delayed functional recovery after reperfusion (chronic hibernating myocardium) show typical cellular and extracellular structural abrormalities. The most important cellular alterations are a redistribution of nuclear heterochromatin, depletion of sarcomeres, aberrantly shaped but healthy mitochond ria and a degradation of structured sarcoplasmic reticulum in the cardiomyocytes [1-3]. These changes give rise to cardiomyocytes with the structural hallmarks of fetal heart cells (dedifferentiated state) and are believed to be at least partially involved in delayed functional recovery after reperfusion [4,5]. The expression pattern of several structural proteins resembles that of embryonic/fetal cardiomyocytes. The highly organized patterns of cardiotin, titin and desmin disappear, while there is a re-expression of $\alpha$-smooth muscle actin. Recently, however, it became dear that these changes are not an exclusive feature of chronic hibernating nyocardium, but can also occur in other pathological situations as in chronic fibrillating atria $|6|_{\text {, infarction }}$ border zones [7], and volume-overloaded myocardium [8]. The mechanisms underlying the phenotypic changes are unknown, but recent findings suggest that in the setting of hibernation, the oxygen shortage due to chronic or repetitive underperfusion accompanied by limited flow reserve, may be the initiating but not the intrinsic causal factor. Indeed, in animal models of both acute $[9]$ and chronic [10] hibernation, structural changes were not only limnited to the underperfused areas, but were also observed in remote, normally perfused regions. However, unraveling a 'cause-effect' relationship in vivo is often complicated. Therefore, cultured cardiac myocytes can be extremely helpful in efforts to directly identify and chatacterize putative pathways leading to hibernation-like dedifferentiation. Previous imvestigations have indicated that the choice of an appropriate cellular model (neonatal/adult, species, culture conditions) is of utmost importance when pathways leading to altered myocyte growth are to be identified. For example, adult rat cardiomyocytes in culture display spontaneous dedifferentiation and partial redifferentiation very quickly after acouiring spontaneous contractile activity [11-13]. However, these structural changes are only partially comparable to the morphological changes seen in dedifferentiation in vivo [14]. Moreover, in order to get more insight in putative triggers, it would be of interest to find a culture system in which dedifferentiation could be induced, instead of occurring spontaneously. It was the aim of this study to develop a cellular model of isolated cardiac myocytes in which the morphological changes of dedifferentiation in wivo could be mimicked. It was previously reported that the growth characteristics of cultured cardiomyocytes could be influenced by non-myocytes and by growth factors $\mid 14,15]$. Therefore we investigated the influence of co-culturing adult rabbit cardiomyocytes with mesenchymal cells (mainly fibroblasts). Since morphological changes are the best characterized 
pathophysiological features of chronic hibernating myocardium, we focused on comparing the morphological characteristics of the myocytes in the culture system with those of hibernating myocytes in patients by using immunocytochemistry and electron microscopy. We found that by co-culturing adult rabbit cardiomyocytes and cardiac mesenchymal cells (mainly fibroblasts), the typical ultrastructural changes and changes in protein expression patterns of dedifferentiation in vivo, could be induced in the cultured myocytes. Therefore, this cellular model can be a valuable tool in identifying and characterizing pathways that control the typical morphological changes of the "hibernating" phenotype of cardiomyocytes in different cardiac pathologies.

\section{Material and methods}

Cell isolation and culture conditions

The investigation conforms with the Guide for the Care and Use of Laboratory Animals published by the US National Institutes of Health (NIH Publication No. 85-23, revised 1996). Cardiomyocytes and cardiac fibroblasts were isolated from adult $N Z$ white rabbits (ca. $2 \mathrm{~kg}$ ) by retrograde collagenase perfusion. Rabbits were anesthetized by intra-arterial injection of pentobarbital (Sanofi, Brussels, Belgium; $70 \mathrm{mg} / \mathrm{kg}$ ), the heart was rapidly excised and perfused in a retrograde Langendorff mode ( $5 \mathrm{~min}-35 \mathrm{ml} / \mathrm{min}$ ) with a modified calcium-free KrebsHenseleit buffer (37(C) containing (in mM): $\mathrm{NaCl} 125, \mathrm{KCl}_{2} .5, \mathrm{KH}_{2} \mathrm{PO}_{4} 1.5, \mathrm{MgSO}_{4} 1.2, \mathrm{HEPES}$ 1.0, glucose 9.5 , pyruvate 5, gassed with $100 \% \mathrm{O}_{2}$. Then, fresh buffer, supplemented with 0.6 $\mathrm{mg} / \mathrm{ml}$ collagenase (Wako, Osaka, Japan), $1 \mathrm{mg} / \mathrm{ml} \mathrm{BSA}$ and $2.5 \mu \mathrm{M} \mathrm{Ca}{ }^{2 *}$, was recirculated for $40 \mathrm{~min}$. The $\mathrm{Ca}^{2+}$ concentration was increased to $75 \mu \mathrm{M}$ and $175 \mu \mathrm{M}$ after 13 and 18 min respectively. The ventricles were gently dissociated in the same medium without collagenase and the cells were filtered through a $200 \mu^{2} \mathrm{~m}^{2}$ mesh. In three subsequent rinsing steps, with the buffer supplemented with $10 \mathrm{mg} / \mathrm{ml} \mathrm{BSA}$, the Ca ${ }^{2+}$ concentration was elevated to $1.4 \mathrm{mM}$. The cells were suspended in Medium 199 (Life Technologies, Paisley, Scotland) supplemented with antibiotics (Penicillin-Streptomycin $0.1 \mathrm{mg} / \mathrm{ml}$; Gentamycin $2 \mu \mathrm{g} / \mathrm{ml}$ ) and seeded at a low density to prevent cell-cell contact $\left(10^{3} \mathrm{ce} 11 \mathrm{~s} / \mathrm{cm}^{2}\right)$ on laminin-coated $(10 \mu \mathrm{g} / \mathrm{ml}$; Life Technologies) cover-glasses in petri dishes, and allowed to attach for 2 hours. Thereafter, fresh medium supplemented with $20 \%$ Fetal Bovine Serum (FBS, Hyclone, Utah USA) was applied to the cells. Cells were kept in a humidified $\mathrm{CO}_{2}$ incubator $\left(5 \% \mathrm{CO}_{2}-37^{\circ} \mathrm{C}\right)$ for up to 21 days, and medium was replaced twice a week. In parallel experiments, $10 \mu \mathrm{M}$ cytosine-1-B-Darabinofuranoside (AraC, Sigma) was added to the culture medium to inhibit proliferation of non-myocytes. Fibroblast-conditioned medium (FCM) was collected by growing cardiac fibroblasts to a sub-confluent state. Fresh medium as described above was applied to these 
cultures and the cells were again collected after $24 \mathrm{~h}$. To investigate the influence of secreted factors, FCM was applied to fresh cardiomyocyte cultures and replaced daily. Alternatively, cardiac fibroblasts were grown on cell inserts ( $0.02 \mu \mathrm{m}$ Anapore, Nunc, Life Technologies) which were applied to petri dishes seeded with freshly isolated cardiomyocytes.

\section{Morphometric analysis}

Individual cardiomyocytes were followed at regular time intervals by use of an Axiovert microscope in phase contrast illumination mode (Carl Zeiss, Oberkochen, Germany), and equipped with a CCD camera. Images were captured and used for morphometric analysis. Cardiomyocytes were outlined and the cell surface area was measured with the software package SCIL-Image version 1.4 (TNO-TPD, Delft, The Netherlands) on an $\mathrm{O} 2$ workstation (SGI, Mountain View, CA).

\section{Immunocy tochemistry}

Cells were fixed immediately after isolation (in suspension), a few hours after seeding (day 0 , $\mathrm{d} 0$ ), and then every other day starting at day $\mathrm{l}$ (d1) and ending at $\mathrm{d} 21$. The medium was discarded and the cells were rinsed with phosphate buffered saline (PBS). Three fixation protocols were used. For the analysis of all structural proteins except cardiotin and (-smooth muscle actin, the cells were fixed by cold $\left(-20^{\circ} \mathrm{C}\right)$ methanol $(3 \times 1 \mathrm{~s})$-acetone $(1 \times 1 \mathrm{~s})$ treatment and air dried. These cells were kept at $-20^{\circ} \mathrm{C}$ until processed further. For determination of cardiotin, the cells were briefly fixed (10 min) in $4 \%$ paraformaldehyde at room temperature. The cover-glasses were then rinsed in PBS and $A D$, air dried, and frozen to $-20^{\circ} \mathrm{C}$ until further use. For the analysis of $\alpha$-smooth muscle actin expression, the cells were fixed in cold ( $4^{\circ} \mathrm{C}$ ) $3 \%$ glutaraldehyde in $0.09 \mathrm{M} \mathrm{KH}_{2} \mathrm{PO}_{4}+1.4 \%$ sucrose $(\mathrm{pH} 7.4$ ) for $20 \mathrm{~min}$. The cover-glasses were rinsed with the buffer and $\mathrm{AD}$, air dried, and then frozen to $-20^{\circ} \mathrm{C}$.

The following primary antibodies, which have been described previously $[6 \mid$, were used: a mouse monoclonal antibody 9D10 to titin (diluted 1:10), a mouse monoclonal antibody RD301 to desmin (undiluted), a mouse monoclonal antibody $R 2 \mathrm{G}$ to cardiotin (undiluted), a mouse monoclonal antibody EA-53 to $\alpha$-actinin (Sigma) and a mouse monodonal antibody SM- 1 (1:100) to $\alpha$-sm actin (DAKO A/S, Glostrup, Denmark).

The following protocol was used for immunofluorescent labeling: the cells were thawed, rinsed with PBS and then incubated with $0.1 \%$ Triton X-100 (Sigma) in PBS. After being rinsed in PBS $+0.5 \%$ bovine serum albumin (BSA, Sigma) ( $3 x$ ), the cells were incubated with the primary antibody for $1 \mathrm{hr}$ at room temperature. The secondary $\mathrm{Cy}^{3}$-labeled goat anti-mouse antibody (Jackson Immunoresearch, West Grove, USA) was applied for $45 \mathrm{~min}$ after 3 rinsing steps in PBS $+0.5 \%$ BSA. The cover-glasses were rinsed in PBS and $f$-actin was stained with phalloidin- 
FITC (Sigma). The glasses went through a final rinsing step in PBS and AD and then mounted with Prolong ${ }^{m}$ antifade reagent (Molecullar Probes, Leiden, The Netherlands). The cells were wisualized by use of a confocal laser scanning microscope (LSM 510, Carl Zeiss). For $\alpha$-sm actin staining, the cells were pretreated with $50 \mathrm{mM} \mathrm{NH} \mathrm{m}_{4} \mathrm{Cl}$ for $10 \mathrm{~min}$ and with $0.2 \%$ Triton X-100 (Sigma) for $5 \mathrm{~min}$. The cover-glasses were incubated overnight at room temperature with the primary antibody diluted in PBS with $0.05 \%$ Tween 20 (Sigma), and then rinsed ( $3 \mathrm{x}$ $5 \mathrm{~min}$ with PBS) and incubated for a further $45 \mathrm{~min}$ with the secondary antibody (biotinylated anti-mouse, Vector Laboratories, Burlingame, USA) diluted in PBS with $0.05 \%$ Tween 20 . The Vectastain ABC-kit (alkaline phosphatase, Vector) together with Vector Blue chromogen (Vector) were used according to the manufacturers instructions for visualizing the immunogen, before the cover-glasses were mounted with Kaiser's glycerol gelatin (Merck, Darmstadt, Germany).

\section{Electron microscopy}

For electron microscopic evaluation of the phenotypical changes, cells were fixed in $3 \%$ glutaraldehyde buffered to $\mathrm{pH} 7.4$ with $90 \mathrm{mM} \mathrm{KH}_{2} \mathrm{PO}_{4}$ and $\mathrm{KOH}$, at regular intervals between $\mathrm{d} 0$ and $\mathrm{d} 21$. After post-fixation with $2 \% \mathrm{OsO}_{4}$ in $50 \mathrm{mM}$ veronal acetate (1h), the cells were dehydrated in graded series of ethanol, and embedded in Epon epoxy resin according to standard procedures. Ultrathin sections were counterstained with uranium acetate and lead citrate, prior to examination in a Philips CM100 electron microscope.

\section{Results}

Morphological changes

After attachment to the laminin-coated surface, the adult rabbit cardiomyocytes remained rod-shaped during the early days of culture (Figure 1 a). The only obvious change that could be noted with the light microscope was a rounding of the previously staircase-like distal ends of the cell. In contrast to the myocytes, the interstitial cells (mainly fibroblasts) proliferated. Because of this proliferation, close appositions between myocytes and fibroblasts became evident from day 3 onwards and increased over time. Rapid morphological changes of the myocytes occurred soon after cell-cell apposition between fibroblasts and cardiomyocytes was established. The first obvious change was a flattening of the myocyte (Figure 1b), with an increase in cell surface area, but without the loss of its elongated shape, i.e. no rounding was observed and no pseudopodia-like structures became evident. The mean increase in cell surface area, when cells of d10 were compared with cardiomyocytes of $\mathrm{d} 2$ was $39.6 \pm 1.7 \%$ (mean \pm SEM). In contrast to myocytes in close apposition with fibroblasts, cardiomyocytes that were not in 

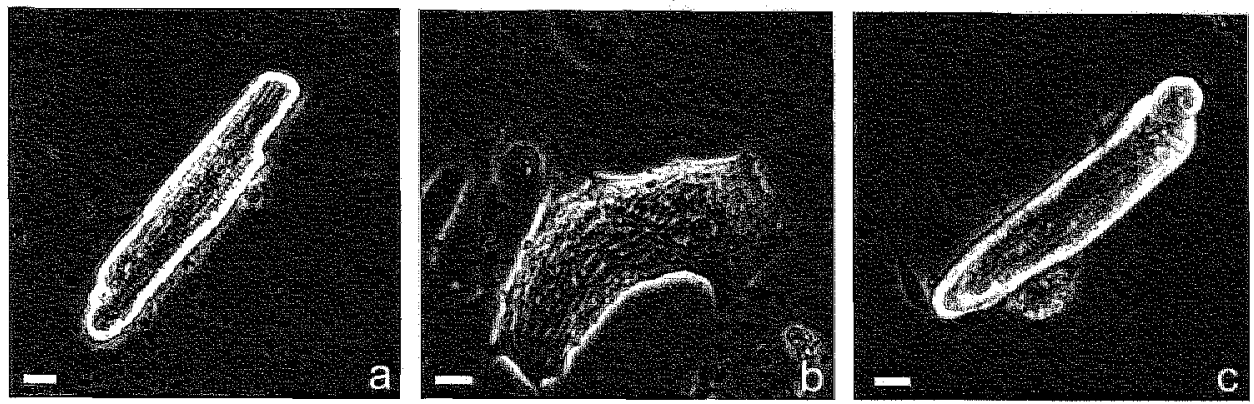

Figure 1:

Phase contrast images of adult rabbit cardionyocytes in concullure (Bars represent $10 \mu$ th)

(a) A cardiomyocyte 2 days after isolation and before close apposition with fibroblasts. The cell is rod-shaped and displays obvious cross strations. The only obvious change compared to freshly isolated cardiomyocytes is the rounding of previously staircase-like distal cell ends.

(b) A candiomyonte, 7 days in culture, spread after close apposition with fibroblasts. Cell surface area increased, but the basic elongated shape of the cell is not last howewer the cross strated pattern is somewhat disalignated.

(c) After 7 days in culture, an adult rabbit cardionyocyte in arac-supplemented culures is still rod shaped and indisguishable from cardiomyocytes in day 2 cultures without arac.

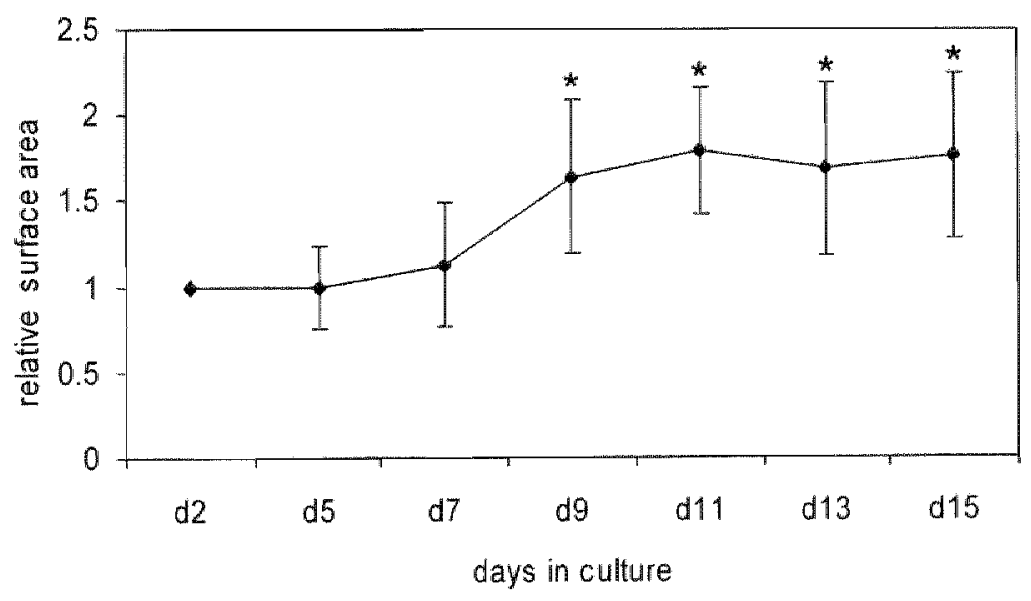

Figure 2a:

Relatwe increase in cell surface area of co-cultured adult rabbit candiompocytes. $($ * p $<0.05$ vs. d $)$ 


\section{Cardiomyocyle surface area}
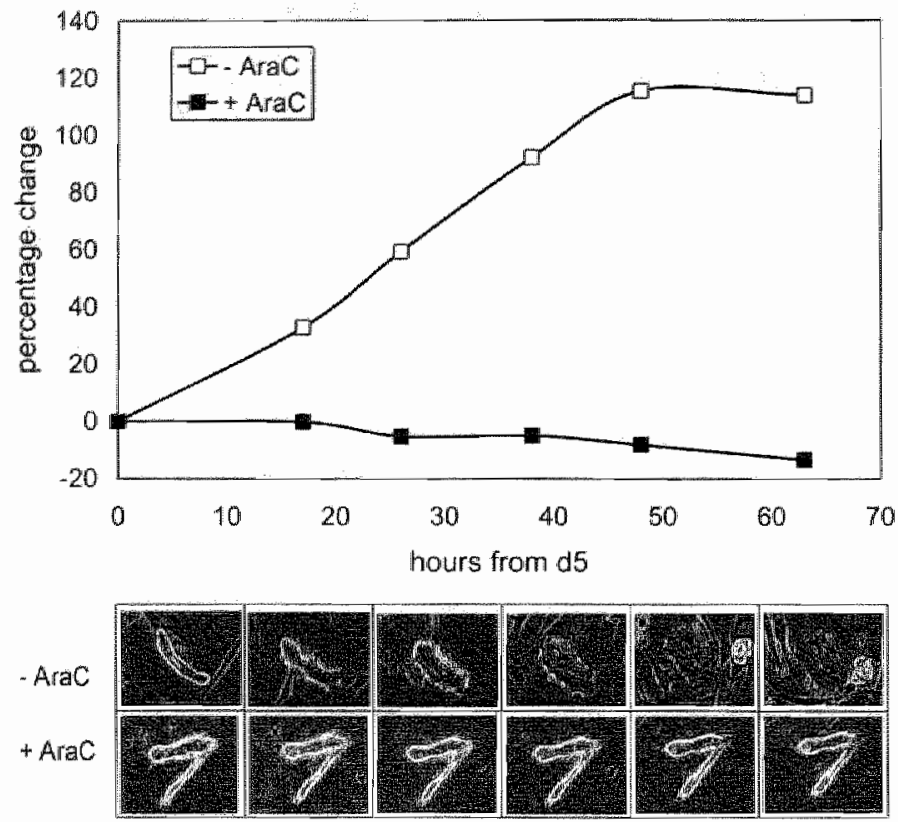

Figure $2 b$ :

Relative increase in cell surface area between $d 5$ and $d 7$ of Cardiomyocytes. in fibroblast wich ( - AraC) and libroblast poor ( + Arac) conditions.

Figure 3: monuthocytochemical detection of dedifferentiation markess (Burs represent 10 um).

(a) Nomeal coss strated titin distribution in Ineshy isolated cardionyocytes.

(b) Concultured cardiomyocyte after 7 days. The first obvious changes in the titin pattem of the cardiomyocytes are, apan from the loss of atigment of the saromeres, a decreased staining intensity in some areas (arrom) and a loss of the nomal cross strigted pallem (arrowhead).

(c) Ater almost three weeks in co-culure the 9010 epitope of tivin is almost completely lost Only some unorganised dottike structures can be delected (in red), however some sarcomere organization can still be seen whith phalloidin frrc (in gieen) Neverthetess, in throblast poor conditions (arac treated aultures) a vintwally nomal hitin pattem remains present hn cardionyocyles (insert).

(d) In heshly isolated catiomyocyles desmin shows a nomal cross striated pattem next to a localization at the distal cell ends of the lomer intercalated disks.

(e) Affer 7 days in co-culture, the cross strated desmin pattern as lost and spread out over the cytoplasm so is its localization at the distal cell ends.

(1) The nomal desmin patten is redistributed in cardiomyoytes co-cultured lor 10 days. Desmin is now present in a Hamentous patten throughout the cell (in red) which will gradually disappear in the cell center, leawing only a network at the cell periphen. Remaining sarcomeres can be obsewed with phatloidm-FTC (in geen).

(g) The R2G antibody ageinst cardiotin recognizes longitudinally orientated punctate arrays in freshy isolated cardiomyootes.

(11) Adrady after 3 days the longitudinal arrays of cardiotin have shortened, leawing only dotlke stuctures.

(i) Small dots reman detectable with the $R 2 G$ antibody in a co-caltured cardionyocyte after 15 days of co-culturing:

(i) Acardiomocyte 1 day in cultute displays a nomal cross-strated a actinin pattern.

(k) Alhough sarcomenes become disarranged after 7 days in co-culture, the $\alpha$ adinin pattem remain nomaly cross-strated.

(1) In remaining sarcomeres, $\alpha$-actinin remains present in a normal cross-striated foshion, after 12 days in co-culture. 


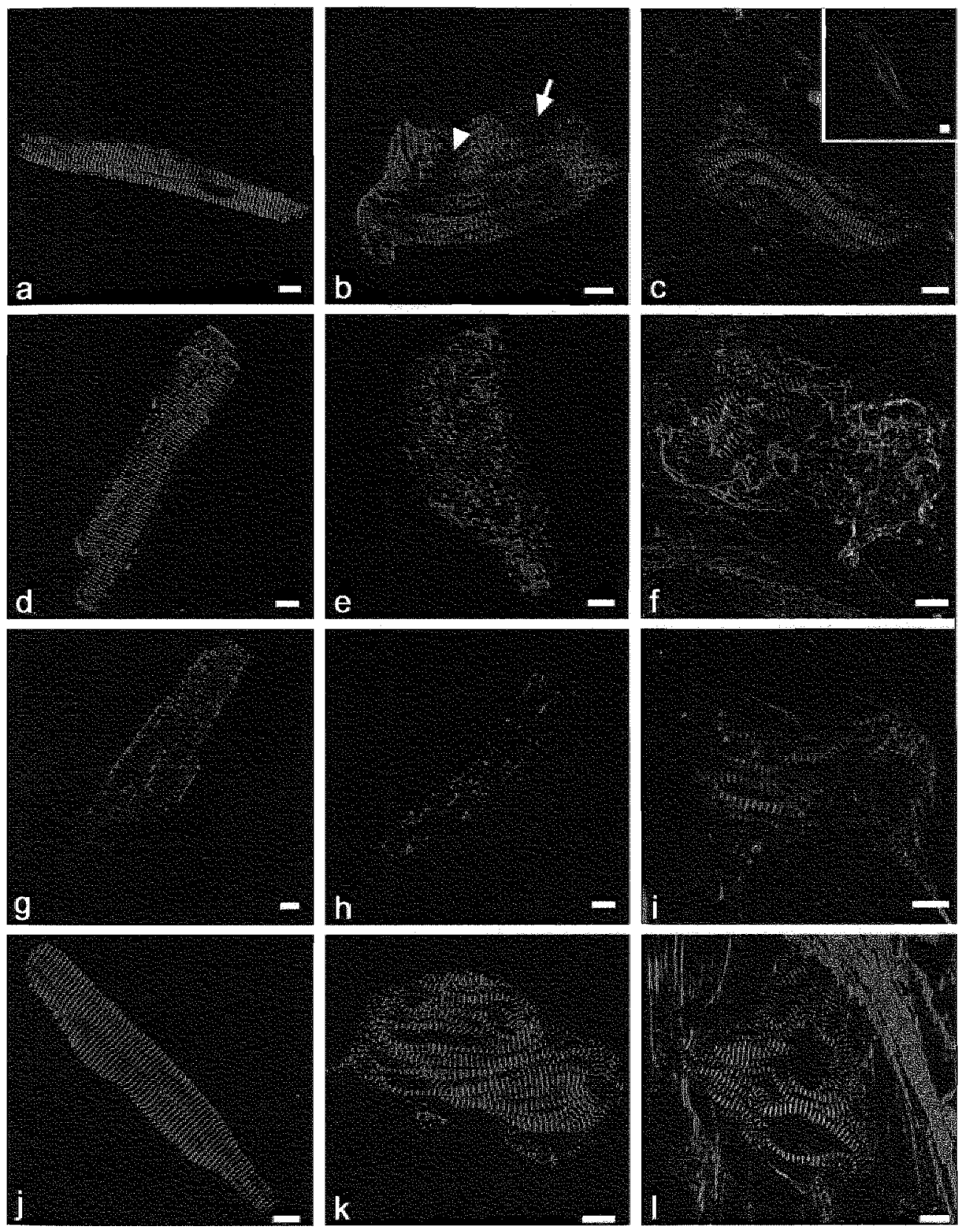

Figure 3 :

mmanocytothertical detection of dedifferentiation markers (Bars sepresent 10 um). 
close apposition with the myocytes did not display this flattening and retained their nomal rod-shaped appearance until contact became evident. Myocyte spreading was maximal between $\mathrm{d} 7$ and $\mathrm{d} 9$, when myocyte cell surface area reached a plateau (Figure $2 \mathrm{a}$ ). In contrast, $\mathrm{d} 7$ myocytes in araC-supplemented cultures were still rod-shaped as fresh isolated cells (Figure $1 \mathrm{c}, 2 \mathrm{~b}$ ). In d7 cultures, virtually all myocytes were in close apposition with fibroblasts, and thus all displayed morphological changes, meaning that it took approximately 4 days between the first changes occurring and the moment when almost all myocytes had spread. Within the same time frame, such typical flattening of the cells could not be induced either by application of FCM on freshly isolated cardiomyocytes, or by use of fibroblast-grown cell inserts in petri dishes with freshly isolated myocytes.

\section{Distribution pattern of structural proteins}

Titin: In freshly isolated cardiomyocytes, the 9D10 antibody showed a typical cross-striated pattern (Figure $3 a$ ). This normal pattern remained present in the following days, as long as the myocytes were not interacting with fibroblasts. The first change that became obvious in the titin pattern paralieled the final stage of flattening of the myocyte after interaction. During the flattening, not only did the sarcomeres lose their regular alignment, but there were areas in which the 9010 epitope (A-I junctional part of titin) showed a decreased intensity (Figure 3b). These changes were obvious in most myocytes after $\mathrm{d} 7 \mathrm{in}$ co-culture. In the following days the decrease became more pronounced, but seemed to parallel a decrease in sarcomere density. However, after about three weeks of co-culture it was obvious that the 9D10 staining was reduced to a punctuate pattern and there were only a few small
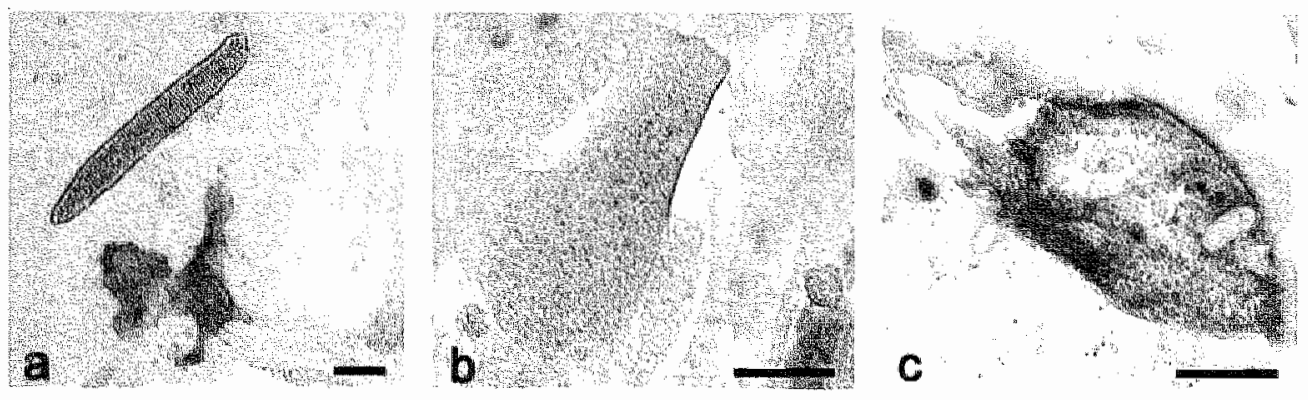

Figure 4: Immunocytochemical detection of a-smooth muscle actin (Bass represent 50 umy)

(a) Cardiomyocytes 4 days in ca-culture do not express a smooth muscle actin, unike some of mesenchymat cells, possibly endotheltal cells.

(b) Aher 10 days in co-culture, cardiomyocytes are still negative for tx-smooth muscle actin.

(c) Some of the more dediferentated cardiomyocytes (less detectable cross-strations) after 15 days in co-culture reexpress a smooth muscle actin. Onty a diftuse staining could be obsewed, and no organization into filaments is seen. 
regions with a recognizable cross striation, while sarcomeres could be observed with phalloidin-FITC (Figure 3c). That the changes were triggered by fibroblast involvement was confirmed by the finding of a virtually normal titin patten in 2121 cardiomyocytes in araC supplemented cultures (Figure $3 c$, insert).

Desmin: The intermediate filament-type protein desmin could be observed in a normal cross-striated distribution pattern in freshly isolated cardiomyocytes. Heavy staining was noted at the distal ends of the cell, at the site of the former intercalated disk (Figure $3 \mathrm{~d}$ ). This pattern stayed stable untill myocyte-fibroblast interaction was obvious. The first changes in the RD301 staining pattern were seen to coincide with the start of the spreading of the myocytes: a decreased staining intensity at the distal cell endings, and a kind of smearing out of the normal cross-striated pattern (Figure $3 \mathrm{e}$ ). Between $\mathrm{d} 7 \mathrm{and} \mathrm{d} 10$, the desmin cross striation was almost completely lost, and transforming into a flamentous pattern throughout the cell. These changes preceded a gradual decrease in the density of myofibrils. The filamentous desmin pattern gradually disappeared in the cell centre, leaving only an irregular desmin network at the cell periphery after three weeks of co-culture (Figure $3 f$ ).

Cardiotin: The $\mathrm{R} 2 \mathrm{G}$ antibody against this protein recognized longitudinally orientated structures (Figure $3 \mathrm{~g}$ ) perpendicular to the cross striations in freshly isolated cardiomyocytes. However, this pattern rapidly disappeared soon after the myocytes had attached. These arrays had already become shorter by $\mathrm{d} l$ in culture. On $\mathrm{d} 3$, the normal cardiotin pattern had completely changed to a punctate pattern, with no more than some short arrays remaining in some cells (Figure $3 \mathrm{~h}$ ). Interaction with fibroblasts seemed not to be a prerequisite for this change in R2G epitopes. Only small dots remained randomly distributed in the cells, visible throughout the rest of the culturing period (Figure $3 i$ ).

a-Actinin: The normal cross striated pattern, as can be seen in freshly isolated cardiomyocytes (Figure 3j) was detectable in remaining sarcomeres for the whole culturing period, and therefore reflected the changes in sarcomere alignment and sarcomere density. From the moment myocytes began to flatten, sarcomere alignment became disrupled (Figure $3 \mathrm{k}$ ). This was followed by a gradual decrease in sarcomere density and length, and after three weeks of co-culture, the myocytes showed only some remnants of sarcomeres displaying a normal cross-striated $\alpha$-actinin pattern (Figure 31 ).

$\alpha$-Smooth muscle actin: Within the first two weeks of couculture, only some interstitial cells, presumably endothelial cells and smooth muscle cells, stained positive with the antibody to a-smooth muscle action. The cardiomyocytes were negative without exception (Figure 4a). However, some myocytes displayed diffuse staining after this period (Figure 4 b). These 
posirive cells had only few sarcomeres left, whereas other myocytes with more sarcomeresmost probably in an earlier stage of dedifferentiation - were negative. No structural organization of $\alpha$-smooth muscle actin into filaments was seen.

\section{Electron microscopy}

At the ultrastructural level, prior to fibroblast contact, isolated myocytes showed a typical highly organized sarcomere structure, with uniformly sized mitochondria in between these sarcomeres. The cardiomyocyte nuclei contained a typical heterochromatin distribution in small clusters at the nuclear membrane (Figure 5a). The first obvious ultrastructural changes coincided with the beginning of cell spreading initiated after interaction with fibroblasts. Many of the Z-lines were disrupted and the sarcomeres started to loose their alignment. Consequently, the mitochondria started to lose their alignment, too (Figure 5b). Small patches of glycogen granules could be noted in some of the myocytes. A gradual depletion of contractile material with loss of myofibrillar organization and structure was accompanied by the occurrence of aberrantly shaped - small and ellongated - but healthy looking mitochondria (Figure 5b). The nuclear heterochromatin became uniformly dispersed throughout the nucleoplasm. After two weeks of co-culture, although retaining a more or less rectangular shape, myocytes were difficult to recognize as such. Only some remnants of myofibrils with small Z-line like structures mostly in the vicinity of the nucleus - enabled their identification (Figure $5 c$ ). Nevertheless, these cells did not show obvious degener ative signs, such as mitochondrial swelling, extensive formation of lysosomes, or the loss of sarcolemmal integrity.

\section{Discussion}

Cardiomyocyte dedifferentiation as seen in chronic hibernation and several other cardiac pathologies, is a poorly understood form of cellular remodeling. It is clear that questions about initiation and progression of the dedifferentiation can only be assessed in model systems, and in this context cellular models are needed in particular. At present, animal models of hibernating myocardium are very scarce and to the best of our knowledge, no work has been reported to characterize cellular models of hibernation-like dedifferentiation. Although there has been considerable attention paid to spontaneous dedifferentiation events in aclult rat cardiomyocytes in vitro, it became clear that this form of dedifferentiation is only partially comparable to the morphological changes in vivo [11-14]. For extensive research into the onset and progression of in vivo dedifferentiation, a cellular model mimicking these changes as much as possible, could be a valuable tool. 


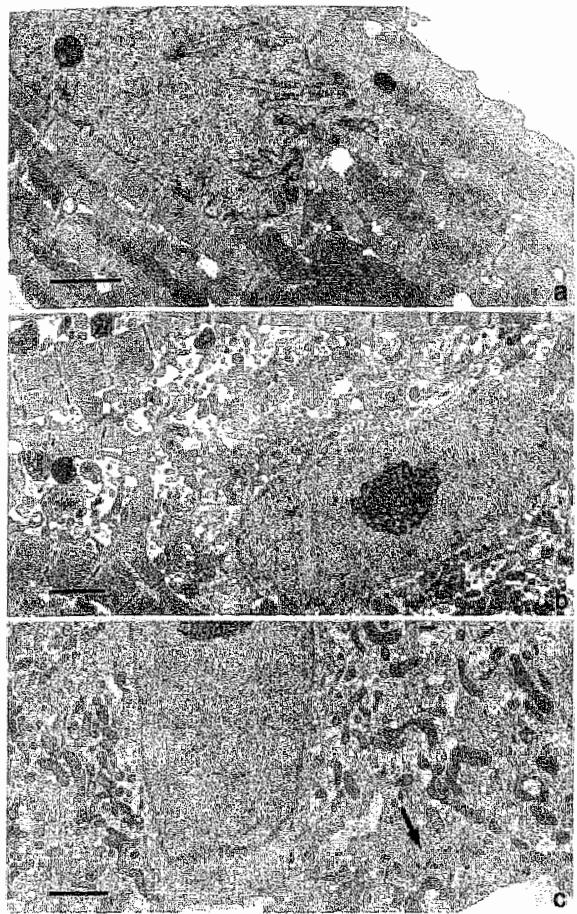

Figure s: Eection michosopy of co-cutured adult rabbit candiompoytes (Bas represent / Hirt)

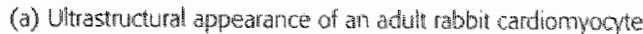
dung the first day of culture. Alignte intact sarcomeres arte present throughout the otosol. Nomal mitochondna are ahgned between the sarcomeres. The heterochomation in the rudcus is clustered near the nuclear membrante.

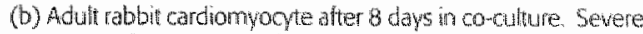
sarcomere depletion and disalignment is obvious and so is the appearance of abnomath shaped (cmall and elongated) mitochondria. Nuclear heterochromatio shows a pathy distribution.

(c) After 13 days in co-culure, cardionyocytes can only be identified by the presence of small sarcomere rements (arrow) Numerous small and elongated mitochondria can be roticed The nucleus displays a homogenous dispersion of heterochromatin.

With this study, we show that by using a co-culture of adult rabbit cardiomyocytes and cardiac mesenchymal cells (mainly fibroblasts), we were able to induce typical morphological changes in the myocytes, which occur neither spontaneously in the same time frame, non after application of FCM or fibroblast-grown cell inserts. With regard to the changes in protein expression and ultrastructure, 'hibernating' cardiomyocytes in wivo and these co-cultured cardiomyocytes showed a high degree of similarity (Table 1 ). The changes in the pattern of expression of the proteins titin, desmin, cardiotin, $\alpha$-actinin and $\alpha$-smooth muscle actin have been described in detail previously in myocardial tissue from patients with chronic hibernating myocardium [16] and in atrial tissue from goats with chronic atrial fibrillation [6]. In the present study, the 9D10 epitope from titin displayed a normal cross-striated pattern in freshly isolated cardiomyocytes and in cultured myocytes prior to fibroblast interaction. After fibroblast interaction, however, this distribution pattern gradually disintegrated. In dedifferentiated cocultured cardiomyocytes, the titin epitope appeared only sparsely and in a punctuate fashion, as it was observed in severely dediferentiated cardiomyocytes from chronic hibernating myocardium and chronic fibrillating atrium $[6,16]$. The sequence of changes of the titin pattern in the co-cultured cardiomyocytes was the reverse of that during embryogenesis. Indeed the punctuated expression pattern could be observed in early stages of cardiac myofibrillogenesis 
of rabbit embryos [17]. In contrast, the titin-associated protein $\alpha$-actinin could be found in a normal pattern in the remaining sarcomeres, just as it is the case in cardiomyocyte dedifferentiation in vivo [6]. During embryonic development desmin changes its organization in the heart from a filamentous into a cross-striated pattern. Thereafter, the epitope showed increased staining at the intercalated disk [17]. The co-cultured cardiomyocytes followed a contrary pathway: desmin was lost at the distal cell ends and gradually lot its normal crossstriated pattern. This change can also be observed in dedifferentiating cardiomyocytes in wivo during chronic hibernation or chronic atrial fibrillation, as well as in other pathologies such as dilated cardiomyopathy $(6,18)$. In spontaneously dedifferentiated adult rat cardiomyocytes a similar changed (filamentous) desmin pattern could be observed in quiescent myocytes in their early phase of spreading [19]. It can be hypothesized that desmin rapidly undergoes organizational alterations in response to changes in extracellular architecture and/or to changes in contractile activity. Indeed, adult rat cardiomyocytes gaining spontaneous contractions in long-term culture, partly regain periodic arrangement of desmin along the Z-line, but a Villamentous network remains present [19].

In chronic hibernating myocardium [16] and chronic fibrillating atrium [6], re-expression of a-smooth muscle actin could be detected in some of the dedifferentiated cardiomyocytes. A similar diffuse staining pattern of this embryonic actin isotype was observed in some of the

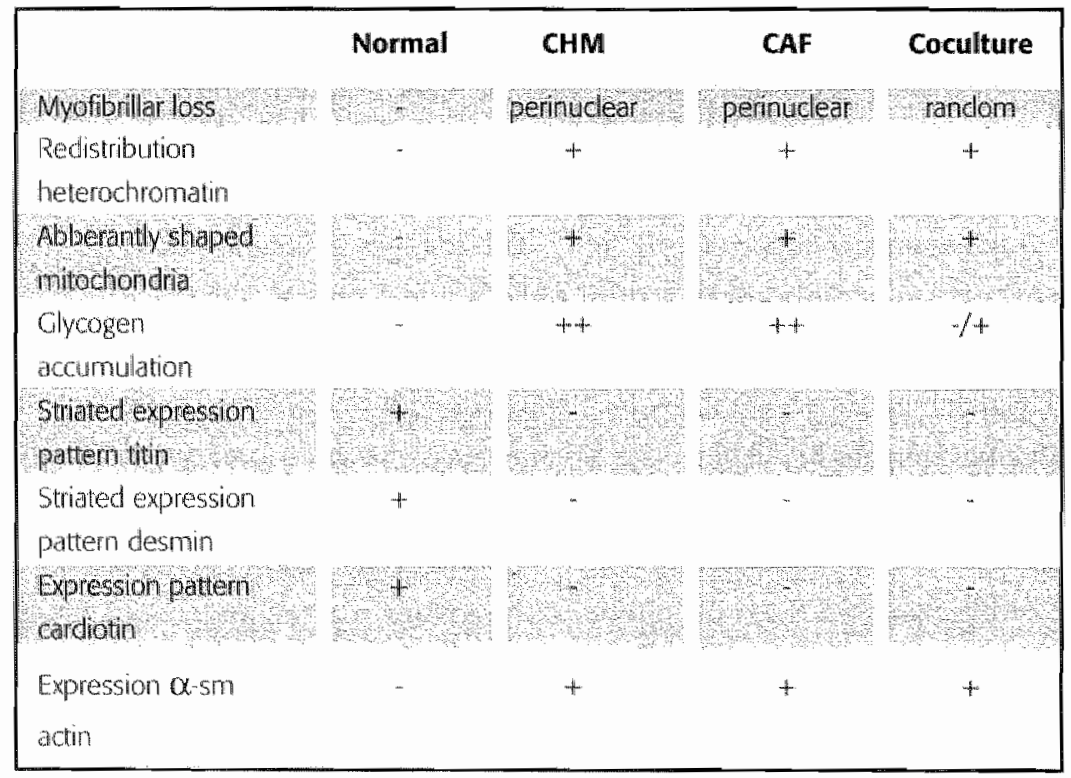

Tabel 1: Overvew of the similarities and differences between cardiomyocyte dedifferentation in co-culture and in wivo. 
co-cultured cardiomyocytes in long-term culture. The heterogeneous response in re-expression of $\alpha$-smooth muscle actin may be explained by different stages of myocyte dedifferentiation in the same culture. Indeed, cardiomyocytes that had still a rather well developed sarcometic apparatus were consistently negative for $\alpha$-smooth muscle actin, whereas only those myocytes that had few sarcomeres left - probably representing a more dedifferentiated state-displayed a strong staining for this protein. In contrast to the situation of cultured adult rat cardiomyocytes [14], no structural organization of $\alpha$-smooth muscle actin was seen. In our hands, $\alpha$-smooth muscle actin only displayed diffuse staining, just as is the case in dedifferentiated cardiomyocytes in vivo. Perhaps the spontaneous contractile activity of adult rat cardiac myocytes in longterm culture accounts for the structural organization of the protein.

Recent findings suggest that the disappearance of the normal longitudinally orientated cardiotin strands recognized by the $R 2 G$ antibody, is one of the first changes that can be detected in a study of dedifferentiating cardiomyocytes in goats with chronic atrial fibrillation [20]. It was reported that the extent of cardiotin disappearance in human biopsies was coupled to the degree of structural alterations. Shorter filaments were noticed in the cells least affected, whereas the cardiotin pattern had completely disappeared in the severely affected cardiomyocytes. Our findings indicate that the normal longitudinally orientated cardiotin arrays could be observed only immediately after isolation. Soon after culturing, these arrays became shorter, to ultimately leave only some minor dots. These findings seem to confirm the changes in vivo, however, it should be emphasized that these changes - unlike the other structural alterations - occurred before fibroblast interaction, thus long before any other changes could be observed. Although the exact role of cardiotin is still obscure, we hypothesize that some dedifferentiation changes occur spontaneously (independent of fibroblast interaction) and very tapidly in cultured cardiomyocytes. Indeed the loss of its normal physical environment and contractile activity leaves the cell in a totally different mechanical and energetic state, which might be enough to trigger some characteristics of dedifferentiation $[21,22]$. It should also be stressed that, with exception of cardiotin, the changes of all of the st ructural proteins examinated, were consistenly linked with cell spreading. Changes in the protein expression pattern of titin, desmin and $\alpha$-smooth muscle actin were not seen before cell spreading occured (after fibroblast interaction). The observed ultrastructural changes in dedifferentiating co-cultured myocytes are in many ways also similar to those in dedifferentiated cardiomyocytes in wivo. Ultrastructural alterations such as myofibril degradation, mitochondrial shape changes, and nuclear heterochromatin redistribution were all very like the changes reported in dedifferentiating cardiomyocytes in chronic hibernating myocardium and chronic fibrillating atria $[1,6]$. However, there were some differences as well: myolysis in vivo occurs perinuclear, whereas it occurred in a more random fashion in the co-cultured cardiomyocytes. The reason for this difference might be the different 
extracellular environment of the cells in wivo and in vitro, and therefore the different passive load (stretch). Is has been shown that stretch is an important factor in maintaining myofibrillar organization, and therefore an altered three dimensional load between in wivo and in vitro might account for the difference in preferential localization of the loss of myofibrils $[21-23]$. One of the most prominent changes in hibernating cardiomyocytes is the extensive glycogen accumulation. This typical change seemed to be barely present in the co-cultured cardiomyocytes. Only some myocytes displayed minor glycogen accumulation, observed ultrastructurally as accumulation of small glycogen clusters. Again a mechanically and energetically different environment compared with the in wivo situation might account for this difference. Alternatively this finding might indicate that, unlike the structural changes, the metabolic changes (increased glycogen accumulation) depend on a persistent or repetitive decreased oxygen avallability [24].

It is known that at least some of these ultrastructural changes and alterations in protein expression patterns also occur spontaneously, without fibroblast interaction. Indeed, Decker et al. $[25\}$ described that quiescent adult rabbit cardiomyocytes spread and showed myofibrillar discuption after two weeks in culture. However, these spontaneous 'dedifferentiating' rabbit cardiomyocytes changed in a somewhat different way from that which we observed. For example, these myocytes rapidly formed extended attachment plaques at their distal ends, which we did not observe in our setting. The ultrastructural appearance was also different from the morphology reported here. However, subtle differences in the experimental setup, such as serum and laminin concentrations might be responsible for the different behaviour. The present study clearly indicates that the fibroblast interaction elicits morphological changes characteristic of dedifferentiation much earlier than would occur without it, indicating that co-culturing with fibroblasts may induce a different kinetic of dedifferentiation. When freshly isollated cardiomyocytes and fbroblast suspensions are seeded to a $2: 1$ ratio, the changes occurred even sooner (after $1-2$ days) than in the current setting, where fibroblast proliferation had to be awaited (Dispersyn, unpublished data). Even though it is beyond the scope of this paper to further characterize the cardiomyocyte - fibroblast interaction, it is obvious from the present lindings that factors secreted by fibroblasts are not solely responsible for the dedifferentiation. Indeed, when considering $\mathrm{d} 5$ or $\mathrm{d} 6$ cultures, cardiomyocytes dedifferentiation could only been seen in cardiomyocytes in close contact with fibroblasts and could not be induced by application of PCM or fibroblast-grown cell inserts. Nevertheless, it cannot be ruled out that locally produced or activated paracrine factors in combination with close cell-cell interactions are essential in this setting.

With their co-culture model of adult rat cardiac myocytes and epicardial mesenchymal cells (non-fibroblasts), Eid et al. [15] showed that co-cultured cells can influence cardiomyocyte 
morphology. But in contrast to our study, Eid et al noted increased differentiation of the rat myocytes in close apposition with the co-cultured counterparts. A possible explanation for these divergent findings is that the co-cultured cells in the aforementioned work induced large amplitude contractions in the myocytes - a behaviour that did not occur in our setting. Active loading of cultured myocytes has been shown to positively influence the degree of differentiation of cultured myocytes $[22,26]$. The increased differentiation could not be induced when fibroblasts rather than epicardial mesothelial cells were used, but is was not stated whether these cells had a "dedifferentiating" effect. Further research is presently ongoing to explore the intercellular interaction and possibly identify important triggers or co-triggers of hibernationlike dedifferentiation in our co-culture model.

In conclusion, we have presented an in vitro model of adult rabbit cardiomyocytes in which dedifferentiation similar to in viwo dedifferentiation can be induced. This model consists of co-culturing adult rabbit cardiomyocytes with cardiac fibroblasts and mimics the most important structural changes of dedifferentiating cardiomyocytes in vivo, and may therefore be an important tool for further investigating possible triggers for and the progression of dedifferentiation in vivo. We suggest that most of the structural changes in dedifferentiating cardiomyocytes in vivo are not directly dependent on changes in oxygen availability. Further research is currently ongoing to characterize the triggers elicited by the fibroblasts on the cardiomyocytes in co-culture.

\section{References}

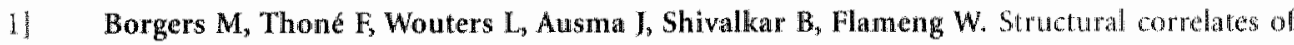
regional myocardial dysfunction in patients with critical coronary artery stenosis: chronic hibernation? Cardiovasc Pathol $1993 ; 2: 237 \times 45$.

2] Maes A, Flaneng W, Nuyts I, Borgers M, Shivalkar B, Ausma J, Bormans G, Schiepers C, De Roo M, Mortelmans L. Histological alterations in chronically bypoperfused myocardium. Correlation with PET Gindings. Circulation 1994; 90:735-45.

3] Vanoverschelde Jl, Wijns W, Borgers M, Heyndrickx G, Depre C, Flameng W, Melin JA, Chronic myocardial hibernation in humans. From bedside to bench. Circulation 1997;95:1961 71.

4) Depré C, Vanoverschelde JL, Gerber B, Borgers M, Melin JA, Dion R. Correlation of functional recovery with myocardial blood flow, glucose uptake, and morphologic features in patients with chronic left ventricular ischemic dysfunction undergoing cononary antery bypass gratting. I Thorac Cardiovasc Surg 1997;113:371-8. 
5] Vanoverschelde IL, Depré C, Gerber BL, Borgers M, Wijns W, Robert A, Dion R, Melin JA. Time course of functional recovery after coronary artery bypass graft surgery in patients with chronic left ventricular ischemic dysfunction. Am J Cardiol 2000;85(12):14:32-9.

61 Ausma J,Wijffels M, wan Eys G, Koide M, Ramaekers $\mathbf{F}$, Allessie M, Borgers M. Dedifferentiation of atrial cardiomyocytes as a result of chronic atrial fibrillation. Am I Pathol 1997;151:985-97.

7) Sharov VG, Sabbah HN, Shimoyama H, Goussev AV, Lesch M, Goldstein S. Evidence of cardiocyte apoptosis in myocardium of dogs with chronic heat failure. Am J Pathol 1996;148:141-9.

8] Dispersyn GD, Donker DW, Volders PGA, Ausma J, Vos MA, Borgers M. Aspects of cardiomyocyte dedifferentation accompany biventricualr hypertrophy in dogs with chronic complete AV block. Europace 2000; 1(suppl): B23 (abstract).

9] Sherman AJ, Klocke FJ, Decker RS, Decker MI, Kozlowski KA, Harris KR, Hedjbeli S, Yaroshenko Y, Nakamura $S$, Parker MA, Checchia PA, Evans DB. Myofibrillar disruption in hypocontractile myocardium showing perfusion-contraction matches and mismatches. Am ) Physiol 2000; $278(4): H 1320-34$.

10] Canty IM Jr, Borgers M, Fallavollita JA, Thomas SA. Myolysis in hibernating myocardium is global and dissociated from regional reductions in coronary flow and SR protein levels. Circulation 2000: in press (abstract).

11) Moses RL, Claycomb WC. Disorganization and reestablishment of cardiac muscle cell ultrastructure in cultured adult rat ventricular muscle cells. J Ultrastruct Res $1982 ; 81: 358-74$.

12) Jacobson SL, Piper HM. Cell cultures of adult cardiomyocytes as models of the myocardium. J Mol Cell Cardiol 1986; 18:661-78.

13 Eppenberger ME, Hauser I, Baechi T, Schanb MC, Brunner UT, Dechesne CA, Eppenberger HM. Immunocylochenical analysis of the regeneration of nyofibrils in long- term cultures of adult cardiomyocytes of the rat. Dev Biol $1988 ; 130: 1-15$.

14! Harder BA, Heft MA, Eppenberger HM, Schaub MC. Differential protein localization in sircomeric and nonsarcomeric contractile structures of cultured cardionyocytes. I Struct Biol $1998: 122: 162-75$

15] Eid H, Larson DM, Springhorn JP, Attawia MA, Nayak RC, Smith TW, Kelly RA. Role of epicardial mesothelial cells in the modification of phenotype and function of adult rat ventricular myocytes in primary coculture. Circ Res 1992;71:40-50.

16) Ausma J, Schaart G, Thoné F, Shivalkar B, Flameng W, Depré C, Vanoverschelde J-L, Ramaekers F, Borgers $M$. Chronic ischemic viable myocardium in mans aspects of dedifferentiation. Cardiovase Pathol 1995;4:29-37. 
17) van der Loop FT, Schaart G, Langmann W, Ramaekers FC, Viebahn C. Expression and organization of muscle specific proteins during the early developmental stages of the rabbit heart. Anat Embryol $1992 ; 185: 439-50$.

18] Schaper J, Froede R, Hein S, Buck A, Hashizume H, Speiser B, Friedl A, Bleese N. Impaiment of the myocardial ulitrastructure and changes of the cytoskeleton in dilated cardiomyopathy. Circulation 1991; 83:504-14.

19] Nag AC, Huffaker SK. Distribution and organization of desmin in cultured adult cardiac musde cells: reflection on function. J Muscle Res Cell Motil 1998; 19:887-95.

20] Ausma J, Lender MH, Mast F et al. Time course of structural changes due to atrial fibrillation in. the goat. Circulation 1998; 98: I-683 (abstract)

21] Decker MI, Behnke-Barclay M, Cook MG, La Pres J), Clark WA, Decker RS. Cell shape and organization of the contractile apparatus in cultured adult cardiac myocytes. I Mol Cell Cardiol. 1991; 23:817-32.

22] Simpson DG, Decker ML, Clark WA, Decker RS. Contractile activity and cell-cell contact regulate myofibrillar organization in cultured cardiac myocytes. I Cell Biol 1993; 123(2):323-36.

23] Decker ML, Janes DM, Barclay MM, Harger L, Decker RS. Regulation of ad ult cardiocyte growth: effects of active and passive mechanical loading. Am J Physiol., 1997; 272:H2902-18.

24] Depre $\mathrm{C}$, Taegtmeyer $\mathrm{H}$. Metabolic aspects of programmed cell survival and cell death in the heart. Cardiovase Res $2000 ; 45: 538-48$.

25] Decker ML, Simpson DG, Behnke M, Cook MG, Decker RS. Morphological analysis of contracting and quiescent adult rabbit cardiac myocytes in long-term culture. Anat Rec 1990; $227.285-99$

26] Sharp WW, Terracio L, Borg TK, Samarel AM. Contractile activily modulates actin synthesis and turnover in cultured neonatal rat heart cells. Circ Res $1993 ; 731: 172 m 83$. 
112 


\section{Dynamic interactions with fibroblasts induce hibernation- like dedifferentiation in adult rabbit cardiomyocytes}

Gerrit D. Dispersyn, Karen Lemmens, Tom Van Dooren, Luc Ver Donck, Stefan van den Eijnde, Frans C.S. Ramaekers, Marcel Borgers 
The mechanism of cardiomyocyte dedifferentiation as seen in chronic libernating myocardium is uniknown. We have recently proposed a cellular model consisting of long term co-cultures of aduit rabbit cardiomyocytes and cardiac fibroblasts, in which typical structural characteristics of hibernation-like dedifferentiation could be induced. Only cardiomyocytes in close contact with fibroblasts underwent these changes. In this study, we further investigated the nature of the fibroblast-cardiomyocyte interaction. Using time-lapse video mictoscopy this interaction was shown to be very dynamic. Upon contact with cardiomyocytes, fibroblasts attach firmly and pull the former cells, resulting in anisotropic stretch. The nature of such cell cell contacts was investigated using immunocytochemical analysis of different proteins involved in cell adhesion. Intercellular communication was studied using Dil and calcein-AM prelabeling of fibroblasts. It was shown that intercellular communication exists between fibroblasts and cardionyocytes, whicl could not be inhibited by blocking gap-junctional communication. Cardionyocyte dedifferentiation could not be minicked by fibroblast secreted factors. It is concluded that the dyaamic passive stretch invoked by the fibroblasts and $/$ or intercellular communication play an important role in the strictural changes accompanying cardionyocyte dedifferentiation: 


\section{Introduction}

The term chronic hibernating myocardium is used to describe the clinical setting of dysfunctional but viable myocardium in patients with coronary artery disease. It is believed that a reduced oxygen availability of chronic duration - with perhaps a repetitive character - is at the basis of the hibernating respons of the left ventricle. After revascularization, the hibernating segments show a delayed recovery of function [1-3]. It is suggested that the typical structural changes which accompany chronic hibernating myocardium are, at least partially, responsible for this delay $[2,4]$. The most obvious subcellular structural changes are sarconere depletion, glycogen accumulation, nuclear heterochromatin redistribution, mitochondrial shape changes and sarcoplasmic reticulum breakdown, giving the cardiomyocytes a fetal-like phenotype [5]. The assumption that chronic hibernating cardiomyocytes dedifferentiate was confirmed by the identification of embryonic/fetal protein expression patterns of structural proteins like titin, cardiotin, desmin and $\alpha$-smooth muscle actin [6]. Al though most thoroughly investigated in the setting of chronic hibernation, it became clear that this kind of cardionyocyte dedifferentiation is not an exclusive feature of this pathology. Indeed, recent findings from both human and animal model studies have pointed out that this typical cellular respons occurs also in cardiomyocytes in chronic atrial fibrillation $[7,8]$, volume-overloaded myocardium [9] and in infarct border zones [10]. Little is known about the possible triggers of carcliomyocyte dedifferentiation in these settings. Therefore there is an urgent need for model systems which would enable investigations to fill up this lacune. Animall models of chronic hibernating myocardium are very scarse at the moment, and provide only limited information as to the causal factor(s) of this particular cardionyocyte adaptation. We have recently proposed a cellular model consisting of long term co-cultures of adult rabbit cardiomyocytes and cardiac fibroblasts, in which the typical structural characteristics of hibernation-like dedifferentiation could be induced. Moreover, the changes in the expression patterns of titin, desmin, cardiotir, o-actinin and $\alpha$-smooth muscle actin were similar to those of hibernating cardiomyocytes $\mid 11\}$. The trigger for this dedifferentiation respons in this cellular system is unknown, but it was striking that only cardiomyocytes in close contact with fibroblasts developed these changes. Given the similarity between the dedifferentiated cardiomyocytes in vivo and in this culturing condition, this cellular model can be a valuable tool for the identification of triggers and pathways leading to the typical morphological changes. In the present investigation, we focussed on the nature of the fibroblast-cardiomyocyte interaction in the co-culture model. We found that this interaction is highly dynamic and that the fibroblast impose mechanical strain on the myocytes. We further investigated the role of paracrine factors and also the structural properties of the cell-cell contact between the fibroblasts and cardiomyocytes. Proteins possibly involwed in the architecture of the contact zones, and thus responsible for the transmission of possible 
mechanical strain, such as $N$-cadherin, vinculin, desmoplakin, B1-integrin and $C \times 43$ were investigated. Intercellular communication was assessed by a dye transfer protocol [12]. Based on the results of these experiments we conclude that dynamic fibroblast interaction, characterized by anisotropically stretching the cardiomyocytes and by intercellular communication, plays an important role in the induction of hibernation-like dedifferentiation of the cultured adult rabbit cardiomyocytes.

\section{Material and Methods}

The investigation is conform to the Guide for the Care and Use of Laboratory Animals published by the US National Institutes of Health (1985).

\section{Cell isolation and culturing conditions}

Cardiomyocytes and cardiac fibroblasts were isolated from adult NZ White rabbits (ca. $2 \mathrm{~kg}$ ) by a retrograde collagenase perfusion as previously described [11]. In brief, rabbits were anesthetized by intra-arterial injection of $70 \mathrm{mg} / \mathrm{kg}$ pentobarbital (Samofi, Brussels, Belgium). The heart was rapidly excised and perfused in a retrograde Langendorff mode ( 5 min at 35 $\mathrm{ml} / \mathrm{min})$ with a modified Krebs-Henseleit solution $\left(37^{\circ} \mathrm{C}\right)$. Thereafter fresh solution supplemented with $0.6 \mathrm{mg} / \mathrm{ml}$ collagenase (Wako, Osaka, Japan) was recirculated for $40 \mathrm{~min}$. The ventricles were gently dissociated in the same medium without collagenase and the cells were filtered. In three subsequent rinsing steps, in solution supplemented with $10 \mathrm{mg} / \mathrm{m}$ l Bovine Serum Albumine (BSA), the $\mathrm{Ca}^{2+}$ concentration was elevated to $1.4 \mathrm{mM}$. Thereafter the cells were suspended in Medium 199 (Life Technologies, Paisley, Scotland), supplemented with antibiotics (Penicillin-Streptomycin $0.1 \mathrm{mg} / \mathrm{ml}$; Gentamycin $2 \mu \mathrm{gg} / \mathrm{ml}$ ). The cells were seeded on laminin ( $10 \mu \mathrm{g} / \mathrm{ml}$; Life Technologies) coated cover glasses in petri dishes at a low density $\left(10^{\circ} \mathrm{cells} / \mathrm{cm}^{2}\right)$ to avoid cell-cell contact. Cells were allowed to attach for 2 hrs. Thereafter, fresh medium, supplemented with $20 \%$ Fetal Bovine Serum (FBS, Hyclone, Utah USA) was applied onto the cells. Cells were kept in a humidified incubator $\left(5 \% \mathrm{CO}_{2}-37^{\circ} \mathrm{C}\right)$ for up to 15 days (d), and medium was replaced twice a week.

Because of their rapid proliferation, cardiac fibroblasts could be grown and passaged up to 6 times, using 0.05\% trypsin-EDTA (Life Technologies). Suspended cells were split 1:3 prior to seeding. The fibroblasts used in the cell-cell communication protocols were used after 1-4 passages. 


\section{Video Time Lapse microscopy}

Individual cardiomyocytes were evaluated over time using video time lapse microscopy. Sixwell plates with co-cultures were placed onto an automatic scanning stage (stage and MAC4000 controller, Märzhäuser, Wetzlar, Germany) of an Axiovert microscope in phase contrast illumination mode (Carl Zeiss, Oberkochen, Germany), and equiped with a CCD camera. Six positions were randomly chosen in each well. At each of these positions a videoimage was captured every $3 \mathrm{~min}$, and stored on disk. Each position on the 6-well plate was sequentially visited every $3 \mathrm{~min}$. Individual movies were compiled from these images. Movie processing was done using the software package SCIL-Image version 1.4 (TNO-TPD, Delft, The Netherlands) on a $\mathrm{O} 2$ workstation (SGI, Mountain View, CA).

\section{Immunocytochemistry}

For immunocytochemcial characterization of structural proteins presumed to be involved in cellular interactions, the antibodies against the following proteins were used: Vinculin (mouse monoclonal $\operatorname{lgG}_{1}$, Sigma), desmoplakin (mouse monoclonal $\operatorname{IgG}_{1}, I_{C N}$, Zoetermeer, The Netherlands), $N$-cadherin (mouse monoclonal $\operatorname{lgG}_{1}$, Santa Cruz Biotechnology, Santa Cruz, California, USA), B1-integrin (goat polyclonal IgG, Santa Cruz) and Cx433 (mouse monoclonal $\lg G_{1}$, Zymed, San Francisco, USA). Immunocytochemical staining procedures were used as previously described [11]. In brief, cultures grown on coverslips were fixed with $-20^{\circ} \mathrm{C}$ methanol $(3 \times 1 \mathrm{sec})$ and ethanol $(1 \mathrm{x} \| \mathrm{sec})$, air dried and frozen $\left(-20^{\circ} \mathrm{C}\right)$ until further use. After thawing, and rinsing in PBS, the cells were pretreated with PBS $+0.1 \%$ Triton X-100 (Sigma). Cells were then rinsed $3 x$ in $\mathrm{PBS}+0.5 \% \mathrm{BSA}$, and subsequently incubated with the primary antibody for thr at room temperature. After three rinsing steps with PBS + 0.5\% BSA the coverslips were incubated for $45 \mathrm{~min}$ with the secondary $\mathrm{CY}^{3}$-labeled appropriate secondary antibody (Jackson Immunoresearch, West Grove, USA). Incubation with phalloidin - FTC (Sigma) was performed, preceeded and followed by rinsing (3x) in PBS. After a final rinsing step in distilled water, the coverslips were mounted with Prolong ${ }^{\mathrm{TM}}$ antifade reagent (Molecular Probes, Leiden, The Netherlands), and examined with a confocal laser scanning microscope (LSM 510, Carl Zeiss).

\section{Cell-cell communication protocols}

To investigate heterocellular communication between fibroblasts and cardionyocytes in culture, the transfer of fluorescent dye was studied [12]. Suspended fibroblasts were pre-loaded with calcein-AM (Molecular Probes) and Vybrant ${ }^{\mathrm{TM}}$ Dil cell labeling solution (Molecular Probes), according to the instructions of the manufacturer. Fibroblasts were then added to 1 or 3 day old unlabeled cardiomyocyte cultures. Involvement of gap juctional communication was tested 
in parallel experiments, by performing the dye transfer protocol in the presence of $100-500 \mu \mathrm{M}$ n-octanol (Sigma) or 10-50uM palmitoleic acid (Sigma). Phospatidylserine exposure during cell-cell contact (a marker of cell membrane fusion) was assessed using $200 \mu \mathrm{M}$ Alexa Green ${ }^{\mathrm{TM}}$ - labeled annexin V (Molecular Probes). To assess a possible involvement of humoral fibroblast factors, cardionyocytes were cultured in fibroblast conditioned medium (FCM). FCM was collected by providing subconfluent fibroblasts cultures with the above described medium for $24 \mathrm{hrs}$. The conditioned medium was thereafter collected and applied to fresh isolated cardionyocyte cultures for a period of 4 days and daily replenished. In another set of experiments, subconfluent fibroblast cultures were grown on permeable cells inserts $(0.02 \mu \mathrm{m}$ Anapore, Nunc, Life Technologies). These inserts were then placed for 4 days in petri dishes containing freshly isolated cardiomyocyte cultures.

\section{Results}

Video time lapse experiments

Video time lapse microscopy revealed dynamic fibroblast activity. Fibroblasts showed proliferation and active migration. While migrating through the petri dish, the fibroblasts made contact with each other as well as with cardiomyocytes. These cellular contacts were sparse in the first 3 days of co-culture, because of the low numbers of fibroblasts, but became gradually more frequent after fibroblast proliferation. Cell contact was not immediately lost when a fibroblast migrated away from a cardiomyocyte after having been in close apposition. This caused an extensive 'pulling' and a profound local extension of the cardiomyocyte. This deformation of the cardiomyocyte lasted until the cell contact was lost. Such an individual cell-cell contact with subsequent extensive pulling lasted for up to 5-7 hrs in duration (figure 1). These cellular interactions between cardiomyocytes and fibroblasts were rapidly followed by profound morphological changes of the myocyte. Although the basic rectangular shape was not lost, the cardiomyocytes spreaded and consequently flattened, however without the formation of large pseudopodia-like structures or extensive attachment plaques (figure 2). The spreading of the cell coincided with a partial loss of cross-striation due to sarcomere depletion [11].

\section{Immunocytochemistry}

All of the investigated structural proteins known to be involved in the costameric organization and in anchoring the cell to other cells or the extracellular matrix, were found to be prominently present at the sites of fibroblast-cardiomyocyte cell contact. Vinculin was found to reorganise 

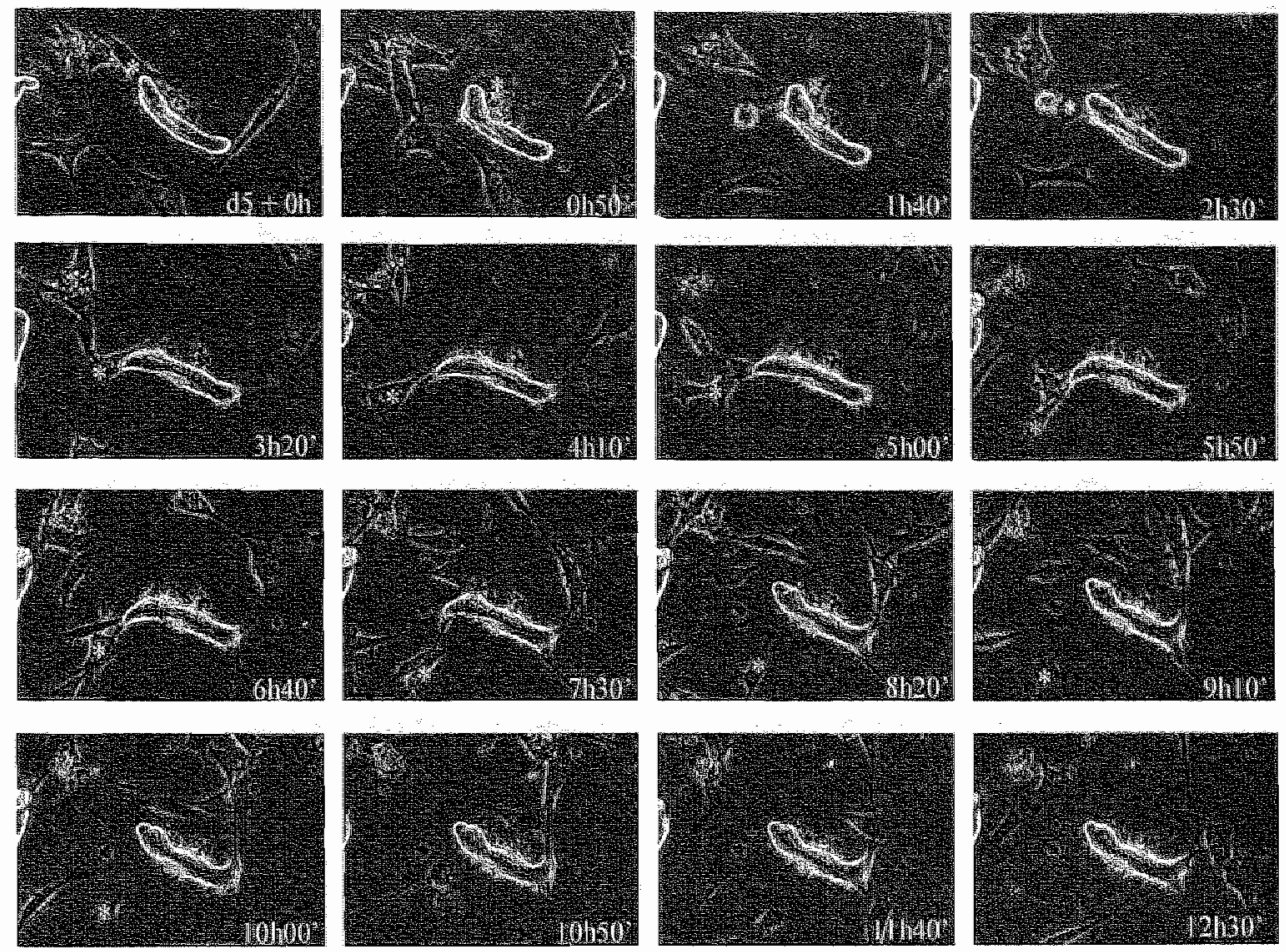

Figure 1: Viceo time-lapse micrascopy of the interaction beween a mowing fibroblast (asterisk) and a cardionyocyte in a day 5 comculture. The sequential images represent 50 min intervals over a 12.5 the the period. Note that the cardionyocyte is being pulled in different directions before detachment of the fibroblast.

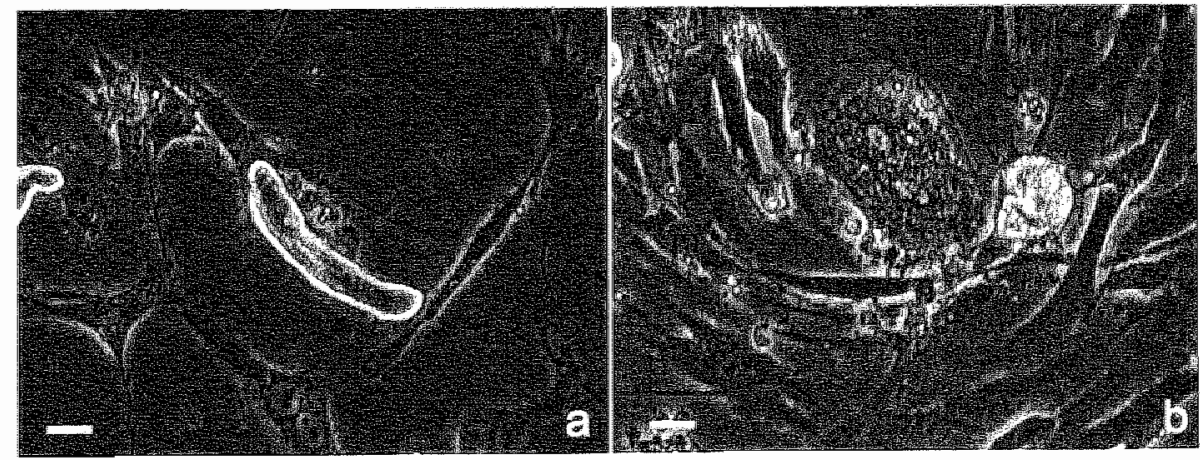

Figure 2: The same cardionvyonte as in figure 1 at the beginning of the thoroblast interaction (a) and 63 hrs ater the

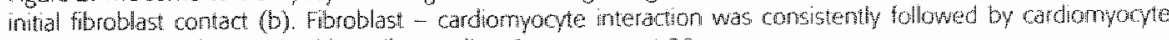
dedfferentiation, characterized by cel speading Bars represent 20 um. 

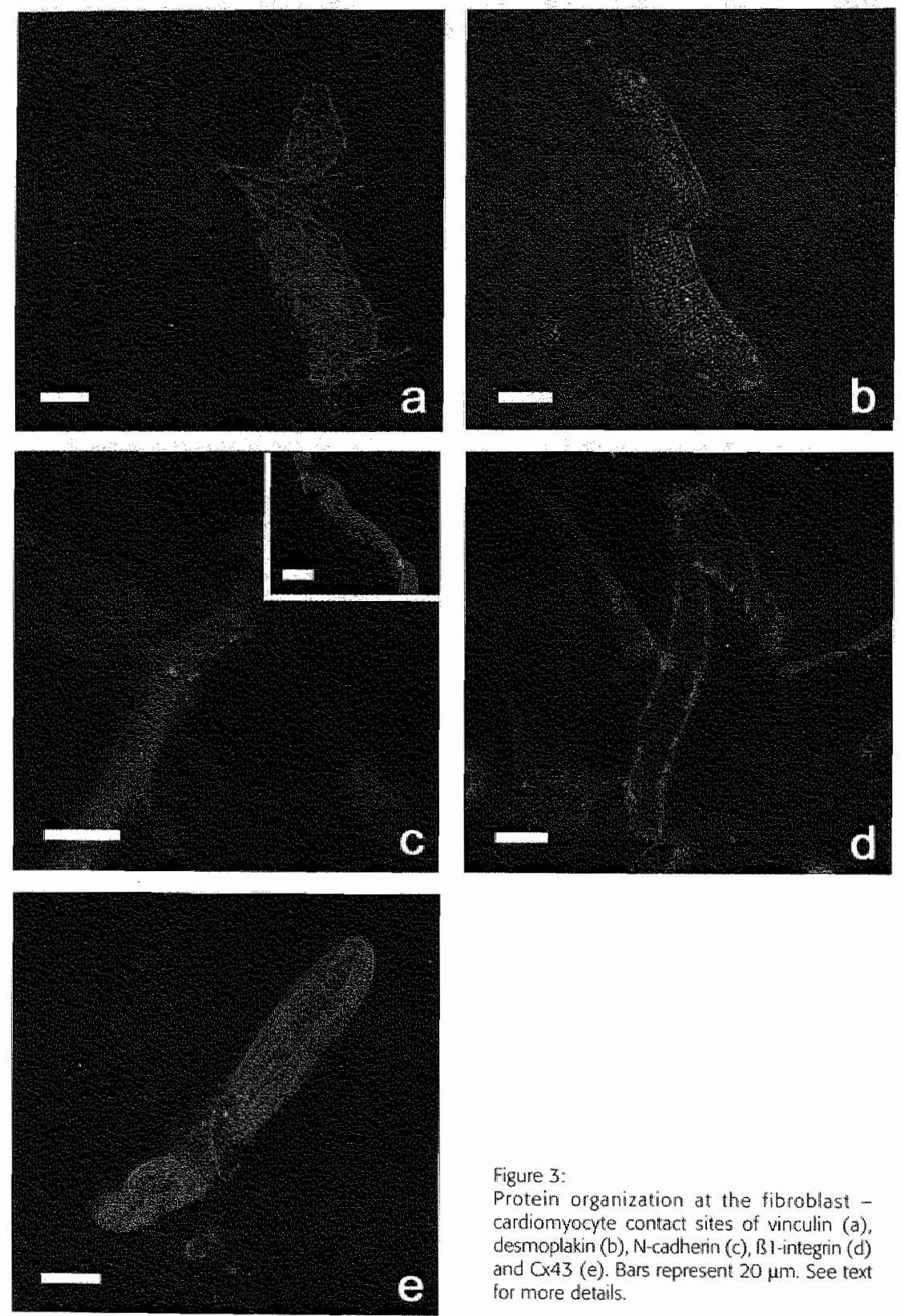

Figure 3 :

Protein organization at the fibroblast cardiomyocyte contact sites of vinculin (a). desmoplakin (b), $N$-cadhein (c), B - integrin (d) and $\mathrm{C} 43$ (e). Bars represent $20 \mu \mathrm{m}$. See text for more details. 
in strands parallel to the direction of the imposed strain (figure 3a). Significant desmoplakin labeling was not only present at the sites of former intercalated disks, but also at intercellular contact sites were mechanical stress was imposed (figure $3 b$ ). The same holds true for $N$ cadherin, which was abundantly present at the intercalated disk between two cardiomyocytes (figure $3 c$, insert) but also appeared at fibroblast-cardiomyocyte contacts. 81 -Integrin in the cardiomyocytes was predominantly found in a costameric organization at distal athesion plaques and the ventral and lateral sides. However increased staining intensity was found laterally where interaction with fibroblasts was obvious (figure $3 \mathrm{~d}$ ). A diffuse or punctuate pattern of $\mathrm{Cx} 43$ was regularly present at the interface between a fibroblast and a myocyte (figure 3 ), however a strand-like organization was never found.

\section{Cell-cell communication}

Heterocellular communication between the fibroblasts and cardiomyocytes was assessed by dye transfer experiments [12]. Fibroblasts were preloaded with calcein-AM and Dil before adding them to cultures of 1 to 3 day old unlabeled cardionyocytes. Approximately 1.5 hr after addition of the fibroblasts, the green fluorescent cytoplasmic calcein label became detectable in some cardiomyocytes in contact with fibroblasts (figure 4a). However, the red fluorescent Dil label could not be observed in those myocytes. As the number of fibroblastcardiomyocytes interactions increased over time, more green fluorescent calcein containing cardiomyocytes could be detected in the following hours. After approximately $4.5 \mathrm{hrs}$, some of the cell-cell contacts were lost and isolated fuorescent myocytes were noticed. Dil positive cardiomyocytes were not observed, even not after 24 hrs. The calcein dye transfer from fibroblasts to cardiomyocytes could not be inhibited by the addition of $\mathrm{n}$-octanol (up to 500 بM) (figure $4 \mathrm{~b}$ ) or palmitoleic acid (up to $50 \mu \mathrm{M}$ ) to the co-culture medium. All these results were similar for 1 and 3 day old cardiomyocyte cultures.

Small dot like annexin $V$ label was present at some but not all of the contact sites between fibroblasts and cardiomyocytes (figure 5a). Especially the areas where cardiomyocytes were touched by pseudopodia like extentions of a fibroblast were positive (figure 5b). Also, Large annexin $V$ positivity was seen in dead cells (figure 5a).

The application of fibroblast conditioned medium for 4 days to freshly isolated cardiomyocyte cultures failed to induce the typical morphological changes which could be noticed in cardiomyocyte-fibroblast co-cultures. Unlike in co-culture, the cardionyocytes supplemented with fibroblast conditioned nedium remained rod shaped and did not show any sign of spreading. Also when medium permeable cell inserts containing subconfluently grown fibroblasts were applied to petri dishes with freslaly isolated cardiomyocytes, no spreading of cardiomyocytes was observed. 

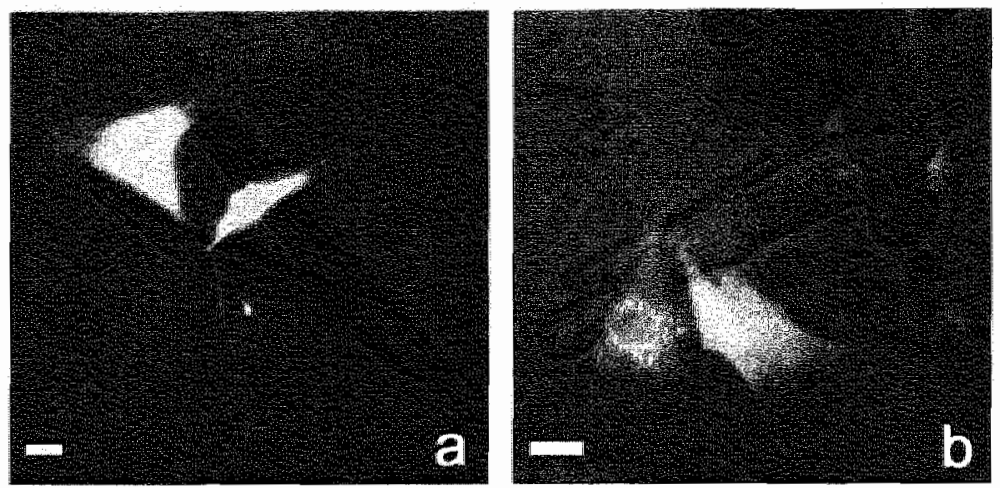

Figure 4: Calcein -Dit prelabeling of fibroblasts prior to addition to cardiomyacyte cultures results in the transter of calcein (green) to cardiomyocytes upon intercellular contact, but nof of an exchange of Dil (red) (a). Addition of $500 \mu$ h noctanol does not inhibit the intercellulat exchange of calcein (b). Bars represent 20 prm.
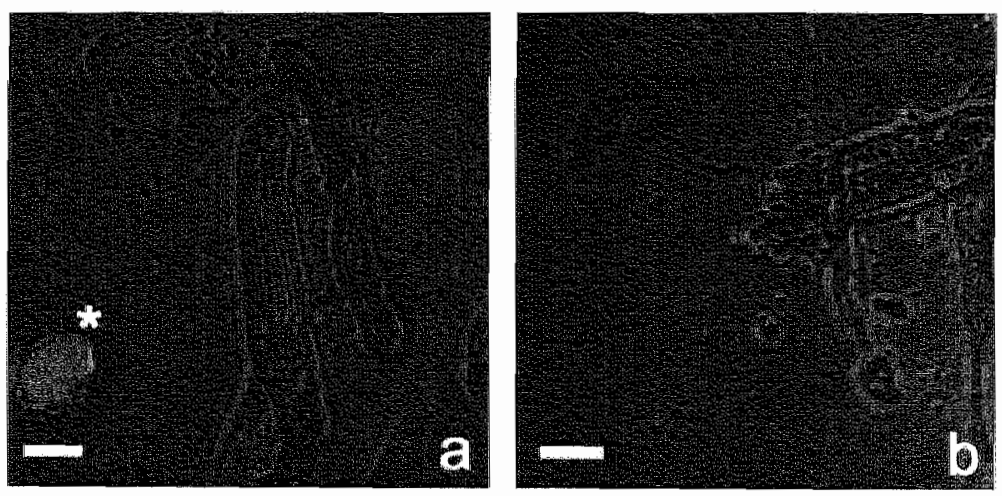

Figure 5: Alexa Green ${ }^{\text {ik }}$ - Annexin $V$ labeling of cardionyocyte - fibroblast co-cultures. Phosphadidylserine exposure is seen at some of the contact sites between cardiomyocytes and fibroblasts (a). This is especially obvious at initial contact sites of fibroblast psevidopodia and cardiomyocytes (b). Marked Amnexin V labeling was seem in a dead cell (asterisk), Bars represent $20 \mu \mathrm{m}$. 


\section{Discussion}

The exact etiology of the typical cellular dedifferentiation which occurs in chronic hibernating myocardium and several other cardiomyopathies is unknown. To investigate in detail the onset and progression of hibernation - like dedifferentiation, a cellular model in which the in vivo changes can be mimicked, may turn out to be extremely helpful. We have recently described a cellular model in which such structural changes could be induced. This was achieved by coculturing adult rabbit cardiomyocytes and cardiac fibroblasts. We demonstrated that both the ultrastructural alterations and changes in expression pattern of several structural proteins were induced in the co-cultured cardiomyocytes [11]. Although the structural changes were characterized in detail and compared to the in vivo changes, the actual trigger of the morphological changes remained unknown. Therefore, in this study we investigated the nature of the fibroblast - cardiomyocyte interaction, hoping to identify factors contributing to these typical morphological changes.

It is known that fibroblast secreted factors can influence the growth characteristics of cardiomyocytes (e.g. CT-1 [13]). However in the present study, fibroblast conditioned medium and fibroblast grown cell inserts were not able to reproduce the changes in cardiomyocyte morphology occuring in the co-cultures. Decker et al. [ 14] already described that co-culturing adult rabbit cardiomyocytes with non-myocytes influenced protein metabolism in the myocytes. Compared to serum depleted cultures, co-culturing the cardiomyocytes induced a marked reduction in proteolitic activity, i.e. whereas no effect on myosin heavy chain (MHC) synthesis was noted, a significant decrease in MHC degradation was observed. The authors did not find any evidence of physical contacts (intercellular junctions) between myocytes and non-myocytes. They investigated the influence of the non-myocytes conditioned medium on protein synthesis and degradation of cytosine-1-B-D-arabinofuranoside (Ara-C) treated cardiomyocyte cultures, however, this set-up failed to evoke a similar reduction in proteolytic activity as seen in the cocultures. Compared to serum deprived cultures, protein synthesis was not increased after treatment with conditioned medium. These findings, as well as our results, indicate that fibroblast secreted humoral factors are unlikely to be critically involved in the induction of the hibernation -like dedifferentiation in co-cultured cardiomyocytes.

The existence of heterocellular communication between fibroblasts and cardiomyocytes was shown by dye transfer experiments, in which the fibroblasts were preloaded with the green fluorescent cytoplasmic label calcein-AM and the red fluorescent cell membrane label Dil. Within a few hours after co-incubation of labeled fibroblasts with unlabeled cardiomyocytes, the calcein label could be detected in some of the cardiomyocytes in close apposition to fibroblasts. That the dye transfer is selective is suggested by the observation that not all cardiomyocytes in close contact with a fibroblast became calcein positive. This indicates that a 
lavage of calcein-AM out of fibroblasts with subsequent uptake by cardiomyocytes is not occuring. Such observations are suggestive for the involvement of gap junctional intercellular communication. However, only diffuse or unorganized punctuate Cx43 patterns could be observed at the intercellular junctions. Some observations, however, suggest that gap junctions cannot be formed in such a short period of time. Kostin et al. [15] recently showed that Cx 43 immunofuorescence significantly drops in adult rat cardiomyocyte cultures after more than $24 \mathrm{hrs}$ in culture, suggestive for a rapid degradation of the internalized gap junctions. When new myocyte-myocyte cell contacts in 5 days old cultures were established, it took approximately 24 hrs between the onset of the contact and the ultrastructural demonstration of intact gap junctions. In contrast, it was shown that pulsatile stretch can cause a rapid upregulation of Cx43 in neonatal cardiomyocytes. Such an upregulation was seen even one hour after the onset of pulsatile stretch [16]. It is not known whether the stretch which the adult cardiomyocytes undergo in the present study, can have a similar effect. Nevertheless it has been shown by Eid et al. [17] that functional gap junctions between heterologous cells in coculture can be formed. In long term co-cultures of adult rat cardiomyocytes and epicardial mesothelial cells, functional gap junctions have been documented with the intracellular injection of the fluorescent dye lucifer yellow. In several instances slow transfer of the dye to heterologous cells, next to a rapid transfer to homologous cell types, was wisualized. However, no ultrastructural evidence for heterocellular gap junctions was found, and therefore the authors suggested that these junctions were small and infrequent [17]. Moreover the gap-junction inhibitors $\mathrm{n}$-octanol and palmitoleic acid were unable to inhibit calcein dye transfer [18], indicating that another form of intercellular exchange is involved in the intercellular communication.

An alternative explanation for the present finding of calcein dye transfer from fibroblasts to cardionyocytes in co-culture might be the occurence of plasma membrane fusion. The annexin $V$ labeling at some fibroblast - cardiomyocyte contacts might indicate that this is indeed happening. It has been described that annexin $V$ positivity is a prerequisite for myoblast fusion | 19|. It is hypothesized that phosphatidylserine translocation is required for succesful plasma membrane fusion. In none of the cases, however, could Dil transfer from fibroblasts to cardiomyocytes be shown, suggesting that no plasma membrane exchange occured during the cell-cell contact. It could be hypothesized that the amount of red Dil transfer is below the limit of detectability. This point requires further investigation.

The video time lapse experiments clearly showed that only cardiomyocytes that have been extensively 'pulled' by neighboring fibroblasts undergo the typical flattening, a response that has been identified as the first obvious change into hibernation-like dedifferentiation in vitro [11]. Conversely, cardiomyocytes that did not undergo these dynamic interactions with 
fibroblasts did not undergo such shape changes. It is obvious that the 'pulling' by the fibroblasts imposed to the cardiomyocytes, subjects these to mechanical load (passive stretch). Immunocytochemical analysis of vinculin, $\mathrm{N}$-cadherin, desmoplakin showed that these proteins became expressed at the site of the intercellular contact and thus are likely to be involved in the transmission of the mechanical strain. The increased BI-integrin labeling at those sites is indicative for a local reactive increased cell-matrix interaction. Stretching cultured neonatal heart cells has been documented to stimulate protein synthesis and elevate the protein content and organization of the stretched cells $[20,21]$, which is presumably at least partially independent of angiotensin II [22]. Conversely, passive load was shown to induce protein synthesis in adult cardiomyocytes as well, but in contrast to neonatal cardiomyocytes, this change in contractile protein synthesis only results in modest cardiomyocyte hypertrophy. Indeed, Decker et al |23]. showed that passive stretching of adult feline cardiomyocytes elicits also a transient increase in protein degradation. This transient increase of contractile protein turnover coincided with a structural remodeling of these cardionyocytes. In an attempt to adapt to the static stretch, the myocytes become flattened, remodeled their cytoskeleton and reorganized their contractile apparatus. In contrast to the aforementioned findings, the myocytes in our co-cultures showed no reorganization of their myofibrils, but instead displayed significant myolysis, suggestive for an increased proteolitic activity which is not counterbalanced by a increased protein synthesis. A possible explanation for this seemingly divergent finding is that in the setting of co-culture, the cardiomyocytes don't undergo a static isotropic stretch, but a dynamic anisotropic one, to which the cardiomyocytes cannot adapt by remodeling their cytoskeleton and reorganizing their contractile apparatus. In this context, these results support the findings of Decker et all. $123 \mid$ that an increased proteolytic activity is an important respons of adult myocytes to stretch. The presence of passive but dynamic stretch is plausible in the different settings in wivo where cardiomyocyte dedifferentiation can be found. Indeed, in chronic hibernating myocardium the affected hypo- or acontractile regions are most likely being stretched by the (hyper)contractile surrounding areas. It can therefore be thypothesized that the presence of dynamic changes in stretch of cardionyocytes is an important factor in inducing structural dedifferentiation. The mechanism of the proteolytic activation is unclear. However, recent findings suggest that an elevated preload induces calpain mediated proteolysis, independently of an ischemic component [24]. It remains to be investigated whether a transient increase in cytosolic calcium as a result of stretch activated cation channels is at the basis of the activation of calpain [25]. Nevertheless, our current findings together with recent reports of myofibrilysis [26] and dedifferentiation [27] of cardiomyocytes in non-ischemic myocardial regions in animal models, llead to the suggestion that not ischemia per se but altered mechanical strain might be responsible for the structural changes in cardiomyocyte dedifferentiation. 
In conclusion, we report evidence that very dynamic fibroblast - cardiomyocyte interactions, involving cardiomyocyte stretch and intercelular communication, precedes hibernation-like dedifferentiation. This cellular reaction could not be mimicked by fibroblast secreted factors. It is suggested that the dynamic passive stretch invoked by the fibroblasts plays an important role in the structural changes accompanying the dedifferentiation. However, the relative contribution of mechanical stress and of intercellular communication requires further study. The present data support the hypothesis that mechanical stretch and / or heterologous cellcell communication are involved in triggering hibernation-like dedifferentiation of cardiomyocytes in co-culture.

\section{References}

1) Rahimtoola SH. The hibernating myocardium. Am.Heart J. 1989; 117:211-221.

21 Maes A, Flameng W, Nuyts J, Borgers M, Shivalkar B, Ausma J et all. Histological alterations in chronically hypoperfused myocardium. Correlation with PET findings. Circulation 1994; 90:735 745.

3! Vanoverschelde $J \mathbf{L}$, Wijns $\mathbf{W}$, Borgers $\mathbf{M}$, et al. Chronic myocardial hibernation in humans. From bedside to bench. Circulation 1997,95:1961-1971.

4) Vanoverschelde JL, Depré C, Gerber BL, Borgers M, Wijns W, Robert A et al. Time course of functional recovery after coronary artery bypass graft surgery in patients with chronic left ventricular ischemic dysfunction. Am J Cardiol 2000; 85:1432-1439.

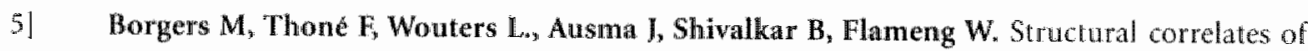
regional myocandial dysfunction in patients with critical coronary artery stenosis: chronic hibernation? Cardiovase Pathol $1993 ; 2: 237-245$.

6) Ausma J, Schart G, Thoné F, Shivalkar B, Flameng W, Depré C et al. Chronic ischenic viable myocardium in man: aspects of dedifferentiation. Cardiovase Pathol 1995; 4:29-37.

7) Ausma J, Wijffels $M$, van Eys $G_{0}$ Koide $M$, Ramaekers $F$, Allessie $M$ et al. Dedifferentiation of atrial cardiomyocytes as a result of chronic atrial fibrillation. Am J Pathol 1997; 151:985-997.

81 Thijssen VL, Ausma J, Liu GS, Allessie MA, van Eys GI, Borgers M. Structural changes of atrial myocardium during chronic atrial fibrillation. Cardiovasc Pathol 2000; 9:17-28.

91 Dispersyn GD, Donker DW, Volders PGA, Ausma J, Vos MA, Borgers M. Aspects of cardiomyocyte dedifferentiation accompany biventricular hypertrophy in dogs with chronic $A V$ block. Eurospace 2000; 1 (Suppl):B23 (Abstract). 
10] Sharov VG, Sabbaht HN, Shimoyama H, Goussev AV, Lesch M, Goldstein S. Evidence of cardioyte apoptosis in myocardium of dogs with chronic heart failure. Am J Pathol 1996; 148:141-149.

11] Dispersyn GD, Geuens E, Ver Donck L, Ramakers FCS, Borgers M. Hibernation-like dedifferentiation in ardiomyocytes cocultured with fibroblasts. Cardiovase Res, submitted for publication.

12] Goldberg GS, Bechberger IF, Naus CCG. A pre-loading method of evaluating gap junctional communication by dye transfer. BioTechniques 1.995; 18:490-497.

13) Kuwahara K, Saito Y, Harada M, Ishikawa M, Ogawa E, Miyamoto Y, Hamanaka I, Kamitani S,

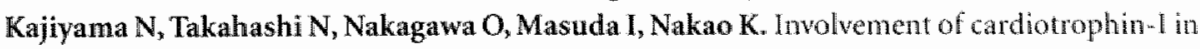
cardiac myocyte-nonmyocyte interactions during hypertrophy of rat cardiac myocytes in witro. Circulation 1999; 100:1116-1124.

14] Decker RS, Cook MG, Behnke-Barclay M, Decker ML. Some growth factors stimulate cultured rabbit ventricular myocyte hyperthrophy in the absence of mechanical loading. Circ Res 1995; $77: 54: 4-555$.

15] Kostin S, Hein S, Bauer EP, Schaper J. Spatiotemporal development and distribution of intercellular junctions in adult rat cardiomyocytes in culture. Circ Res 1999; 85:154-167.

16. Zhuang J, Yamada KA, SaffitzJE, Kleber AG. Pulsatile stretch remodels cell-to-cell communication in cultured myocytes. Circulation Research 2000; 87:316-322.

17) Eid H, Larson DM, Springhorn JP, Attawia MA, Nayak RC, Smith TW, Kelly RA. Role of epicardial mesothelial cells in the modification of phenotype and function of adult rat ventricular myocytes in primary coculure. Circ Res 1992;71:40-50.

18] Rohr S, Kucera JP, Kléber AG. Slow conduction in cardiac lissue, I: Fffects of a reduction of excitability versus a reduction of electrical coupling on microconduction. Circ Res 1998; 83:781794.

19] van den Eijnde SM, Boshart L, Reutelingsperger CPM, De Zeeuw CI, Vermey Keers C. Phosphatidylserine plasma membrane asymmetry in vivo: a pancellular phenomenon which alters during apoptosis. Cell Death Different 1997; 4:311-317.

20] Sadoshima J, Jahn L, Takahashi T, Kulik J, Izumo S. Molecular characterisation of the stretch induced adaptation of cultured cardiac cells: an in vitro model of load-induced cardiac hyperthrophy. J Biol Chem 1992; 267:10551-10560.

21) Kent RL, McDermott PJ. Passive load and angiotensin II evoke differential responses of gene expression and protein synthesis in cardiac myocytes. Circ Res 1996; 78:829-838. 
22. wan Kesteren CAM, Saris J,, Dekkers DHW, Lamers JMI, Saxena PR, Schallekamp MADH, Danser AHJ. Cultured neonatal rat cardiac myocytes and fibroblasts do not synthesize renim or angiotensinogen: evidence for stretch-induced cardiomyocyte hyperthrophy independent of angiotensin II. Cardiovase Res 1999; 43:148-156.

23] Decker ML, Janes DM, Barday MM, Harger L, Decker RS. Regulation of adult cardiocyte growth: effects of active and passive mechanical Loading. Am J Physiol 1997; 272:H2902-2918.

24. Feng I, Schaus BJ, Canty IM Jr. Elevated preload induces troponin-I degradation independently of ischemia in the rat: stretch-induced calpain mediated proteolysis. Circulation 2000; 102 : II. 215 (Abstract).

25] Sigurdson W, Ruknudin A, Sachs F. Calcium imaging of mechanically induced fluxes in tissuecultured chick theart: role of stretch-activated ion channels. Am J Physiol 1992;262;H1110-1115.

26] Sherman AJ, Klocke FJ, Decker RS, Decker ML, Kozlowski KA, Harris KR et al. Myofibrillar disruption in hypocontractile myocardium showing perfusion-contraction matches and mismatches. Am I Physiol 2000; 278:H1320-H1334.

27] Canty JM, Jr., Borgers M, Fallavollita JA, Thomas SA. Myolysis in hibenating myocardium is global and dissociated from regional reductions in coronary flow and SR protein level. Circulation 2000; 102: 11-136 (Abstract). 


\section{General discussion}

based on:

Clinical pathophysiology of chronic hibernating myocardium. Gerrit D. Dispersyn, Frans C.S. Ramaekers, Marcel Borgers 


\subsection{Introduction}

Our current knowledge of the pathophysiology of chronic hibernating myocardium is mainly based on results from clinical studies, because of the paucity of appropriate and validated animal models. These clinical observations have given rise to two major controversies: the role of reduced blood flow and the impact of structural remodeling of the hibernating segments. In this discussion, these two subjects will be briefly discussed, and put into perspective by comparing the clinical data with experimental findings emerging from recently developed animal models.

In patients with coronary artery disease, chronic reversible left ventricular (LV) contractile dysfunction, often referred to as 'chronic hibernating myocardium', is a frequently encountered clinical entity. The reduced LV function in this setting is thought to be an adaptive response to inadequate myocardial perfusion. By doing so the myocardium again matches its metabolic demand to the decreased supply, and thus preserves its viability and prevents irreversible injury [1]. Although the concept of hibernating myocardium has an important clinical impact, its underlying pathophysiological mechanisms are largely unknown. Because of the absence of appropriate animal models, current knowledge of chronic hibernating myocardium in man is mainly based on the results of clinical studies, and has lead to two major controversies. The first controversy relates to whether the functional abnormalities are a result of chronically reduced myocardial perfusion on the one hand or of repetitive episodes of acute ischemia despite normal resting perfusion on the other, i.e. whether or not chronic hibernation actually represents chronic repetitive stunning. The second controversy results from the finding of complex structural changes, both cellular and extracellular, in the human hibernating myocardium. Given the severity of these structural changes, it is likely that these changes affect contractile function. It is however not clear whether or not these structural changes are adaptive (and thus reversible). Some observations suggest that they represent the first stage of a degenerative pathway, leading to irreversible damage [2]. In this overview, the most important recent findings regarding these two controversies, will be briefly focussed.

\subsection{Histopathology of chronic hibernating myocardium}

Several structural abnormalities can be found in transmural needle biopsies from chronic hibernating myocardium, taken during coronary bypass surgery. Concerning cellular changes, perinuclear sarcomere depletion is found in a substantial number of cardiomyocytes, which however do not become atrophic, but instead increase their volume by accumulating glycogen in the sarcomere-depleted perinuclear areas. These cells also display numerous small and 
abnormally shaped mitochondria, nuclei with homogeneously dispersed heterochromatin, and loose their well organized sarcoplansic reticular system [3]. These changes make that such cardiomyocytes adopt features that resemble the fetal phenotype, and suggest that cellular dedifferentiation has taken place. This has been confirmed by the finding of an embryonicl fetal expression pattern of several proteins, like titin, desmin, cardiotin and the re-expression of $\alpha$-smooth muscle actin in these cardiomyocytes [4]. It has been suggested that this process of dedifferentiation represents a kind of programmed cell survival: the cells are transformed from an energy consuming active contractile phenotype to an energy saving acontractile phenotype [5]. Indeed, an increased tolerance of dedifferentiated cells to acute ischemia with preservation of mitochondrial oxidative phosphorylation has been shown [6]. Moreover, the role of glycogen storage could have a similar role as in cardiomyocytes during cardiac development, where it was suggested that glycogen storage plays a crucial role in maintaining a certain degree of turgor, necessary for cell survival [7].

It is likely, although not proven, that these structural changes are reversible. This is suggested by the reversible nature of contractile dysfunction. Because the structural changes are unlikely to be immediately reversible, it is hypothesized that the delay in recovery of function is at least partly attributable to these structural abnormalities $[8,9]$. However, it must be stressed that both the contribution of the structural changes to the functional abnormalities, and the contribution of the hypothesized reversibility of these changes to the recovery of function remain to be settled. Although it is possible that the functional abnormalities are independent from the structural changes, the recent finding that the rate of functional recovery correlates with the percentage of structurally altered cardiomyocytes, strongly favors such a relationship [9].

The trigger for cardiomyocyte dedifferentiation is unknown. Although dedifferentiated cardiomyocytes are consistently found in biopsies from patients with chronic reversible LV dysfunction, it is not a unique feature of chronic hibernating myocardium. Indeed, the same cellular changes are found in several other cardiomyopathies, like volume and pressure overload [10], chronic atrial fibrillation in humans [11] and goats [12], in infarct border zones |13|, and in explanted failing hearts [14]. A common denominator in both chronic hibernation and several of these other cardiomyopathies in which cardiomyocyte dedifferentiation is found, is an increased dillatation of the LV or atrial wall. It is therefore suggested that (moderate) cellular stretch might be involved in triggering cardiomyocyte dedifferentiation. Hibernation-like dedifferentiation characteristics are found in cultured adult rabbit cardiomyocytes undergoing transient and repetitive stretch [15]. These findings suggest at least that a decreased oxygen availability is not per se necessary for triggering dedifferentiation. That increased preloadinduced stretch may play a role in the induction of the histopathological changes is also suggested 
in a pig model of chronic hibernating myocardium, in which cardiomyocyte dedifferentiation was not only found in the regions with reduced perfusion, but to a similar extent in the remote areas [16]. Conversely, an acute disassembly of myofibrils - possibly preceding the myolysis accompanying dedifferentiation - was found in both the ischemic and normally perfused remote areas in a model of prolonged partial coronary artery occlusion in chronically instrumented dogs [17].

Apart from myolysis a possible alternative explanation for the contractille dysfunction was suggested in a recent investigation of Shan et al. [18], reporting that a changed adrenoreceptor density in hibernating myocardium might also be involved in the mechanism of the depressed myocardial function. "They found that in patients with hibernating myocardium an increase in density of $\alpha$-adrenergic receptor and a decreased $\beta$-adrenergic receptor density could be detected in viable segments. Although, as it is the case for cellular changes, a cause/effect relation is not proven. Nevertheless this finding is important in unraveling the pathophysiology of chronic hibernation, and deserwes further attention. Another relevant obserwation made in chronic hibernating myocardium in patients, which might explain the initiation and the maintainance of the contractile dysfunction, concerns the altered cell-cell interaction through defective gap junctions [19].

Apart from cellular changes, also extracellular alterations are present in chronic hibernating myocardium. Even in carefully selected patients, excluding the ones with prior myocardial infarction, an increase in interstitial fibrosis can be found [20]. Without other patient selection criteria, however, the amount of interstitial fibrosis varies enormously, suggesting that in many patients (micro-)infarctions co-exist with hibernating segments [21]. It was found that the contractile reserve and the function after reperfusion are inversely correlated with the amount of fibrosis $[22,23]$. Nagueh et al. $[23]$ found that viable segments (identified by dobutamine echocardiography) which recovered function after coronary bypass surgery - thus truly

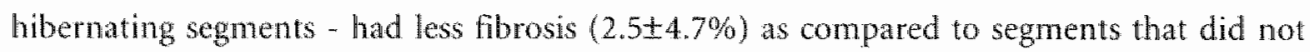
recover $(10.3 \pm 8.4 \%)$. The amount of fibrosis in the truly hibernating segments corresponds with earlier findings in meticulously selected patients [3]. The finding of increased amounts of fibrosis together with an incomplete recovery of function in such patients is suggestive for the occurrence of replacement fibrosis due to myocyte loss. "Therefore, a causal relationship between cardiomyocyte dedifferentiation and apoptosis has been suggested by some investigators, thereby considering dedifferentiation as a kind of pro-apoptotic state [2, 21]. However, it cannot be excluded that hibernation-like adaptational changes occur in the surviving border zone of infarcts, so that in some patients hibernation is the consequence rather than the cause of increased fibrosis. In favor of this hypothesis is the experimental finding that dedifferentiating cardiomyocytes appear in border zones of micro-embolization induced micro- 
infarctions $[13,24]$. This might explain also the occurrence of cardionyocyte cell death through apoptosis in porcine models of prolonged acute ischemia, in which also significant necrosis was present. Indeed, apoptosis is known to contribute to both acute and subacute cell death in infarctions. The latter models may be the experimental equivalent of patients with hibernating myocardium in which high levels of fibrosis and ultrastructural evidence of apoptosis were found [21]. Nevertheless, in pigs with chronically decreased coronary flow reserve, which show physiological features of hibernating myocardium without necrosis, an increase in subendocardial apoptosis was found, next to a minimal increase in connective tissue [25]. Interestingly, cardiomyocyte dedifferentiation and apoptosis were found in both areas with decreased coronary reserve as well as normally perfused remote areas, although to a lessen: extent in the latter. In patients in which myocardial infarction was meticulously excluded, only a minumal increase of connective tissue and no evidence of cardiomyocyte apoptosis was found [26]. These findings suggest that there is no causal relationship between cardiomyocyte dedifferentiation and apoptosis, but instead, that apoptosis is a temporal phenomenon occuring only at a certain stage in the development of hibernating myocardium. lit can be hypothesized that at an early stage of progression of the abnormalities in function or perfusion, only part of the cell population is capable to adopt a protective phenotype, while the other part dies through apoptosis. In favor of this hypothesis are the recent findings that in the aforementioned porcine model the percentages of apoptosis peaked at 3 months after induction of the decreased coronary reserve [27] and that in infarct border zones dedifferentiated and apoptotic cardiomyocytes presumably belong to different cell populations [28]. This hypothesis would also be in line with the suggestion that cardiomyocyte dedifferentiation might even represent a form of programmed cell survival [29]. Apart from the findings that dedifferentiated cardionyocytes are more ischemia tolerant than normally structured counterparts $[6]$, its has recently been shown that endogenous protective mechanisms, like the increased expression of the stress protein HSP-70, are induced in cardiomyocytes in an experimental model of chronic hibernation [30]. Moreover, in pigs with hibernating myocardium, adenosine triphosphate and creatine phosphate levels were similar in dysfunctional and remote areas $|3| 1$. Undoubtedly, the development of reproducible animal models for chronic hibernating myocardium without confounding necrosis, is of crucial importance to further unrawel these issues, and might provide us with a clear insight into the role of cardiomyocyte dedifferentiation and apoptosis in hibernating myocardium. 


\subsection{Flow in chronic hibernating myocardium}

In its original definition, chronic hibernating myocardium was described as being characterized by a chronic and severe resting myocardial blood flow. However, unlike the situation in acute ischemia where there is a close coupling between regional myocardial function and subendocardial blood flow, several studies have indicated that in the case of chronic hibernation, the decrease in blood flow is not as severe or permanent as originally thought $(32,33)$. Using quantitative positron emission tomography (PET), most of the recent studies (reviewed in [34]) suggest either a normal or only moderately decreased blood flow in the dysfunctional regions. This would implicate that chronic repetitive ischemia and subsequent overlapping periods of stunning are at the basis of hibernating myocardium. It can however be criticized that in patient studies only relative differences in flow are evaluated, i.e. that in the same patient the flow in the dysfunctional areas is compared to the flow in remote nondysfunctional regions in which an increased flow (according to the increased compensatory function) could be present. However quantitative analysis of flow in the nondysfunctional areas in patients with the flow in normal volunteers resulted in similar values [33]. Whereas transmural differences in histological changes have consistently been demonstrated, the presence of transmural differences in blood flow, although expected, is not shown by PET because of the limited spatial resolution of this imaging technique. Observations in an experimental model of hibernating myocardium have indeed suggested the existence of such a transmural difference, the decrease in blood flow being most pronounced in the subendocardial layers [35]. Based on these and clinical studies, it is likely that chronic reversible dysfunctional myocardium can be the consequence of both sustained and repetitive underperfusion. Shen and Vatner [36] showed that chronic stumning can be at the basis of chronic dysfunctional myocardium in an experimental model where necrosis is absent and histologically identified hibernating myocardium present. In the dysfunctional regions, base-line blood flow was normal, and multiple episodes of demand ischemia during excitement and subsequent stunning were observed. The effect of repetitive stunning was cumulative, resulting in continuously dysfunctional myocardium. Using a reproducible model of chronic coronary stenosis resulting in viable chronically dysfunctional. myocardium, Fallavolita et al. 135 ) have proposed that chronic stunning and chronic hibernation form a continum. Initially, repetitive ischemia caused chronic stunning, while resting blood flow in these dysfunctional regions was normal. This situation lasted for up to two months, but after three months, the blood flow at rest is reduced in the dysfunctional areas, leading to the physiologic findings of hibernating myocardium. The transition from stunning to hibernation seemed to occur at the time of a critical reduction in the coronary flow reserve caused by a progressive increase in stenosis severity. Moreover, it has been shown recently that an accelerated progression from stumning to hibernation can be induced in less than two 
weeks - when without an initial reduction in resting perfusion - an acute critical reduction in coronary flow reserve is produced [27]. Based on clinical data and the findings from experimental animal models, it is clear that viable chronically dysfunctional myocardium in patients can represent chronic stunning, chronic hibernation or a combination of both. Possibly a correlation exists between the underlying mechanism (stunning or hibernation), the degree of dysfunction, the degree of histological change, and the time frame of recovery of function after revascularization. Further research using reproducible animal models of viable chronically dysfunctional myocardium will have to elucidate this issue.

\subsection{Conclusion}

Based on the currently available clinical and experimental data it is obvious that viable chronically dysfunctional myocardium is likely to be caused by different pathophysiological mechanisms, and moreover is often confounded by the presence of irreversibly damaged tissue, from which it not clear whether it occurs as a consequence of chronic dysfunction, or whether it is a preceding or even unrelated event. This makes a proper interpretation of the data difficult. Fortunately, several reproducible animal models are emerging, which will definitely contribute to a more adequate understanding and interpretation of its clinical counterpart.

\subsection{References}

1) Rahimtoola SH. The hibernating myocardium. Am.Heart J. 1989;117:211-221.

2] Schwarz ER, Schaper J, vom DJ Altehoefer $C_{k}$ Grohmann B, Schoendube F et al, Myocyte degeneration and cell death in hibernating human myocardium. I Am Coll Cardiol 1996;27:1577. 1585.

3] Borgers $M$, Thoné F, Wouters L., Ausma J, Shivalkar B, Flameng W. Structural correlates of regional myocardial dysfunction in patients with critical coronary artery stenosis: chronic hibernation? Cardiovasc Pathol 1993; 2:237-245.

Ausma J, Schaart G, Thoné F, Shivalkar B, Flameng W, Depré Cet al. Chronic ischemic viable myocardium in man: aspects of dedifferentiation. Cardiovasc Pathol 1995:4:24:37.

Depre Cand Taegtmeyer H. Metabolic aspects of programmed cell survival and cell death in the heart. Cardiovase Res 2000; 45;538-548. 

Dedifferentiated cardionyocytes from chronic hibernating myocardium are ischemia-tolerant. Mol Cell Biochem 1998; 186:159-168.

7) Knaapen MW, Vrolifk BC, Wenink AC. Ultrastructural changes of the myocardium in the embryonic rat heart. Anat Rec 1997; 248:233- 241.

8] Maes $A$, Flameng W, Nuyts I, Borgers $M$, Shivalkar $B$, Ausma J et al. Histological alterations in. chronically hypoperfused myocardium. Correlation with PET findings. Circulation 1.99:; 90:735745 .

9] Vanoverschelde IL, Depre C, Gerber BL, Borgers M, Wijns W, Robert A et al. Time course of functional recovery after coronary artery bypass graft surgery in patients with chronic left ventricular ischemic dysfunction. Am J Cardiol 2000; 85:1432-1439.

10) Dispersyn GD, Donker DW, Volders PGA, Ausma J, Vos MA, Borgers M. Aspects of cardionyocyte dedifferentiation accompany biventricular hypertrophy in dogs with chronic AV block. Eurospace 2000; 1 (Suppli):B23 (Abstract).

11) Thijssen VL, Ausma J, Liu GS, Allessic MA, van Eys GI, Borgers M. Structural changes of atrial myocardium during chronic atrial fibrillation. Cardiovasc Pathol 2000; 9:17-28.

1.2] Ausma J, Wijffels $M$, van Eys $G$, Koide M, Ramaekers F, Allessie $M$ et al. Dedifferentiation of atrial cardiomyocytes as a result of chronic atrial fibrillation. Am J Pathol 1997; 151:985-997.

13] Sharow VG, Sabbah $H N_{\text {, }}$, Shimoyama $H$, Goussev AV, Lesch M, Goldstein S. Evidence of cardiocyte apoptosis in myocardium of dogs with chronic heart failure. Am J Pathol 1996; 148:141-149.

14) Miserez M. Characteristics of contractile dysfunction in human theart failure. Acta Biomedica Lowaniensis 1994. (PhD Thesis) Leuven University Press.

15. Dispersyn GD, Geuens E, Ver Donck L, Ramaekers FCS, Borgers M. An in vitro model for dedifferentiation ss in hibernating myocardium. J Mol Cell Cardiol 2000;32:A18 (Abstract).

16. Canty IM, Jr., Borgers M, Fallawollita IA, Thomas SA. Myolysis in hibernating myocardium is global and dissociated from regional reductions in coronary flow and SR protein level. Circulation 2000; 102: 11-136 (Abstract).

17) Sherman AJ, Klocke FI, Decker RS, Decker ML, Kozlowski KA, Harris KR et all. Myofibrillar disruption in hypocontractile myocardium showing perfusion-contraction matches and mismatches. Am. J.Pbysiol Heart Circ Physiol 2000; 278:-H1320-H1334.

181 Shan $K_{*}$ Bick RI, Poindexter BI, Nagueh SF, Shimoni S, Verani MS et al. Altered adrenergic receptor density in myocardial hibernation in humans: A possible mechanism of depressed myocardial function. Circulation 2000; 102:2599-2606. 
19] Kaprielian RR, Gunning M, Dupont E, Sheppard MN, Rothery SM, Underwood R et al.. Downregulation of immunodetectable connexin 3 and decreased gap junction size in the pathogenesis of chronic hibernation in the human left ventricle. Circulation 1998; 97:651-660.

20] Ausma J, Cleutjens J, Thone F, Flameng W, Ramaekers F, Borgers M. Chronic hibernating myocardium: interstitial changes. Mol Cell Biochem 1995; 147:35-42.

21] Elsässer A, Schlepper M, Klowekorn WP, Cai WJ, Zimmermann R, Muller KD et al. Hibernating myocardium: an incomplete adaptation to ischemia. Circulation 1997; 96:2920-2931.

22] Chen $\mathrm{C}$, Liu J, Hua D, Ma L, Lai T, Fallon JT et al. Impact of delayed reperfusion of myocardial hibernation on myocardial ultrastructure and function and their recoveries after reperfusion in a pig model of myocardial hibernation. Cardiovasc Pathol 2000;9:67-84.

23] Nagueh SF, Mikati I, Weilbaecher D, Reardon MI, AI Zaghrimi GI, Cacela D et al. Relation of the contractile reserve of hibernating myocardium to myocardial structure in humans, Circulation $1909 ; 100: 490-496$.

24] Mesotten L, Dispersyn GD, Maes A, Zietkiewicz M, Nuyts J, Bormans G et al. PET reversed mismatch in an experimental model of subacute myocardial infarction. Eur I Nucl Med 2001, in press.

25] Lim H, Fallavollita JA, Hard R, Kerr CW, Canty JM, Jr. Profound apoptosis-mediated regional myocyte loss and compensatory hypertrophy in pigs with hibernating nnyocardium. Circulation $1999 ; 100: 2380-2386$.

26) Dispersyn GD, Ausma I, Thone F, Flameng W, vanoverschelde IL, Allessie MA et al. Cardiomyocyte remodelling during myocardial hibernation and atrial fibrillation: prelude to apoptosis? Cardiovasc. Res. 1999; 43:947-957.

27] Canty IM, Jr. and Fallavollita JA. Chronic hibernation and chronic sumnings a continumm. INucl. Cardiol 2000; 7.509-527.

28] Dispersyn GD, Mesotten L, Mortelmans L, Flameng W, Borgers M. Dissociation of cardiomyocyl apoptosis and cardiomyocyte dedifferentiation in infaret border zones. Circulation 2000; 102: 11343 (Abstract).

29] Dispersyn GD and Borgers M. Apoptosis in the heart: About programmed cell death and surwivat. News Physiol. Sci. $2001 ; 16: 41-47$.

301 Fallawollita JA, Jacob S, Young RF, Canty IM, Ir. Regional alterations in SR Ca(2+)-ATPase, phospholamban, and HSP-70 expression in chronic hibernating myocardium. Am I Plysiol 1999 ; 277:H 1418-H1428. 
31) McFalls EO, Baldwin D, Palmer B, Marx D, Jaimes D, Ward HB. Regional glucose uptake within. hypoperfused swine myocardium as measured by positron emission tomography. Am J Physiol $1997 ; 272: 1343-4349$.

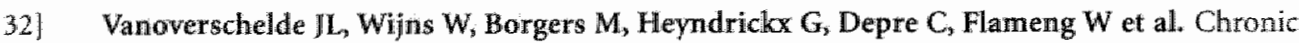
myocardial hibernation in humans. From bedside to bench. Circulation 1997; 95:1961-1971.

33] Camici PG, Wijns W, Borgers $M$, De Silva R, Ferrari $R_{,}$Knutili / et al. Pathophysiological mechanisms of chronic rewersible left ventricular dysfunction due to coronary artery disease (hibernating myocardium). Circulation 1997; 96:3205-3214.

34) Canty $\mathbf{M M}, \mathbf{J r}$. and Fallavollita JA. Resting myocardial flow in hibernating myocardiun: validating animal models of human pathophysiology. Am J' Physiol 1999; 277:H-14:17-H422.

35] Fallavollita JA, Perry BJ, Canty JM, Jr. 18F-2-deoxyglucose deposition and regional flow in pigs with chronically dysfunctional myocardium. Evidence for transmural variations in chronic hibernating myoardium. Circulation 1997; 95:1900-1909.

36. Shen YT and Vatner SF. Mechanism of impaired myocardial function during progressive coronary stenosis in conscious pigs. Hibernation versus stuming? Circ Res 1995; 76:479-488. 
The background of this thesis subject is given in chapter 1 . Chronic hibernating myocardium is an important clinical entity, characterized by dysfunctional, but viable left ventricular myocardium in the setting of coronary heart disease. It is believed that the reduced function represents a protective response of the myocardium to cope with the chronically or repetively reduced coronary blood flow, thereby matching again the metabollic demand of the heant to the decreased supply. The 'golden standard' to indentify hibernating regions in the heart is positron emission tomography (PET), using radiolabeled ammonia and fluorodeoxyglucose as blood tracer and gitucose analog respectively. Regions with a decreased blood flow compared to the glucose utilization - a so called fow-metabolic "mismatch'- are characteristic for" hibernating myocardium. After revascularization of these regions, for example by coronary bypass surgery, the dysfunctional hibernating myocardium recovers its function, however this functional recovery may take months to a year, and is often incomplete. It has been shown that the hibernating myocardium undergoes profound structurial changes, both cellular and extracellular. It is however unknown whether these changes are adaptive, and thus reversible, or maladaptive, i.e degenerative. Some observations suggest that the cellular changes represent dedifferentiation, potentially reversible, while others daim that degenerative changes (cell death through apoptosis) are an inherent part of the structural changes. It was the aim of this study to gain more insight into the histopathological changes accompanying chronic hibernation. Both animal and cellular models might help identifying a possible relation between cardiomyocyte dedifferentiation and degeneration. 
In chapter 2 , it was investigated whether or not apoptosis is present in myocardial biopsies from patients with hibernating myocardium and in biopsies from goats with chronic atrial fibrillation. It was previously shown that in this animal model similar structural changes occur, characteristic for cardiomyocyte dedifferentiation, as seen in human hibernating nyocardium. Light- and electron microscopy, terminal deoxynucleotidyl transferase nick-end labeling (TUNEL), and immunohistochemical detection of apoptosis / cell damage related proteins were used to assess the existence of apoptosis. Only cardiomyocyte dedifferentiation but no evidence for cell degeneration through apoptosis was found. It was concluded that, unlike the conclusion of some other studies, apoptosis is not present or only to a very low extent in dedifferentiated myocardium. Moreover, cardiomyocyte dedifferentiation might even represent a stereotypic respons of the heart to unfavorable circumstances such as a relatively decreased oxygen availability, an increased wall stress, or both.

More evidence that cardiomyocyte dedifferentiation might represent an adaptational feature comes from the study in chapter 3. Using ultrastructural calcium localization, it was shown that after an initial calcium overload after the onset of chronic atrial fibrillation, dedifferentiating cardiomyocytes are able to adapt to a new calcium homeostasis after some weeks. This study dearly indicates that dedifferentiated cardiomyocytes are protected against calcium overload, a known trigger for apoptosis. It is noteworthy that the regression of the initial calcium overload after the onset of atrial fibrillation coincides with the structural dedifferentiation, however a cause effect relationship is unknown. Nevertheless, using the same techniques for ultrastructural calcium localization, it was also previously shown that dedifferentiated cardiomyocytes from human chronic hibernating myocardium are not overloaded with calcium, supporting the hypothesis that dedifferentiation of cardiomyocytes is an effective protective mechanism rendering the cells more resistant to intracellu lar calcium overload after for example an ischemic insult.

Cardiomyocyte dedifferentiation is not anique feature of chronic hibernating myocardium and chronic atrial fibrillation. It was previously shown that aspects of cardiomyocyte dedifferentiation can be found in regions surrounding infarcted myocardial tissue. This was confirmed by the study in chapter 4. Using intracoronary microinjection of marcobeads in sheep, microinfarctions were induced in the left ventricle, resulting in a persistently decreased blood flow and global and regional function as detected with PET and serial echocardiography respectively. Interestingly, at 6 weeks after embolization, ghucose uptake was more decreased compared to the blood flow, resulting is a flow-metabolic 'reversed mismatch" Thereafter, at 16 weeks, glucose metabolism had significantly recovered, and again matched to the blood flow. 
Light-and electron microscopy confirmed the existence of microinfarcted tissue in these regions and, both at 6 and 16 weeks, evidence of cardionyocyte dedifferentiation was found in the regions surrounding the microinfarcted tissue. Those cells were dearly non-ischemic as shown ultrastructurally by the presence of intramatricial osmophilic granules in the mitochondria. This finding is indicative that dedifferentiated cardiomyocytes adapted themselves to the likely presence of an altered mechanicall load or chronic/repetitive underperfusion in those periinfarct regions. Furthermore, it can be hypothesized that the presence of significant microinfarcted areas obscures of the PET mismatch pattern, typical for hibernating myocardium.

Because it was previously shown that cardiomyocyte apoptosis is present in peri-infarct regions - areas in which allso cardiomyocyte dedifferentiation can be found - the animal model presented in chapter 4 , represents a suitable model to investigate whether or not a relationship exists between cardiomyocyte dedifferentiation and apoptosis. This study is presented in chapter 5 . First of all, the cellular changes in the peri-infarct regions were further investigated for their similarity with cardiomyocyte dedifferentiation in chronic hibernating myocardium. It was indeed shown that the changes in the expression pattern of titin, desmin, cardiotin and $\alpha$-smooth muscle actin in this animal model are similar to those found in biopsies from patients with chronic hibernating myocardium and from goats with chronic atrial fibrillation. The existence of cardiomyocyte apoptosis was confirmed by the use of the TUNEL method and the immunohistochemical detection of activated caspase-3. Unlike cardiomyocyte dedifferentiation, cardiomyocyte apoptosis was found in both regions surrounding the microinfarctions and in remote, non-embolized regions, although to a lesser extent in the latter. TUNEL positive nuclei, suggestive for apoptosis were, not found in cells with morphological distinctive dedifferentiation, i.e. in cells showing perinuclear myolysis. To further investigate the co-occurrence of cardiomyocyte dedifferentiation and apoptosis, detection of re-expression of the fetal protein $\alpha$-smooth muscle actin, was combined with the "TUNEL. method. It was found that none of the $\alpha$-smooth muscle actin positive cardiomyocytes were TUNEL positive and vice versa. These findings are suggestive that dedifferentiated cardiomyocytes and those that undergo apoptosis represent two different cell populations. This finding together with the discrepancy between the amount of dedifferentiated cardiomyocytes and apoptotic ones, suggest that dedifferentiation does not lead to apoptosis per se. It is hypothesized that cardiomyocytes which succesfully adopt the dedifferentiation state survive, while others die through apoptosis. 
It is currently unclear which trigger(s) causes cardiomyocytes to dedifferentiate. Hibernation like dedifferentiation in wivo is characterized by specific morphological changes, but to investigate more in detail putative triggers for these cellular changes, it is obvious that an in vitro model of isolated cells would be helpful in unraveling this enigma. In chapter 6 such an in witro model is presented. We found that by co-culturing adult rabbit cardiomyocytes with fibroblasts, cardiomyocyte dedifferentiation mimicking the morphological features of in wivo dedifferentiation could be induced. However, no dedifferentiation could be seen when fibroblast growth was inhibited. Cardiomyocyte dedifferentiation was characterized by cell spreading. Electron microscopy and immunocytochemistry showed that the main features of in vivo dedifferentiation could be found in those cells: sarcomere depletion, heterochromatin redistribution, abnormally shaped but healthy mitochondria, and the fetal expression patterns of titin, desmin, cardiotin and $\alpha$-smooth muscle actin. Moreover, the sequence of changes in the expression pattern of those structural proteins was simular to that observed in the goat model of chronic atrial fibrillation, and the reverse sequence of normal cardiomyocyte differentiation. The major differences between in wivo dedifferentiation and the presented in vitro model are the absence of a prominent glycogen accumulation and the topography of myolysis. Possibly different biochemical and/or structural environment might account for those differences. Dedifferentiation was only seen in cardiomyocytes in close contact with fibroblasts and could not be induced by fibroblast conditioned medium or by culturing the cardiomyocytes in petri dishes with fibroblasts grown on cell inserts. Therefore it was hypothesized that fibroblast secreted factors are not solely responsible for the dedifferentiation. Moreover, this in vitro model indicates that the development of most of the characteristics of in vivo dedifferentiation do not rely on a reduced oxygen environment.

The nature of the fibroblast-cardiomyocyte interaction was further investigated in chapter 7 . Using time-apse video microscopy we were able to show that this interaction is very dynamic. Fibroblasts "travel' through the petri dish seeking contact with other cells. Upon contact with a cardiomyocyte they attach firmly and pull this cell, resulting in anisotropic stretch. This pulling lasts for circa five to seven hours in duration, and was consistently followed by features of dedifferentiation. The nature of the cell-cell contact was investigated using immunocytochemical analysis of different proteins inwolved in cell adhesion, and of intercellular communication using Dil and calcein-AM prelabeling of fibroblasts. It was indeed shown that intercellular communication exists between fibroblasts and cardiomyocytes, which could not be inhibited by blocking gap-junctional communication. The dynamic passive stretch and the intercellular communication play an important role in the induction of the structural dedifferentiation. 
In conclusion, data in this thesis supports the hypothesis that cardiomyocyte dedifferentiation does not represent a stage on the degenerative pathway of programmed cell death (apoptosis), but in stead can be considered as an adaptive respons to survive under unfavorable circumstances, and hence may be considered as a form of programmed cell survival. Both animal models of in vivo cardiomyocyte dedifferentiation as well as the in vitro model might provide a basis for further research to elucidate more this fascinating stereotypic cellular behaviour. 


\section{Samenvatting}

De achtergrond van het thesisonderwerp staat beschreven in hoofdstuk 1. Chronische myocardiale hibernatie is een belangrijke klinische entiteit, gekarakteriseerd door slecht functionerend, maar leefbaar hartspierweefsel in de linker hartkamer, zoals dit kan voorkomen bij patiënten met coronair lijden. Er wordt aangenomen dat de verminderde functie van het myocard een protectieve reactie is van het hart om een chronische of repetitieve daling van de coronaire bloedtoevoer het hoofd te kunnen bieden, en aldus de balans te herstellen tussen de metabole vraag van het hart en het verminderde aanbod. De 'gouden standaard' ter identificatie van hibernerende regio's in het hart is positron emissie tomografie (PET), waarbij radioactief gemerkte ammonia en fluorodeoxyglucose worden gebruikt als respectievelijk bloed merker en glucose analoog. Het voorkomen van regio's waarin de bloedtoevoer lager is relatief t.o.v. de glucose opname - met een zogenaamde flow-metabolische 'mismatch'- is cen indicatie voor hibernerend myocard. Na revascularisatie van deze gebieden, door bijvoorbeeld coronaire overbruggingschirurgie, zal een herstel plaatsvinden van de verminderde functie. Nochtans, dit herstel kan enkele maanden tot een jaar duren en is vaak onvolledig. Onderzock heeft aangetoond dat hibernerend myocard uitgebreide structurele veranderingen ondergaat, en dit zowel intracellulair als extracellulair. Het is echter onbekend of deze veranderingen adaptief en omkeerbaar zijn, dan wel maladaptief en dus degeneratief. Sommige observaties hebben geleid tot de hypothese dat de cellulaire veranderingen kenmerkend zijn voor dedifferentiatie van de hartspiercellen, en dus potentieel omkeerbaar. Andere bevindingen suggereerden dat degeneratieve veranderingen (celdood door apoptose) deel uitmaken van het proces. Het was dan ook het doel van deze thesis om meer inzicht te verkrijgen in de histopathologische veranderingen die voorkomen in het chronisch hibernerende myocard. Zowel proefdiermodellen als cellulaire modellen kunnen behulpzaam zijn bij het opsporen van een eventuele relatie tussen hartspiercel dedifferentiatie en degeneratie. 
In hoofdstuk 2 werd onderzocht of apoptose voorkomt in hartbiopten van patienten met chronisch hibernerend myocard en van geiten met chronische atriale fibrillatie. Er werd eerder aangetoond dat in dit proefdiermodel gelijkaardige structurele veranderingen als in humaan hibernerend myocard voorkomen. Ex werd gebruik gemaakt van licht en elektronenmicroscopie en immunohistochemische detectie van apoptose / cel schade gerelateerde proteinen om het bestaan wan apoptose aan te tonen. Enkel aspecten wan hartspiercel dedifferentiatie, maar geen bewizen voor het voorkomen van hartspiercel degeneratie werden gevonden. Er werd geconchudeerd dat, in tegenstelling tot de besluiten van andere studies, apoptose niet of nauwelijks voorkomt in gededifferentieerd nyocard. Het tegendeel zou zelfs mogelijk zijn, met name dat hartspiercel dedifferentiatie een stereotiepe "overlevings-respons" is van het hart ten overstaan van ongunstige omstandigheden, zoals een daling in de beschikbaarheid van zuurstof, een verhoogde mechanische stress, of beiden.

Een bijkomend argument voor hartspiercel dedifferentiatie als adaptieve respons is gegeven in hoofdstuk 3. Door middel van ultrastructurele calcium lokalisatie werd aangetoond dat dedifferentiërende bartspiercellen, na een initiële calcium overbelasting bij het begin van atriale fibrillatie, na enkele weken een nieuwe calcium homeostase verwerven. De studie toonde duidelijk aan dat gededifferentieerde hartspiercellen beschermd zijn tegen een calcium overbelasting, dewelke een bekende oorzakelijke factor is voor apoptose. Opvallend is dat de overgang nar de nieuwe homeostase samenvalt met het begin van de structurele dedifferentiatie. Een oorzaak-gewolg verband is echter nog onduidelijk. Met dezelfde technieken voor het onderzoeken van ultrastructurele calcium lokalisatie werd eerder angetoond dat gededifferentieerde hartspiercellen wan humaan hibernerend myocard eveneens niet overbelast zijn met calcium, zodat dit de hypothese ondersteunt dat dedifferentiatie van hartspiercellen een protectieve reactie is die de cellen meer resistent makt tegen een intracellulaire calcium overbelasting bij een ischemisch insult.

Hartspiercel dedifferentiatie komt niet alleen voor bij chronische hibernerend myocard en chronische atriale fibrillatie, maar kan o.a. ook gevonden worden in de regio's rond een hartinfarct. Dit werd bevestigd door de bevindingen in hoofdstuk 4. Door gebruik te maken van intracoronaire microinjectie van zogenaamde 'macrobeads' werden micro-infarcten geünduceerd in het linker ventrikel bij schapen. Een persisterende daling in bloedtoevoer en van globale en regionale hartspierfunctie werden geobserveerd met respectievelijk PET en met seriele echocardiografie. Echter, 6 weken na embolisatie was de ghucose opname sterker gedaald in vergelijking met de bloed toevoer, wat resulteerde in een zogenaamde 'omgekeerde mismatch* Nadien, 16 weken ma embolisatie, bleek de glucose opname terug gestegen te zijn en in balans 
met de gedaalde bloedtoevoer. Licht- en elektronenmicroscopisch onderzoek bevestigde het bestaan van microinfarcten in de geëmboliseerde regio, en het voorkomen van gededifferentieerde hartspiercellen in de omliggende gebieden. Deze cellen waren duidelijk niet ischemisch, zoals kon afgeleid worden uit het voorkomen van intramatriciële osmofiele granules in mitochondria. Deze bevinding vormt een bijkomend argument waaruit blijkt dat gededifferentieerde hartspiercellen zich aanpassen aan veranderde omgevingsfactoren in periinfarct gebieden zoals verhoogde mechanische stress en chronisch / repetitief gedaalde bloedtoevoer. Micro-infarcten zijn vermoedelijk verantwoordelijk voor de afwezigheid van een PET' 'mismatch', het typische kenmerk van hibernerend myocard.

Vermits het eerder was aangetoond dat hartspiercel apoptose plaatsvindt in peri-infarct gebieden - regio's waar ook hartspiercel dedifferentiatie kan gevonden worden - is het proefdiermodel uit hoofdstuk 4 geschikt voor onderzoek naar het bestaan van een verband tussen hartspiercel dedifferentiatie en apoptose. Dit werk is gepresenteerd in hoofdstuk 5 . In eerste instantie werd onderzocht in hoeverre de cellulaire veranderingen in de peri-infarct gebieden overeenkomen met hartspiercel dedifferentiatie in chronisch hibernerend myocard. Gelijkaardige veranderingen in de expressiepatronen van titine, desmine, cardiotine en $\alpha$-glad spiercel actine zoals in chronisch hibernerend myocard en chronische atriale fibrillatie, werden inderdaad ook teruggevonden in de gededifferentieerde cellen van peri-infarct regio's. Het voorkomen van hartspiercel apoptose werd aangetoond aan de hand van TUNEL en de immunohistochemische detectie van geactiveerd caspase-3. In tegenstelling tot de dedifferentiatie van thartspiercellen, werd apoptose waargenomen in zowel de peri-infaret gebieden, als in niet-geëmboliseerde regio's, hoewel in mindere mate in deze laatstgenoemde. TUNEL positieve kernen, suggestief voor apoptose, werden niet gevonden in gededifferentieerde hartspiercellen herkend op basis van peri-nucleaire myolyse. Om verder te onderzoeken of apoptose voorkomt in gededifferentieerde hartspiercellen, werd de cletectie van de re-expressie van het foetale $\alpha$-glad spiercel actine gecombineerd met TUNEL. Er werd gevonden dat $\alpha$ glad spiercel actine positieve hartspiercellen TUNEL negatief waren en omgekeerd. De bevindingen zijn een indicatie dat gededifferentieerde hartspiercellen en deze die apoptose ondergaan twee verschillende celpopulaties zijn. Deze vaststelling en het verschil in het aantal gededifferentieerde en apoptotische hartspiercellen suggereert dat dedifferentiatie niet per se leidt tot apoptose. Een mogelijke hypothese is dat hartspiercellen die er in slagen te dedifferentiëren kunnen overleven, terwijl de anderen afsterven door apoptose.

De factoren die dedifferentiatie van hartspiercellen veroorzaken zijn grotendeels onbekend. Hibernatie-achtige dedifferentiatie in vivo wordt gekarakteriseerd door specifieke mor fologische 
veranderingen. Het is echter duidelijk dat om de mogelijke oorzaken voor deze cellulaire veranderingen te kunnen identificeren, een in vitro model van geïsoleerde hartspiercellen behulpzaam zou zijn. In hoofdstuk 6 wordt zulk een model gepresenteerd. Door hartspiercellen van adulte konijnen samen met cardiale fibroblasten in cultuur te brengen, dedifferentieerden de hartspiercellen met gelijkaardige morfologische veranderingen als deze van hartspiercel dedifferentiatie in vivo. Echter, deze dedifferentiatie vond niet plaats wanneer fibroblastgroei werd geïnhibeerd. Elektronenmicroscopie en immunocytochemie toonden aan dat de hoofdkenmerken van in vivo dedifferentiatie aanwezig zijn in deze cellen: sarcomeerdepletie, herverdeling van het heterochromatine in de kern, abnormaal gevormde maar gezonde mitochondria en de foetale expressiepatronen van titine, desmine, cardiotine en $\alpha$-glad spiercel actine. Daarenboven was de sequentie van veranderingen gelijkaardig aan deze waargenomen bij chronische atriale fibrillatie in de geit, en de omgekeerde sequentie van veranderingen bij normale hartspierceldifferentiatie. Opmerkelijke verschillen tussen de in vitro dedifferentiatie en deze bij in vivo modellen is de afwezigheid van glycogeenstapeling en een veranderd myolyse patroon. Het is mogelijk dat verschillen in biochemische en/of structurele omgevingsfactoren hiervoor verantwoordelijk zijn. Dedifferentiatie werd enkel gezien in hartspiercellen in nauw contact met fibroblasten, en kon niet geinduceerd worden door fibroblast geconditioneerd medium of door hartspiercellen te cultiveren in petri platen met 'cel-inserts' waarop fibroblasten werden gegroeid. Deze bevindingen leiden tot de hypothese dat factoren gesecreteerd door fibroblasten niet of niet alleen verantwoordelijk kunnen zijn voor de dedifferentiatie. Daarenboven suggereren ze dat de ontwikkeling van in vivo dedifferentiatie niet afhankelijk is van een gereduceerd aanbod aan zuurstof.

De aard van de fibroblast - thartspiercel interacties werd verder onderzocht in hoofdstuk 7 . Door gebruik te maken van video 'time-lapse' microscopie hebben we kunnen aantonen dat deze interacties zeer dynamisch zijn. Fibroblasten doorkruisen de petri plaat op zoek naar andere cellen. Na fysisch contact met een hartspiercel, hechten ze zich en trekken ze aan deze cellen, resulterend in een anisotrope rek. Dit trekken duurt ongeveer vijf tot zeven uur en wordt consistent gevolgd door aspecten van dedifferentiatie. De aard van de cel-cel interacties werd onderzocht door middel van immunocytochemische analyse van verschillende proteïnen betrokken in cel adhesie, en door intercellulaire communicatie te bestuderen door fibroblasten te merken met Dil en calceïne-AM. Er werd aangetoond dat er intercellulaire uitwisseling platsvindt tussen fibroblasten en hartspiercellen, die niet geïnhibeerd kon worden door gap juncties te blokkeren. De dynamische passieve rek en de intercellulaire communicatie zijn belangrijk voor het induceren van de structurele dedifferentiatie. 
Concluderend kan er gesteld worden dat de gegevens in dit proefschrift de hypothese ondersteunen dat hartspiercel dedifferentiatie niet een fase vertegenwoordigt op weg naar cel degeneratie. Integendeel, hartspiercel dedifferentiatie is een adaptieve respons die de cel toelaat te overleven onder ongunstige omstandigheden, en dus mag beschouwd worden als een worm van geprogrammeerde celoverleving. De beschreven proefdiermodellen van in wivo dedifferentiatie, en het in vitro model vormen degelijk onderzoeksmateriaal ter opheldering van dit fascinerende stereotiepe cellulaire gedrag. 
150 


\section{Dankwoord}

Het schrijwen van het dankwoord is op zich een hele klus. Zeker wanneer je, zoals ik, in de loop van het promotieonderzoek, het geluk hebt gehad om met vele boeiende personen ir contact te komen, die op een of andere wijze hebben bijgedragen tot het tot stand komen van dit werk. Voor al diegenen die ik vergeten ben: toch bedankt!

Prof. Marcel Borgers, mijn promotor, kent niet alleen het hart door en door, maar heeft ook het hart op de juiste plaats. Beste Marcel, an jou heb ik dit alles te danken. lle was voor mij de initiator en katalysator voor mijn interesse in cardiovasculair onderzock, en gaf ane de kans me hierin te ontwikkelen. Ondanks je drukke werkschema, wist je steeds tijd voor me te maken en kon je me telkens opnieuw inspireren en motiveren. Je kennis is fenomenaal on $\mathrm{k}$ ben blij dat ik daarvan een fractie kon absorberen. Bedankt, Marcel, ik hoop dat de wetenschap nog lang van jou bijdragen mag genieten.

Prof. Frans Ramaekers, was eveneens mijn promotor. Beste Frans, telkens ik in Mastricht was, werd ik steeds a angenaam werrast door je betrokkenheid en stimulerende begeleiding van mijn werk. Op het goede moment bracht je doordachte suggesties en terechte opmerkingen aan, en leerde je me de zaken eens vanuit een ander perspectief te zien. Bedankt hier woor.

Dr. Luc Ver Donck, heeft me tijdens mijn eerste jaar op Janssen Pharmaceutica op het juiste spoor gezet. Beste Luc, zonder jou begeleiding zou er geen sprake geweest zijn van een in wito model. Je bracht me vele praktische vaardigheden bij en je blijvende interesse, ondanks je vroegtijdige afscheid van cardiovasculair onderzoek, was woor mij steeds een opsteker. Becankt dat ik steeds bij jou terecht kon, ook op de momenten waarop het eens wat minder goed ging. 
Dr. Jannie Ausma, ben ik heel wat dankbaarheid verschuldigd voor de prettige samenwerking. Jannie, ik theb steeds bewondering gehad woor jou gedrevenheid. Je kritische opmerkingen en de vele ideeën waren onmisbaar. Je was altijd goed gehumeurd en dankzij jou voelde ik me telkens welkom in Maastricht.

Fred Thoné, op jou kennis en vaardigheden met betrekking tot de morfologie kon ik steeds terugvallen, waarvoor hartelijk bedankt.

De samenwerkingen met de Katholieke Universiteit Leuven waren voor mij cen hele eer. Prof. Willem Flameng (Cardiale Heelkunde), bedankt voor uw bereidwillige samenwerking en uw interesse. Uw schapenmodellen vormden een essentiële bijdrage tot het onderzoek. Dankzij u kon ik verscheidene aspecten van het proefdierkundig onderzoek van dichtbij meemaken. Dr. Bart Meuris en Veerle Leunens, het was steeds leuk terug te keren naar het CEHA en plezierig met jullie te mogen samenwerken. Zonder jullie had ik nooit deftige biopten tot mijn beschikking gekregen. Prof.Luc Mortelmans en Prof.Alex Maes, bedankt dat ik steeds welkom was op de afdeling Nucleaire Geneeskunde. De interessante en aangename gesprekken waren steeds een watar genoegen. Dr. Liesbet Mesotten, beste Liesbet, jij was de 'duivel-doet-al' in het PET gebeuren. Zonder jou engagement zou er maar een fractie van het werk met de schapen in de goede baan gelopen zijn. Bedankt voor de toffe samenwerking, en natuurlijk ook voor het zorgen voor de pizza's, pita's en ander lekkers tijdens de lange PET nachten. Succes nog met je eigen onderzoek en bedankt dat je één van mijn paranimfen wilde zijn. Dr. Johan Nuyts, en alle andere medewerkers van de Nucleaire Geneeskunde: bedankt.

De leden van de beoordelingscommissie: Prof. Mat Daemen, Prof. Harry Crijns, Prof. Arnoud van der Laarse, Dr. Chris Reutelingsperger en Prof. Van Meir, wil ik bedanken voor hun bereidheid het manuscript kritisch door te lezen en tijdens de verdediging te opponeren.

De leden van de 'hibernatie-club' die nog niet aan bod kwamen, Guillaume, Dirk, Hans, Victor, Stefan: allemaal bedankt voor de boeiende gesprekken en jullie interesse. Stefan, hopelijk komt er nog veel interessants uit het co-cultuur model, succes ermee, en bedankt voor de morele bijstand als paranimf ! Alle andere medewerkers van de afdeling Moleculaire Celbiologie die ik nog niet vernoemd heb, bedankt voor de hulp.

Tevens ben ik verschillende personen van andere afdelingen van de Universiteit Maastricht dank verschuldigd voor de hulp en interesse: Prof. Luc Snoeckx, Prof. Jos Smits, Prof. Rob Reneman, Dr. Marc Vos, Dr. Paul Volders, Dr. Marc Van Bilsen.

Gelukkig stonden er ook verscheidene mensen klaar op de Janssen Research Foundation, woor problemen allerhande maar ook voor een gezellige babbel. Bedankt Annik, Bruno, Carla, Christ, Christel, Christoph, David, Diana, Dieter, Eddy, Edwin, Ellen, Frans, Geofrey, Greet V, Gerd, Guy D, Guy J, Ilse, Johan, Jos, Katrien, Luc A, Luc B, Luc W, Marcel S, Mark H, Mark M, Mark V, Mies, Mirjam, Mohammadine, Paul, Peter B, Peter Vo, Roger, Rony, Tina, ... Wie ben ik 
nog vergeten? Nog een speciaal bedankje voor de meer administratieve hulp aan Greet DK en Chris (secretariaat), alle mensen van de JRF bibliotheek en aan Jeff Lubin (taalcorrecties). Wat zou er geworden zijn van de lay-out van mijn posters en artikels zonder de deskundige hulp van Lambert, Bob, Hans en Gert? Ook op de dienst reprografie kon ik steeds terecht met 'last-minute' werk. Bedankt allemaal, maar Roland in het bijzonder! Jan-Mark, bedankt dat je tijdens je Janssen-jaren me steeds hebi geholpen met de SCLL problemen en dat je mijn interesse in de beeldverwerking hebt aangewakkerd, dit geldt ook voor jou Peter. Ook bedankt aan de studenten die ik begeleid heb: Hans, Eva, Karen en Tom.

Gelukkig mocht ik buiten mijn werk ook op de steun en interesse rekenen van schoonouders, familie en vrienden. Graag wil ik hen dan ook speciaal danken. Een speciale positie neemt echter mijn zus Gwenda in, zij betekende voor mij een steun zowel op het werk als erna. Gwenda, bedankt voor alle hulp, zowel 'professioneel' als 'emotioneel'. Ik heb veel aan je steun gehad. Jij gaf me het goede voorbeeld met jou doctoraat en het succesvolle verwolg daarop. Ik mis het 'carpoolen'. Een simpele bedanking in dit proefschrift volstaat niet om mijn dankbaarheid tegenover mijn ouders te omvatten. Mama en papa, dankzij jullie immense steun en uitgebreide interesse is dit proefschrift tot een goed einde kunnen komen. Ik zal jullie altijd dankbaar blijven voor de kansen die ik van jullie gekregen heb. Ik zou dan ook dit werk aan jullie willen opdragen. En tot slot, liefste Sonja, jij bent er altijd voor mij en maakt me steeds gelukkig. Dit is het dankbaarste geschenk dat je me kan geven. Bedankt. 


\section{Curriculum Vitae}

Gerrit Dieter Dispersyn werd geboren te Schoten (België) op 24 juni 1974.

Nadat hij in 1993 zijn diploma van Algemeen Secuncair Onderwijs behaalde an het SintAgnesinstituut te Antwerpen-Hoboken, vatte hij op het Universitair Centrum Antwerpen (RUCA) de opleiding Biomedische Wetenschappen aan. In 1995 behaalde hij hiervan het kandidatuursdiploma. Hij vervolledigde de opleiding aan de Universitaire Instelling Antwerpen (UIA), en behaalde in 1997 het licentiatsdiploma Medische Biochemie met grote onderscheiding. De onderzoeksstage in het kader van zijn licentiaatsthesis vond plats in de labo's van de afdeling Life Sciences van de Janssen Research Foundation en deze van de vakgroep Moleculaire Celbiologie van de Universiteit Maastricht.

In 1997 werd hij in deze vakgroep aangesteld als Assistent in Opleiding, op een door de lanssen Research Foundation gefincancierd project, en dit onder leiding van Prof. Dr. Marcel Borgers en Prof. Dr. Frans C.S. Ramaekers. In het kader van dit project vond het onderzoek plaats bij Janssen Pharmaceutica te Beerse.

In de periode 1999-2000 behaalde hij aan de Universiteit Antwerpen het diploma Biomedische Beeldvorming met de grootste onderscheiding.

Sinds 1 januari 2001 is hij tewerkgesteld in de divisie 'Medical Imaging' van Agfa-Gevaert N.V. 


\section{List of publications}

Jannie Ausma, Fred Thoné, Gerrit D. Dispersyn, Willem Flameng, Jean-Louis J. Vanoverschelde, Frans C.S. Ramaekers, Marcel Borgers. Dedifferentiated cardiomyocytes from chronic hibernating myocardium are ischemia-tolerant. Molecular \& Cellular Biochemistry. 186(12):159-68, 1998

Gerrit D. Dispersyn, Jannie Ausma, Fred Thoné, Willem Flameng, Jean-Louis J. Vanoverschelde, Maurits A. Allessie, Frans C.S. Ramaekers, Marcel Borgers. Cardiomyocyte remodelling during myocardial hibernation and atrial fibrillation: prelude to apoptosis? Cardiovascular Research 43(4): 947-957, 1999

Stéphane Heymans, Aernout Luttun, Dieter Nuyens, Gregor Theilmeier, Esther Creemers, Lieve Moons, Anne Angellilo, Jack P.M. Cleutjens, Gerrit D. Dispersyn, Pieter Doevedans, Michael Shipley, Sandra Jansen, Andrew H. Baker, Marcel Levi, Ilse Van Horebeck, Eli Keshet, Oliver Nuesse, Florca Lupu, Jean Marc Herbert, Jos F.M. Smits, Stephen Shapiro, Myriam Baes, Marcel Borgers, Désiré Collen, Mat J.A.P. Daemen, Peter Carmeliet. Inhibitors of plasminogen activators or matrix metalloproteinases prevent fatal cardiac rupture but predispose to cardiac failure after myocardial infarction. Nature Medicine 5(10):1135-1142, 1999

Mirek Zietkiewicz, Bartek Perek, Bart Meyns, Liesbet Mesotten, Gerrit Dispersyn, Yosuke Nishimura, Willem Flameng. Chronic heart failure model induced by coronary embolization in sheep. International Joumal of Artificial Organs 22(7):499-504, 1999 
Gerrit D. Dispersyn, Marcel Borgers, Willem Flameng. Apoptosis in chronic hibernating myocardium: sleeping to death? Cardiovascular Research 45(3):696-703, 2000

Jannie Ausma, Gernit D. Dispersyn, Hans Duimel, Fred Thoné, Luc Ver Donck, Maurits A. Allessie, Marcel Borgers. Changes in ultrastructural calcium distribution in goat atria during atrial fibrillation. Jourmal of Molecular and Celluar Cardiology 32(3):355-364, 2000

Monika Szilard, Liesbet Mesotten, Alex Maes, Xiaoshun Liu, Johan Nuyts, Guy Bormans, Tjibbe De Groot, Sorin Pislaru, Yanming Huang, Beiping Qiang, Gerrit D. Dispersyn, Marcel Borgers, Willem Flameng, Frans Van De Werf, Luc Mortelmans, Ivan De Scheerder. A non-surgical porcine model of left ventricular dysfunction: validation of myocardial viability using dobutamine stress echocardiography and positron emission tomography. International Journal of Cardiovascular Intervention 3: 111-120,2000

Gerrit D. Dispersyn \& Marcel Borgers. Apoptosis in the heart: about programmed cell death and survival. News in Physiological Sciences 16:41-47, 2001

Liesbet Mesotten, Gerrit D. Dispersyn, Alex Maes, Mirek Zietkiewicz, Johan Nuyts, Bartek Perek, Guy Bormans, Tjibbe de Groot, Marcel Borgers, Luc Mortelmans, Willem Flameng. Reduced glucose uptake relative to perfusion in an experimental model of subacute myocardial infarction. European Journal of Nuclear Medicine: 28: 457-465, 2001

Liesbet Mesotten, Alex Maes, Gerrit D. Dispersyn, Johan Nuyts, Willem Flameng, Frans Van de Werf, Marcel Borgers, Luc Mortelmans. PET reversed mismatch pattern after myocardial infarction: experimental and clinical ewaluation. Tijdschrift voar Nucleatre Geneeskunde 23: 35,2001

Gerrit D. Dispersyn, Frans C.S. Ramaekers, Marcel Borgers. Clinical pathophysiology of chronic hibernating myocardium. Coronary Artery Disease, in press.

Geruit D. Dispersyn, Eva Geuens, Luc Ver Donck, Frans C.S. Ramaekers, Marcel Borgers. Adult rabbit cardiomyocytes undergo hibernation-like dedifferentiation when co-cultured with cardiac fibroblasts. Cardiovascular Research, in press. 
Rozalia Racz, Shigeyuki Ozaki, Takahiro Nishida, Gerrit D. Dispersyn, Marcel Borgers, Willem Flameng. Chronic impairment of coronary vasodilatory reveserve induces lefi ventricular dilatation and myocardial myolysis in sheep. Submitted for publication.

Gerrit D. Dispersyn, Liesbet Mesotten, Bart Meuris, Luc Mortelmans, Willem Flameng, Frans Ramaekers, Marcel Borgers. Dissociation of cardiomyocyte apoptosis and dedifferentiation in infarct border zones. Submitted for publication. 